Comprehensive Approach To Dietary Inclusion Of High Oleic Soybean Oil

In Monogastrics

A Dissertation presented to The Faculty of the Graduate School University of Missouri-

Columbia

In Partial Fulfillment of the Requirements of the Degree

Doctor of Philosophy

By

TYLAN PECKMAN

Dr. Bryon Wiegand, Dissertation Supervisor

DECEMBER, 2020 
The undersigned, appointed by the Dean of the Graduate School, have examined the dissertation entitled

Comprehensive Approach To Dietary Inclusion Of High Oleic Soybean Oil

In Monogastrics

presented by Tylan Peckman

a candidate for the degree of Doctor of Philosophy

and hereby certify that in their opinion it is worthy of acceptance.

Dr. Bryon Wiegand

Dr. Allison Meyer

Dr. Jeffre Firman

Dr. Harley Naumann

Dr. John Tummons 


\section{ACKNOWLEDGEMENTS}

To put this experience into words and recognize all the individuals who helped to make a dream, a reality is a difficult task. I must begin by giving thanks to God for planting this dream in my heart when I was young and setting me on this path. You called me to be all that I could be and to do everything with integrity. All I have done is to bring glory and honor to you.

My success in achieving this milestone is the result of the investment of many individuals into me throughout the journey I have had to get here. One of the most critical people put in my life that lead to this is Dr. Wiegand. I can still remember the day eight years ago, when you approached me after Live Animal Meat Evaluation and said, "I hear you are going to meats judge for us." Little did I know the future that was held in that simple statement. Fast forward to years later, after all the miles on the road, all the different experiments, all the crazy lab memories, and all the words of wisdom, I cannot fully put into words my thanks to all the opportunities you have given me. To the rest of my committee members, thank you for the one on one conversations, the words of wisdom, and mentorship. Your support through this process, has made it a great experience. I must also give a tremendous thank you to Dr. Ledoux for taking a chance on a freshman undergraduate and hiring him to work in his lab. You will never fully know how grateful I am to you for opening the door of animal science research to me.

They say it takes an army and with the Wiegand Lab Crew, an army is what I had. I want to give a special thanks to Zach Callahan and Teagan Schnurbusch for their constant support and for always being there to lend a helping hand. Now to my graduate mentor, coach, lab mate, and friend, Katy Shircliff. Your friendship and guidance mean 
the world to me. For the other members of the Wiegand Lab Crew, both undergraduate and graduate students, you have each played a role in getting me to this point and I am indebted to each of you.

To my family, who have been equally important throughout this process, thank you for being my rock and cheer team. I greatly appreciate my wife Jaelyn for standing with me through the long hours of reading, studying, and writing and for being an extra hand in checking on birds when I needed help. There is no other person that I would want to have checking birds with me, or to listen to my "fun" meat facts. My drive to achieve my dreams and my work ethic were both instilled in me by my parents. I cannot thank you enough Mom and Dad, for supporting me in everything that I do and for pushing me to reach my potential. This degree is dedicated to you both for all the energy, time, and sacrifices you gave to support and encourage me in chasing my dreams. 


\section{TABLE OF CONTENTS}

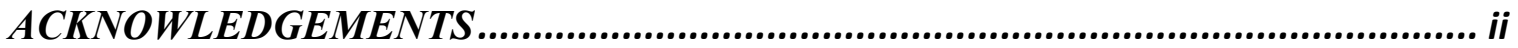

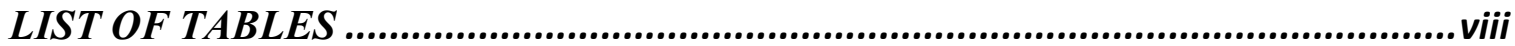

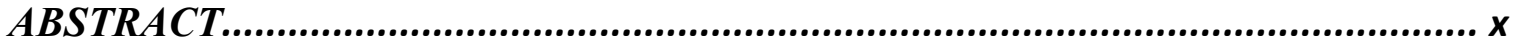

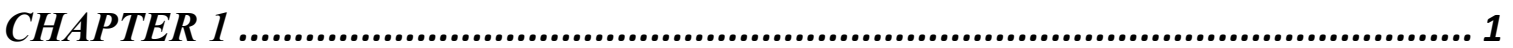

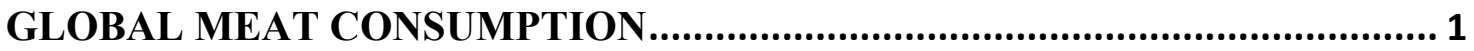

RELATIONSHIP OF MEAT AND FAT IN THE HUMAN DIET ....................... 2

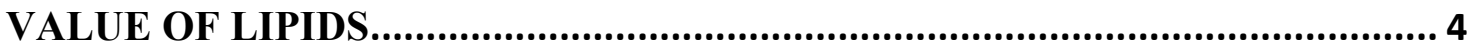

LIPID METABOLISM IN MONOGASTRICS ................................................. 6

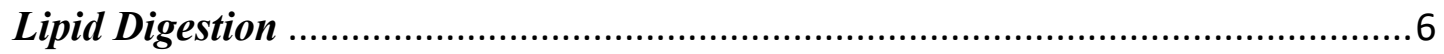

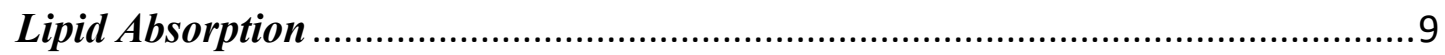

Assimilation of Dietary Lipids in Tissues ........................................................12

De Novo Synthesis of Lipids.............................................................................14

MANIPULATION OF DIETARY FATTY ACID SUPPLY ............................... 15

IMPACT OF FATTY ACID MANIPULATION ON PIG PERFORMANCE, CARCASS COMPOSTION, AND MEAT QUALITY ......................................... 16

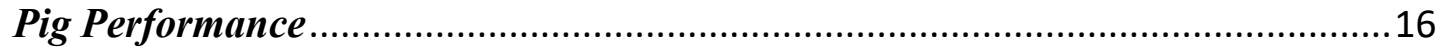

Pork Carcass Composition ………………......................................................17

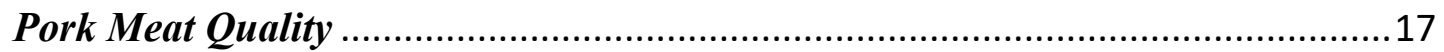




\section{IMPACT OF FATTY ACID MANIPULATION ON BROILER}

PERFORMANCE, CARCASS YIELD, AND MEAT QUALITY ........................ 20

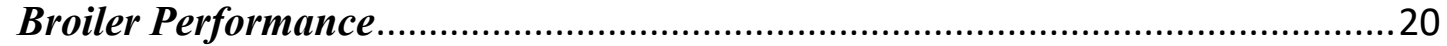

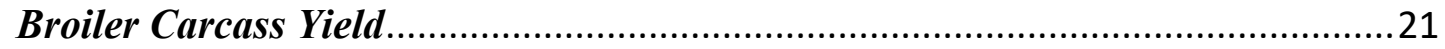

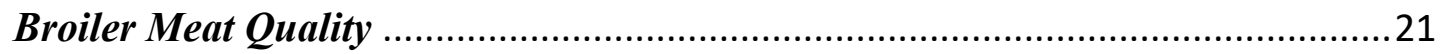

ALTERING FATTY ACID PROFILES IN MONOGASTRICS ........................ 23

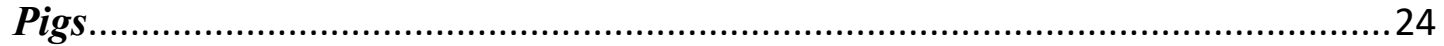

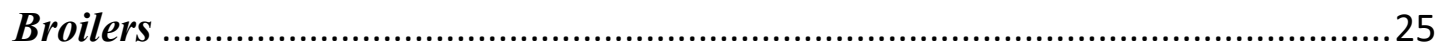

ROLE OF HIGH OLEIC OILS ...................................................................... 26

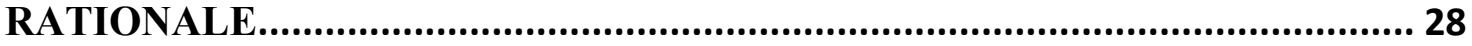

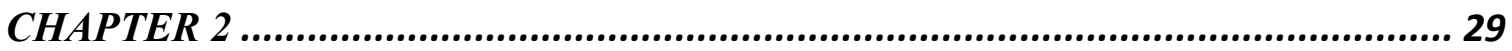

ABSTRACT

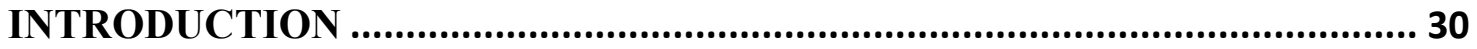

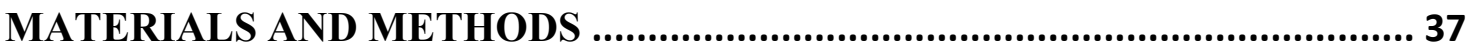

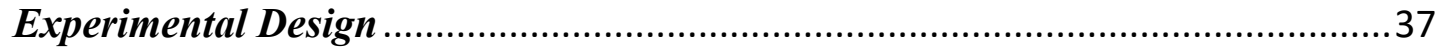

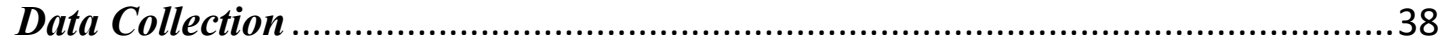

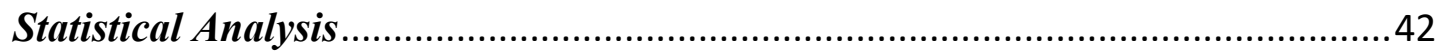

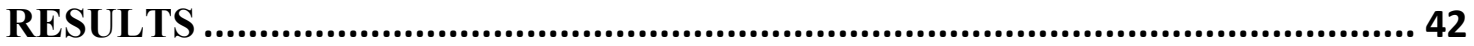

Growth Performance ……..............................................................................42

Carcass Weight and Breakdown ......................................................................4

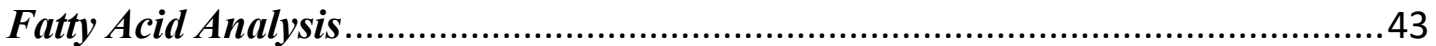




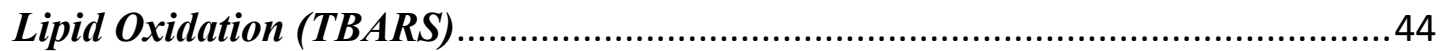

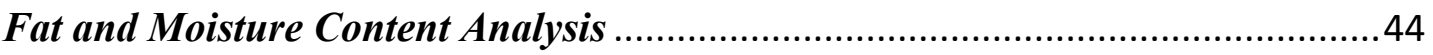

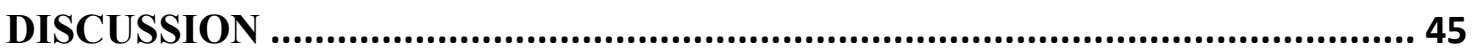

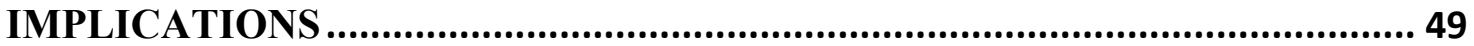

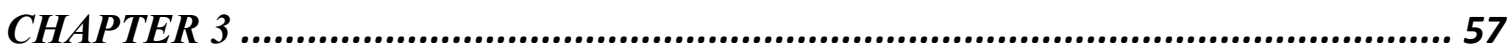

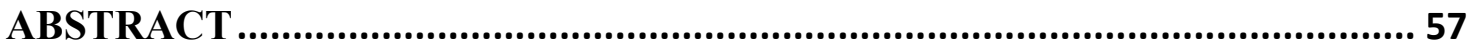

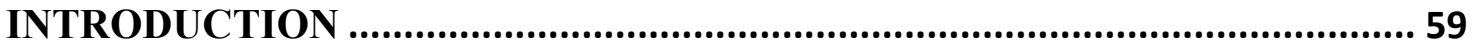

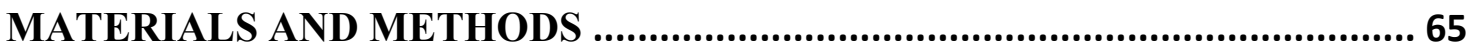

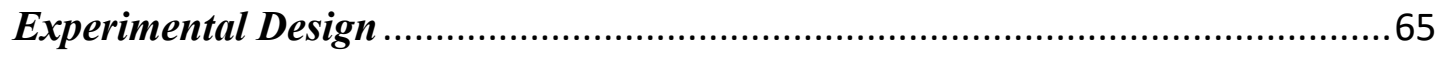

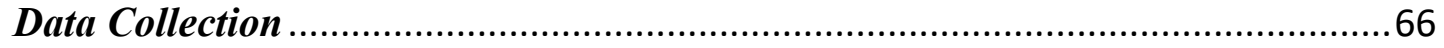

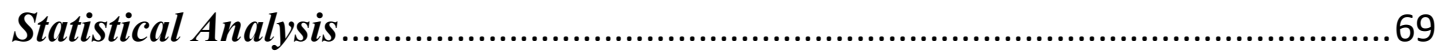

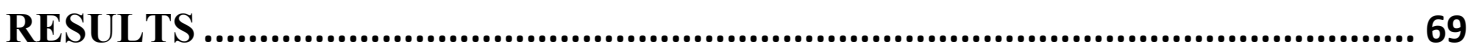

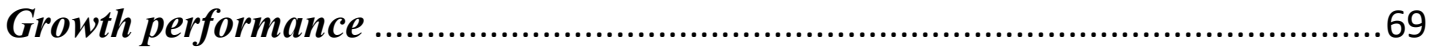

Carcass weight and dressing percentage …………...........................................70

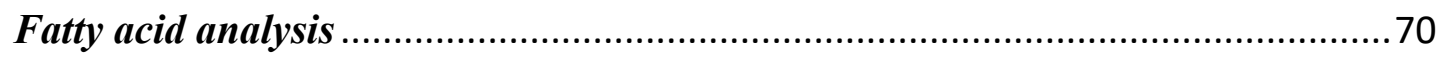

Fat and moisture content analysis ...................................................................72

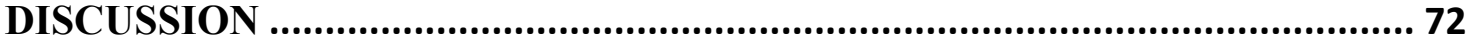

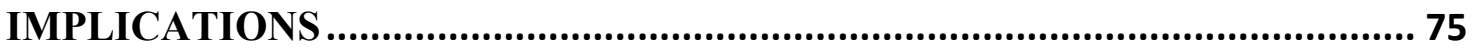

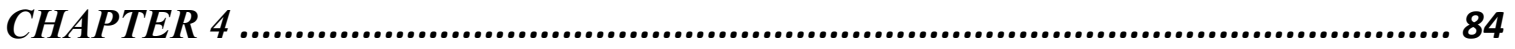

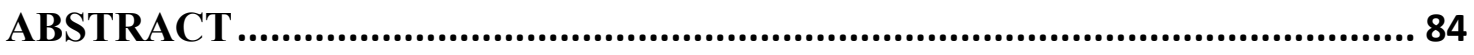


INTRODUCTION

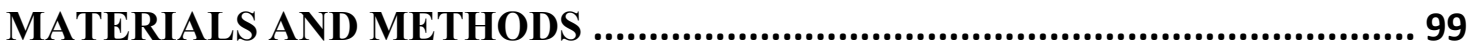

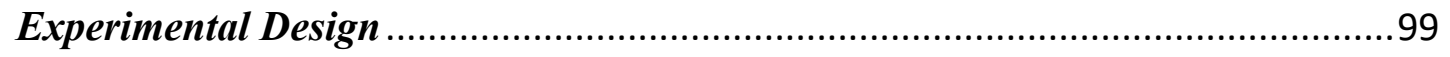

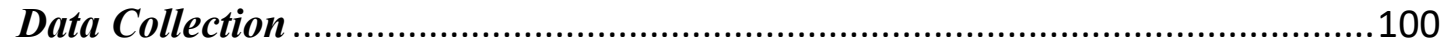

Bacon Slice Yield and Quality .........................................................................103

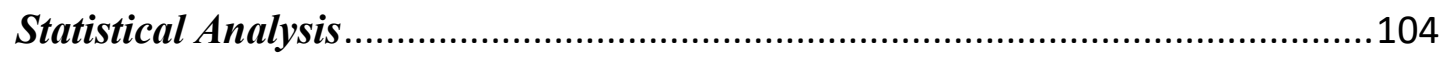

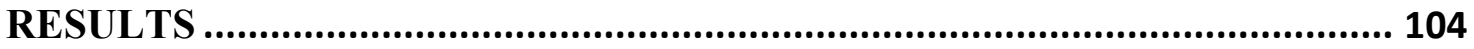

Growth Performance …….............................................................................104

Carcass Yield and Quality Measurements ......................................................104

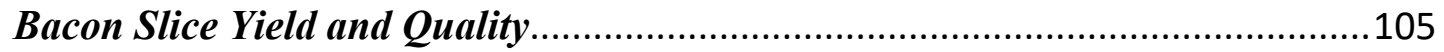

Fatty Acid Profile Analysis .........................................................................105

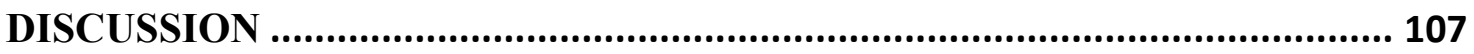

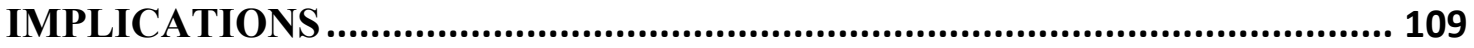

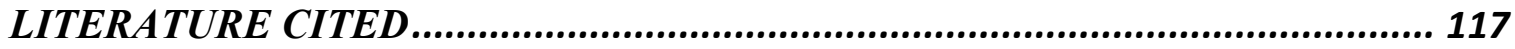

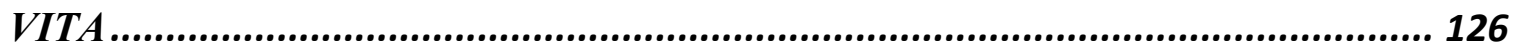


Table

\section{LIST OF TABLES}

2.1. Composition of treatment diets comparing commodity and Missouri high oleic soybean oil and meal......................................................... 50

2.2. Growth Performance least squares means of broilers fed commodity soybean oil and meal and Missouri high oleic soybean oil and meal...............................51

2.3. Carcass yield least squares means of broilers fed commodity soybean oil and meal and Missouri high oleic soybean oil and meal.................................52

2.4. CEM moisture and fat percentages of boneless, skinless breast and thigh meat from broilers fed commodity soybean oil and meal and Missouri high oleic soybean oil and meal.

2.5. Influence of High Oleic Soybean Oil and Meal on Lipid Oxidation of Boneless, Skinless Breast Meat.

2.6. Fatty acid profile of broiler boneless, skinless breast meat from broilers fed commodity soybean oil and meal and Missouri high oleic soybean oil and meal....

2.7. Fatty acid profile of broiler thigh meat from broilers fed commodity soybean oil and meal and Missouri high oleic soybean oil and meal .............................56

3.1. Composition of broiler starter diets containing commodity soybean oil and Plenish ${ }^{\circledR}$ high oleic soybean oil................................................... 76

3.2. Composition of broiler grower diets containing commodity soybean oil and Plenish ${ }^{\circledR}$ high oleic soybean oil.................................................. 77

3.3. Composition of broiler finisher diets containing commodity soybean oil and Plenish ${ }^{\circledR}$ high oleic soybean oil............................................ 78

3.4. Growth performance least squares means of broilers fed diets with commodity

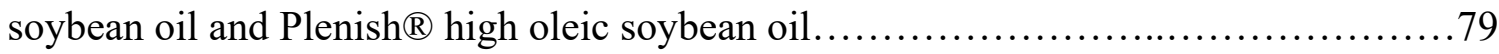

3.5. Carcass yield least squares means of broilers fed diets with commodity soybean oil

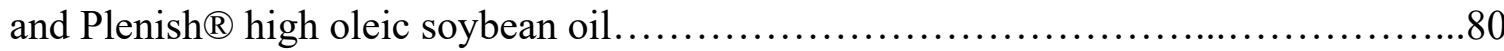

3.6. Moisture and fat content least squares means of boneless, skinless breast meat from broilers fed diets with commodity soybean oil and Plenish ${ }^{\circledR}$ high oleic soybean oil......81

3.7. Fatty acid composition of boneless, skinless breast meat from broilers fed diets with commodity soybean oil and Plenish ${ }^{\circledR}$ high oleic soybean oil........................82

3.8. Fatty acid composition of abdominal fat pads from broilers fed diets with commodity

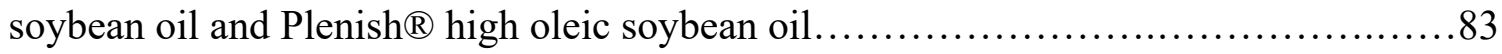

4.1. Composition of swine finisher treatment diets containing various dietary oils.....110 
4.2. Growth Performance least squares means of hogs finished on traditional and novel

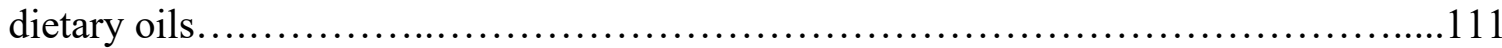

4.3. Carcass composition and quality of hogs finished on traditional and novel dietary

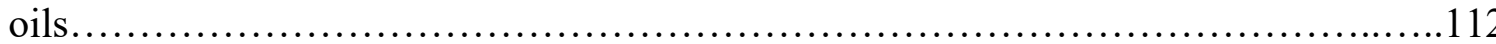

4.4. Moisture and fat percentages of loin chops from hogs finished on traditional and

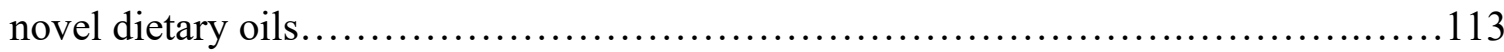

4.5. Bacon slice yield and quality of hogs finished on traditional and novel dietary

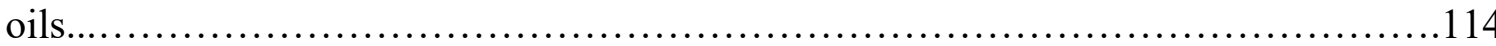

4.6. Fatty acid composition of intramuscular fat from pigs fed various dietary

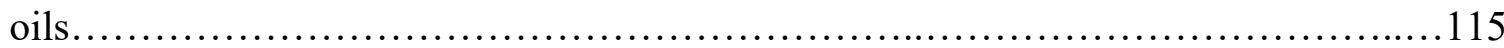

4.7. Fatty acid composition of intermuscular fat from pigs fed various dietary

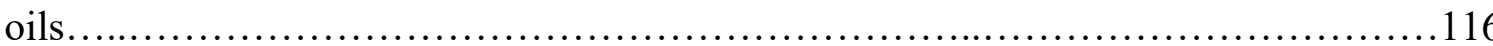




\title{
COMPREHENSIVE APPROACH TO DIETARY INCLUSION OF HIGH OLEIC SOYBEAN OIL IN MONOGASTRICS
}

Tylan Peckman

Dr. Bryon Wiegand, Advisor

\begin{abstract}
The banning of partially hydrogenated oils in food processing by the FDA has led to a search for alternative oil sources with a decreased potential for oxidation. While marketed and founded for use in the food industry, it is only a matter of time before this oil source makes its way into the livestock feed sector. Novel feed ingredients and different feed ingredient processing methods can vary the fatty acid supply in diets. Thus, when formulating diets, due to the potential effects on animal performance and the downstream effects on fresh meat properties, nutritionists must consider possible alterations in the fatty acid profile of a diet.

In experiment 1, Male Ross 308 broiler chicks $(\mathrm{n}=160)$ were sorted by weight and randomly assigned to one of two treatments containing 10 replicate pens with 8 broilers each. Treatment groups consisted of a control corn-soy diet that included commodity soybean meal and oil (CON) and a corn-soy diet containing high oleic soybean meal and oil (MOS). Broilers received, ad libitum, a two-phase diet consisting of starter (d0-21) containing 5\% oil and grower (d21-42) containing 3\% oil. Body weight (BW) and feed intake (FI) were recorded on days 0,21 , and 42 and used to calculate feed to gain ratio (F:G). Broilers were slaughtered on d42, after which carcasses were weighed and fabricated. Weights of fabricated parts were recorded for carcass yield. Samples of
\end{abstract}


boneless, skinless breast and thigh meat were taken for fatty acid profile analysis. To measure lipid oxidation, boneless, skinless breast halves chosen randomly from each pen were placed on Styrofoam trays and overwrapped with oxygen permeable, polyvinyl chloride and placed in retail storage $\left(4^{\circ} \mathrm{C}\right)$ and used for collection of thiobarbituric acid reactive substances (TBARS) on day 1,3 , and 5 of storage. Data were analyzed using PROC GLM procedure in SAS, with level of significance set at $\mathrm{P} \leq 0.05$. CON pens had a greater $(\mathrm{P}=0.002)$ change in weight $(2.90 \mathrm{~kg}$ vs $2.72 \mathrm{~kg})$, however, the CON treatment had an increase in FI $(\mathrm{P}=0.002)$ compared to the MOS treatment (2647.61 g vs. 2451.67 g). Thus, there was no difference in F:G between treatments. While there was no difference in percent carcass yield or boneless, skinless breast yield, the CON treatment had a greater $(\mathrm{P}=0.01)$ percent thigh yield compared to the MOS treatment $(16.36 \%$ vs 15.86\%). Results of lipid oxidation demonstrated an effect of day ( $\mathrm{P}<0.001)$, but no treatment or interaction effects were observed. Diet changed $(\mathrm{P}<0.001)$ the proportion of SFA, MUFA, and PUFA in breast and thigh meat. MOS treatment increased the proportion of MUFA and decreased the proportion of PUFA and SFA in both boneless, skinless breast and thigh meat. Both boneless, skinless breast and thigh samples from the MOS treatment had increased $(\mathrm{P}<0.001)$ proportions of $\mathrm{C} 18: \ln 9$ and decreased proportions of $\mathrm{C} 18: 2 \mathrm{n} 6$ compared to the control. Inclusion of MOS soybean meal and oil in broiler diets resulted in increased uptake of MUFA (C18:1) and decreased PUFA (C18:2) in both boneless, skinless breast and thigh meat, while having no impact on broiler feed efficiency. Pull through effect of MOS acid seen in fatty acid analysis of broiler meat, shows the ability to serve as a mechanism to increase oleic acid inclusion in human diets. 
Plenish $₫$ is a novel high oleic soybean oil product that has been developed, as a result of the FDA banning of partially hydrogenated oils in the food processing industry. The objective of experiment 2 was to evaluate the effects of replacing commodity soybean oil in the diets of broilers with Plenish ${ }^{\circledR}$, at two levels of inclusion, on broiler performance and tissue fatty acid composition. Cobb 500 as-hatched broiler chicks $(n=1344)$ were sorted by weight and then randomly assigned to one of four treatment groups, containing 12 replicate pens with 28 broilers each. Diets consisted of two control corn-soy diets with commodity soybean oil at 2.5\% (C2.5) and 5.0\% (C5) and two cornsoy diets containing Plenish ${ }^{\circledR}$ (high oleic soybean oil) at 2.5\% (P2.5) and 5.0\% (P5). Pens and feed were weighed and recorded to calculate changes in body weight (BW), average daily gain (ADG), feed intake (FI), and feed to gain ratio (F:G) for each treatment. Broilers were slaughter on $\mathrm{d} 49$, after which carcasses were weighed and fabricated. A breast fillet was removed and weighed for yield. Breast meat samples were collected by pen and used for moisture and fat analysis. Furthermore, samples of breast meat and abdominal fat pads were lotted by pen and used for fatty acid analysis. Data were analyzed using the PROC GLM procedure in SAS 9.4, with level of significance set at $\mathrm{P} \leq 0.05 . \mathrm{C} 2.5$ pens had the heaviest final live weights $(\mathrm{P}=0.016)$ and the greatest amount of weight gain $(\mathrm{P}=0.016)$ compared to the other treatments, which were all similar $(\mathrm{P}>0.05)$ in final live weight and weight gain. Furthermore, broilers receiving a diet with $2.5 \%$ commodity soybean oil consumed a greater amount $(\mathrm{P}=0.003)$ of feed compared to the other treatment pens. However, there was no significant difference between treatments for $F: G(P=0.202)$, or dressing percentage $(P=0.435)$. Fatty acid analysis of boneless, skinless breast meat and fat pads suggests broilers receiving diets 
with Plenish ${ }^{\circledR}$ had greater portions of MUFA, specifically C18:1n9 and a decrease in PUFA, specifically C18:2n6 (linoleic acid) and C20:4n6 (arachidonic acid).

Replacement of commodity soybean oil with Plenish ${ }^{\circledR}$ can successfully shift the fatty acid profile of broiler meat to have a greater proportion of MUFA, without having a deleterious effect on broiler feed efficiency.

The objective of the experiment 3 was to evaluate the impact of the inclusion of traditional and novel dietary oils in finishing pig diets on performance, carcass composition, and meat/lipid quality. Finisher pigs $(\mathrm{n}=80)$ were weighed and randomly sorted into 8 treatment groups containing 10 individually housed pigs per treatment. Treatment diets included the follow oil sources, control (choice white grease), commodity soybean oil (CS), coconut oil (CO), control+Missouri high oleic soybean oil (C+MOS), Missouri High Oleic Soybean Oil (MOS), 4\% Missouri high oleic soybean oil (MOS4), Plenish ${ }^{\circledR}(\mathrm{P})$, and 4\% Plenish ${ }^{\circledR}$. Pig and feed weights were recorded on days 0 , 14, and 28 and were used to determine ADG, feed intake, and F:G. Pigs were slaughtered under in two-groups on day 28 at a target-finished weight of $280 \mathrm{lbs}$. (127 kg.). Carcasses were weighed and chilled for 24 hours, after which, carcass measurements of loin eye area, last rib and $10^{\text {th }}$ rib fat thickness, ham and loin $\mathrm{pH}$, objective color $\left(\mathrm{L}^{*}, \mathrm{a}^{*}, \mathrm{~b}^{*}\right)$, and subjective marbling and color scores were recorded. Carcasses were fabricated to obtain samples for further analysis. Loin chop sample was collected for CEM moisture and fat content. Bellies were fabricated and commercially processed into sliced bacon slabs for quality analysis. Finally, jowl, subcutaneous, intermuscular, intramuscular fat samples were obtained for fatty acid analysis. Data was analyzed using PROC GLM procedure in SAS, with level of significance set at $\mathrm{P} \leq 0.05$. 
Growth performance and feed efficiency was not affected $(\mathrm{P}>0.05)$ by the source of dietary oil, with no differences observed for final body weight, feed consumption, ADG, and F:G. Furthermore, no treatment effect $(\mathrm{P}>0.05)$ was detected when looking at the predetermined indicators of pork carcass composition and pork carcass quality. Loin chop samples from yielded similar $(\mathrm{P}>0.05)$ moisture and fat percentages between treatments. Analysis of the bacon slice yield and quality data only showed a significant difference $(\mathrm{P}=0.003)$ for treatment effect in the yield of Number 1 slices. Bacon from pigs receiving the coconut oil diet had the greatest amount of number 1 slices at 25.30. The other treatments followed in the order of P at 21.44 slices, $\mathrm{CON}$ at 20.30 slices, $\mathrm{P} 4$ at 18.70 slices, $\mathrm{C}+\mathrm{MOS}$ at 18.56 slices, $\mathrm{CS}$ at 16.60 slices, MOS at 15 slices, and MOS4 at 10.90 slices. No significance difference $(\mathrm{P}>0.05)$ was observed in the fatty acid profile of intramuscular fat samples between treatments. Analysis of intermuscular fat samples showed significant differences in the concentration of $\mathrm{C} 12: 0(\mathrm{P}<.0001), \mathrm{C} 16: 0(\mathrm{P}=$ 0.028), $\mathrm{C} 16: 1(\mathrm{P}=0.002), \mathrm{C} 18: 0(\mathrm{P}=0.015), \mathrm{C} 18: \ln 9(\mathrm{P}=<.0001)$, total SFA $(\mathrm{P}=$ 0.005), and total MUFA $(\mathrm{P}=<.0001)$. These results suggest that traditional dietary oils can be replaced by novel high oleic soybean oils to shift the proportion of fatty acids in tissues, without causing deleterious effect on finishing pig performance, carcass composition, and fresh pork quality. 


\section{CHAPTER 1}

\section{LITERATURE REVIEW}

\section{GLOBAL MEAT CONSUMPTION}

It is well established that when it comes to meeting dietary needs, meat serves as a nutritious foodstuff that is rich in high quality protein, fats, vitamins, and minerals (Aberle et al., 2012; Vahmani et al., 2020). Rising consumption of meat has been evidence of improving individual economic status within developing countries (Meade \& Rosen, 2013). Thus, as the buying power of global consumers increases, so does the proportion of disposable income that is spent on meat. Based on data gathered from the Food and Agriculture Organization of the United Nations, Henchion et al. (2014) reported that global per capita consumption of meat increased by $25 \%$ from $33.7 \mathrm{~kg}$ to $41.9 \mathrm{~kg}$, during the period of 1990 to 2009 . Specifically, pork and poultry saw increased rates of consumption increased by $20 \%$ for pork and $75 \%$ for poultry, while global beef consumption fell by $8 \%$ (Henchion et al., 2014). This shows that while today's consumers are provided a variety of species sources, chicken continues to dominate the animal protein market. This is the result of a combination of factors including price, religious restrictions, convenience, production efficiency, and health perceptions. While consumption of meat will continue to grow in developing countries, the same cannot be said for developed countries due to the existing elevated amounts of meat consumed per capita (Henchion et al., 2014). Meat consumers in developed nations have taken a greater interest in extrinsic factors of food, such as production systems, food safety, animal welfare, and meat quality, rather than price (OCED, 2013). Therefore, producers 
and processors must find new ways to distinguish their meat products from competitors, if they hope to maintain their share in the market in these developed countries.

\section{RELATIONSHIP OF MEAT AND FAT IN THE HUMAN DIET}

Meat serves as a high biological-value protein source due to increased levels of essential amino acids and digestibility (Pereira \& Vicente, 2017). Furthermore, meat is a source of high-quality micronutrients, such as B vitamins, iron, and zinc (Vahmani et al., 2020). Fat found within, or added to, a diet primarily serves as a source of energy and essential fatty acids, while also supplying fat soluble vitamins (Aberle et al., 2012). It is speculated that the inclusion of meat in the diet of early humans provided essential fatty acids, such as arachidonic acid (20:4) and docosahexaenoic acid (22:6n-3), served as developmental trigger for a more complex brain (Crawford et al., 1970). Maxiner et al. (2018) analyzed the stomach contents of 5,300-year old mummy that was found preserved in a glacier in Europe, with the goal of better understanding the diet of early humans. Results found that the "Iceman's" diet consisted of high proportions of fat along with wild meat and cereals (Maxiner et al., 2018).

The difference in fat content and composition of fatty acids across meat producing species and between meat products has resulted in mixed opinions of how fat from meat can play a role in a healthy diet (Pereira \& Vicente, 2017). Meat offers a diverse fatty acid profile that includes saturated, monounsaturated, and polyunsaturated fatty acids (Pereira and Vicente, 2017). Due to increased amounts of saturated fatty acids and cholesterol, consumption of meat in the human diet has been associated with negative health implications that can lead to diseases such as diabetes, obesity, and cardiovascular 
disease (Bellavia et al., 2016; Larsson \& Orsini, 2014). One factor contributing to the viewpoint of meat consumptions negative impact on human health is its potential contribution to the increase in the dietary omega-6/omega-3 ratio found in Western diets (Simopoulos, 2009). Diets in the Western world have come to reach levels of 25:1, while the ideal ratio is approximately 5:1, or less (Raes et al., 2004). Fat content has been perceived as a negative attribute in meat products by some consumers (Guadalupe et al., 2019). Cardona et al. (2020) concluded that consumers have an awareness of the negative effects of high fat foods and understand the health importance of diet. Thus, fat content and composition has become one of the central figures in the trends and fads in human dieting.

Studies have shown monounsaturated fatty acids have the ability to reduce the risk of heart disease and improve overall health. A study by Bonanome et al. (1992) concluded that the risk of coronary heart disease could be reduced by consuming a diet high in monounsaturated fatty acids. This was based on a reduction in blood cholesterol and oxidation of plasma LDL when subjects consumed increased amount of monounsaturated fatty acids (Bonanome et al., 1992). Data from the Seven Countries Study conducted by Sinclair and O'Dea (1999) provides evidence of the potential health benefits from dietary inclusion of monounsaturated fatty acids. This study of Cretian men who regularly consumed olive oil through their diet had a lower incidence of coronary heart disease (Sinclair and O'Dea, 1990). Furthermore, anecdotal evidence of the health benefits of consuming a diet with increased consumption of olive oil, vegetables, and fruit, led to the creation of what has been termed the Mediterranean Diet (Gibney, 1999). More recent research by Wood and Enser (2017) reported that other 
metabolic studies have demonstrated a similar efficacy of oleic acid in its ability to decrease levels of LDL cholesterol, compared to linoleic acid.

One attribute that is driving change in the meat industry is the growing interest of consumers in low fat meat products (Mir et al, 2017; Cardona et al., 2020). The greater than 10 year idea that low fat diets are the solution to diet related induced health risks has recently undergone review, as more recent research points to the conclusion that fat composition, rather than total fat content, may be the true solution (Forouhi et al., 2018). This is the purpose behind the concept of functional food design, as a means to create foods that can be used in the diet to promote overall health (Rossi et al., 2010). It has become a well-established viewpoint that the fatty acid profile of the tissues of monogastrics reflects the fatty acid profile of the diet (Mir et al., 2017). Being nutrient dense and containing lower amounts of fat, pork and chicken are poised to meet the health demands of consumers (Mir et al., 2017). However, as we look to altering the fat content and composition within meat products, we must consider the potential negative impact it may have on consumer likability of a product, as a result of changes in flavor and palatability (Webb \& O’Neill, 2008). The above discussion shows evidence of the potential of providing health benefits to humans through increased consumption of monounsaturated fatty acids, potentially utilizing meat products from monogastric food animal species, such as pigs and poultry, as the vehicle.

\section{VALUE OF LIPIDS}

Lipids are complex organic compounds that are unique due to being insoluble in water. The primary component of lipids are the neutral lipid factions, known as 
triglycerides (Aberle et al., 2012). Triglycerides are made up of a glycerol backbone bound to three fatty acid chains (Aberle et al., 2012). Other components found in lipids include cholesterol esters and fat-soluble vitamins (Aberle et al., 2012). Lipids found within the body serve in many different capacities. While the primary function of lipids is to serve as an energy source for bodily functions, lipids support and engage in other far reaching roles. Some lipids play a key role in cellular membrane structure and function (Aberle et al., 2012). Other components of lipids include compounds that exist in the forms of hormones and vitamins, aid the body by supporting metabolic processes (Aberle et al., 2012). While the terms "fat" and "lipid" can be used interchangeably, lipids are a component of fat and do not possess the water content, enzymes, and connective tissue that is found in fat (Shircliff, 2016).

Contributing $94-96 \%$ of the total weight of fats, fatty acids are considered the building blocks of fats (Rossi et al., 2010). According to Webb \& O’Neill (2008), fatty acids as "amphiphilic" molecules, having a hydrocarbon chain at the non-polar end, with a polar end containing a carboxyl-group. The form and function of individual fatty acids are influenced by the length of the carbon chain and the degree of saturation of hydrogen (Rossi et al., 2010). Based on degree of saturation, fatty acids are subdivided into one of three categories, saturated fatty acids (SFA) containing no double bonds, monounsaturated fatty acids (MUFA) containing one double bond, and polyunsaturated fatty acids (PUFA) containing more than one double bond (ISEO, 2006). The generation of SFA primarily occurs within the body utilizing glucose or acetate as substrates (Enser, 1984). Major forms of synthesized SFA include palmitic acid (16:0) and stearic acid (18:0) (Wood and Enser, 2017). MUFA are sourced from in vivo modification of fatty 
acids and dietary uptake, with the primary form being oleic acid (18:1n9) (Wood and Enser, 2017). Sourcing of the two most common forms of PUFA, linoleic acid (18:2n6) and linolenic acid (18:3n3) is heavily dependent on dietary uptake, with low levels of de novo synthesis occurring within the liver (Wood and Enser, 2017).

\section{LIPID METABOLISM IN MONOGASTRICS}

In trying to understand how to influence human health through the use of designer food products, one must have an understanding of how nutrients, such as fatty acids, are digested, absorbed, and assimilated. Monogastric food animal species, such as pigs and poultry, present a model that is more easily malleable to alter the post-absorptive supply of fatty acids, as a result of a more simplified digestive system.

\section{Lipid Digestion}

Alongside other macronutrients found within feed, large fat globules undergo size reduction via the process of mastication. During this process, lingual lipase is produced in the Ebner's gland, then released in small quantities in the mouth. The amount of lingual lipase varies depending on the species. Lingual lipase plays a greater role in lipid digestion in neonates, as a result of the greater presence of short chain fatty acids (Lieberman and Peet, 2015). In adults, rather than making a large contribution to the total fat digestion process, lingual lipase more likely contributes in the detection of flavors (Lieberman and Peet, 2015). Detection of these flavors is the result of the release of short- and medium-chain fatty acids bound to triglycerides. 
The masticated food bolus leaves the mouth and travels to the gastric stomach via the esophagus. In the gastric stomach, the food bolus mixes with gastric secretions including hydrochloric acid, pepsin, and gastric lipase. Gastric lipase is released alongside pepsinogen from Chief cells found in the corpus and fundus regions of the lining of the stomach. As with lingual lipase, gastric lipase plays a greater role in the digestion of fat in pre-weaning mammals, with a reduced efficacy in adults. Gastric lipase cleaves the outer ester linkages of triglycerides, yielding diglycerides and free fatty acids. The level of enzymatic activity of gastric lipase may be limited due to the low $\mathrm{pH}$ environment found within the stomach. Fat digestion will still occur in the absence of gastric lipase, as a result of the presence of pancreatic lipase in the small intestine.

The digesta mixture, now called chyme, is released from the stomach into the duodenum of the small intestine. As chyme enters the duodenum its presence initiates the release of a signaling molecule, known as cholecystokinin (CCK) (Johnson, 2007). CCK slows gastric motility, stimulates the pancreas and gallbladder to release secretions that aid in the digestion and future absorption of fat (Johnson, 2007). The stimulated pancreas releases pancreatic lipase-colipase, phospholipase $\mathrm{A}_{2}$, and cholesterol lipase (Johnson, 2007). Concurrently, the gallbladder is stimulated causing it to contract and release stored bile produced by the liver (Lieberman and Peet, 2015). Bile contains bile salts, which are derivates of cholesterol that exist in acid form. Bile salts function in a bimodal capacity in the digestion of lipids. The first function of bile salts is to aid in the emulsification of lipid molecules. This process of emulsification is important for enzyme hydrolysis of lipids, as it aids in the reduction of larger lipid molecules, resulting in an increase in the surface area of the lipid molecules. The second mode of action of bile 
salts is the inactivation of pancreatic lipase. This is a result of the ability of bile salts to displace pancreatic lipase from the lipid droplet-water interface. Due to the downstream importance of lipid digestion for absorption and assimilation into tissues, a system must be in place to overcome the inactivation ability of bile salts and allow pancreatic lipase to carry out its function.

Although bile salts possess the ability to inhibit the enzymatic activity of pancreatic lipase, this ability is blocked by the presence of colipase in the system (Lieberman and Peet, 2015). Colipase is a polypeptide that is secreted into the system as procolipase (Johnson, 2007). Procolipase is activated via hydrolysis by trypsin to form colipase (Johnson, 2007). Colipase, which is secreted alongside pancreatic lipase in a one to one ratio, first attaches to the lipid droplet at the lipid droplet-water interface and acts as an anchor for pancreatic lipase to bind to the complex and carry out its enzymatic function on the lipid droplet (Johnson, 2007).

Now that it is in contact with the lipid droplet, pancreatic lipase can begin to breakdown triglycerides found within the lipid droplet. Pancreatic lipase hydrolyzes the first and third ester linkages of a triglyceride, yielding 2-monoglyceride and two free fatty acids (Johnson, 2007). Simultaneously, the other lipid targeting enzymes released alongside pancreatic lipase begin to digest their target molecules. Other enzymes present include phospholipase A2 and cholesterol esterase. Phospholipase A2 is another enzyme secreted in a proenzyme form and is activated by trypsin (Johnson, 2007). Trypsin cleaves amino acids from the N-terminus of the proenzyme, yielding an active phospholipase A2 (Johnson, 2007). In the presence of bile salts, phospholipase A2 hydrolyzes dietary phospholipids at the 2-position, yielding lysophospholipids and free 
fatty acids (Johnson, 2007; Lieberman and Peet, 2015). Cholesterol esterase hydrolyzes the ester forms of both cholesterol and the fat-soluble vitamins A, D, and E (Johnson, 2007). Cholesterol esterase is also known as a non-specific lipid enzyme, as it is capable of hydrolyzing the 3-ester linkage of triglycerides (Johnson, 2007). As lipid digestion takes place, the lipid portion is also prepped for absorption by the small intestine.

\section{Lipid Absorption}

Lipid absorption takes place in the mid-jejunum through the ileum of the small intestine (Johnson, 2007). Digested lipid components must be processed in a manner to allow for absorption. During the process of emulsification, small lipid structures called micelles are formed, with the aid of bile salts and their hydrophobic and hydrophilic regions (Johnson, 2007). Micelles are different from simple emulsion particles, as they exist in true solution. During micelle formation, bile salts interact with the products of lipolysis to create a structure in which the polar, hydrophilic portion of the molecules align at the surface and orientate their non-polar, hydrophobic tails towards the core of the micelle (Lieberman and Peet, 2015). It is the hydrophilic surface layer that allows the micelle to disperse within the aqueous environment. Formation of micelles is critical for the digested components of lipids to be properly absorbed.

The new formed micelles pass through the unstirred layer within the small intestine, which is found between the brush border and bulk of the lumen solution (Johnson, 2007). The arrival of the micelle outside the brush border increases the concentration of long chain fatty acids at the plasma membrane of the enterocyte. The acidic microenvironment next to the plasma membrane helps to protonate the long chain fatty acids within the micelle, which results in the release of the long chain fatty acids 
from the carrier micelle (Johnson, 2007). It is widely known that the majority of long chain fatty acids are absorbed via passive diffusion across the plasma membrane of enterocytes. However, evidence does exist that indicates some absorption of long chain fatty acids may be carrier dependent (Johnson, 2007). This has been seen with linoleate, or linolenic acid, which shows saturable uptake by enterocytes. Saturable uptake is used to describe the point at which an increase in the quantity supplied does not equal an increase in the quantity absorbed (Johnson, 2007).

When it comes to absorption, not all fatty acids are created equal, as some have less restrictions on travel through the enterocyte and circulation within the bloodstream. Short and medium chain fatty acids do not rely on micelles for absorption and do not pass through the enterocyte (Johnson, 2007). Their structure provides a different pathway for absorption and transportation into the bloodstream. Due to increased solubility, short and medium chain fatty acids diffuse directly into the bloodstream through space between enterocytes. These fatty acids then pass through the cytosol in their absorbed form and are released into the neighboring capillaries (Johnson, 2007). Short- and medium chain fatty acids travel from the capillaries into the bloodstream and are circulated for use by other tissues in the body (Johnson, 2007).

Due to their decreased solubility, long chain fatty acid absorption requires supporting systems to pass from one side of the enterocyte to the other. After being absorbed into the enterocyte, monoglycerides and free long chain fatty acids are resynthesized into triglycerides. Prior to being resynthesized, long chain fatty acids used as building blocks for the triglycerides must first be transported from the outer membrane of the enterocyte to the site of triglyceride reformation, the endoplasmic reticulum. Fatty 
acid binding proteins bind to absorbed long chain function on the apical side of the outer membrane, then transport them to the endoplasmic reticulum (Johnson, 2007). The existence of fatty acid binding proteins also functions as a means to prevent the build-up of free fatty acids within the plasma membrane. The result of which could lead to the potential to solubilize the lipid plasma membrane (Johnson, 2007). Fatty acid affinity of fatty acid binding protein appears to be influenced by differences in the fatty acid chain length, as well as the degree of saturation.

Reformation of triglycerides within the endoplasmic reticulum, occurs via the monoglyceride acylation pathway, or the phosphatidic acid acylation pathway (Johnson, 2007). In the monoglyceride acylation pathway, triglycerides are synthesized through the combination of 2-monoglycerides and CoA-fatty acids. Fatty acids are acylated by AcylCoA synthetase, which are then added to monoglycerides and diglycerides via monoglyceride and diglyceride acyltransferases (Johnson, 2007). When reassembling the triglycerides, it appears that a preference exists for fatty acids to be used for assembly. This is a result of the difference in affinity shown by fatty acid binding protein for different fatty acids. The phosphatidic acid acylation pathway utilizes one mol alphaglycerophosphate and two mol of fatty acid-CoA to form phosphatidic acid (Johnson, 2007). Phosphatidic acid is dephosphorylated to form a diglyceride, which is then acylated into a triglyceride. The phosphatidic acid acylation pathway is also used to synthesize phospholipids (Johnson, 2007).

After reformation, triglycerides are still not able to move freely through and out of the enterocyte, thus a transport mechanism must be used. Within the endoplasmic reticulum, resynthesized triglycerides are packaged, along with cholesterol esters and fat- 
soluble vitamins, at the core of a particle known as a chylomicron. Chylomicrons are lipoprotein particles that incase an insoluble core with an outer coating of apolipoproteins, phospholipids, and free cholesterol (Johnson, 2007). After packaging in the endoplasmic reticulum, the newly created chylomicrons are released from the Golgi apparatus (Johnson, 2007). Chylomicrons are then secreted via exocytosis into the interstitial space between enterocytes, from which they enter the central lacteal of the microvilli (Johnson, 2007). Due to their large size, chylomicrons are unable to enter the bloodstream via the capillary pores. Traversing the lymph vessels, chylomicrons bypass the liver before entering the bloodstream and moving on to target tissues.

\section{Assimilation of Dietary Lipids in Tissues}

Assimilation of fatty acids into tissues takes on one of two forms, storage via deposition into adipose tissue, or energy generation within a cell via beta-oxidation. In a state of energy excess, circulating chylomicrons are utilized to increase fatty acid deposition into adipose tissue. This process begins with the activation of lipoprotein lipase by apolipoproteins found on the surface of the chylomicron. Acting as anchor for the chylomicron, Lipoprotein lipase is bound by a polysaccharide chain to the lumen side of the endothelial cell. Next, the activated lipoprotein lipase releases fatty acids and glycerol from the chylomicron. The released glycerol travels via the bloodstream to the liver for further use, while the free fatty acids diffuse into the cell.

Excess dietary fatty acids are stored with cells called adipocytes, which when grouped together make up adipose tissue. Adipocytes contain a specialized storage organelle, known as a lipid droplet, in which fatty acids are deposited. The process of fatty acid deposition into adipocytes is known as lipogenesis. Fatty acid binding proteins 
attached to the inside of the membrane bind to free fatty acids that have diffused across the cellular membrane and transport the fatty acids within the adipocyte. Free fatty acids are re-esterified to form triglycerides using glycerol synthesized within the cell from glucose. Reformed triglycerides are then stored within the lipid droplet for later use as an energy source.

When glycogen stores are low, ATP can be generated utilizing fat stores through a process known as beta-oxidation (Pompei, 2010). A rise in circulating glucagon levels stimulates the release of stored long chain fatty acids from adipose tissues through a process known as lipolysis, which utilizes lipases to release long chain fatty acids from triglycerides in adipose tissue (Lieberman and Peet, 2015). Free fatty acids bound to serum albumin are then transported to target tissues via the bloodstream (Lieberman and Peet, 2015).

Upon reaching the target tissue, free fatty acids pass through the plasma membrane of the cell and are transported within the cell by fatty acid binding proteins to the mitochondria to undergo beta-oxidation (Lieberman and Peet, 2015). Long chain fatty acids must be first activated by the addition of CoA to form fatty acyl-CoA prior to undergoing oxidation (Lieberman and Peet, 2015). Carnitine binds with the newly formed fatty acyl-CoA to aid in transportation of the long chain fatty acid across the inner mitochondrial membrane into the matrix of the mitochondria where the beta-oxidation pathway is located (Lieberman and Peet, 2015). Carnitine palmitoyl transferase 1 is the catalyst responsible for the binding of carnitine to the long chain fatty acyl-CoA (Haug et al., 2014). Beta-oxidation of long chain fatty acids consists of a repeating four step spiral process, which yields FADH2 and NADH (Lieberman and Peet, 2015). These molecules 
are utilized for ATP production through oxidization via the Electron Transport Chain (Lieberman and Peet, 2015). The process is repeated until the carbon chain is converted completely to acetyl-CoA units and varies based on the length of the fatty acid being oxidized. (Lieberman and Peet, 2015).

\section{De Novo Synthesis of Lipids}

In times of limited supply of dietary fatty acids, or excess supply of carbohydrates and/or protein, fatty acids can be directly synthesized within the body via de novo synthesis (Lieberman and Peet, 2015). Malonyl-CoA formation from acetyl-CoA, which is catalyzed by acetyl-CoA carboxylase, is the rate limiting step in de novo synthesis of fatty acids (Shircliff, 2016). New fatty acids formed through the de novo synthesis process is centered around a four-step repeating process, until the final length is reached (Nelson and Cox, 2013). This four-step process is driven by the enzyme fatty acid synthase, which catalyzes the addition of two carbons, donated from malonyl-CoA, to the growing fatty acid chain (Nelson and Cox, 2013). The process yields a single molecule of palmitic acid (C16:0), which can undergo further desaturation and elongation to form other long chain fatty acids (Nelson and Cox, 2013).

Desaturases and elongases play a critical role in the success of the de novo synthesis of fatty acids (Nakamura and Nara, 2004; Ntambi and Miyazaki, 2004). Monounsaturated fatty acids are synthesized from the desaturation of saturated fatty acids through enzymatic activity of delta-9 desaturase (Haug et al., 2014). In this reaction, delta-9 desaturase catalyzes the insertion of a single double bond at carbon-9 location of a long chain fatty acid (Haug et al., 2014). De novo fatty acid synthesis in food animal models primarily results in the production of saturated fatty acids (16:0 and 18:0) and 
monounsaturated fatty acids (16:1 and 18:1) (Shircliff, 2016). In the absences of dietary fats, Flanzy et al. (1970) concluded that pigs yielded carcasses with fatty acid profiles containing 55 percent oleic and palmitoleic acids and 45 percent palmitic and stearic acids. This buildup of oleic acid is due to the fact mammals lack the desaturase enzyme capable of inserting a double bond from the carbon-10 location to the end of the carbon chain (Nelson and Cox, 2013). Thus, to receive certain long chain fatty acids that are of biological importance, animals must obtain them from their diets. These fatty acids are known as essential fatty acids.

\section{MANIPULATION OF DIETARY FATTY ACID SUPPLY}

Feed costs are a major contributor to the overall cost of animal production (NPB, 2014). The addition of fats and oils to livestock diets serves a key source of dietary energy (Rossi et al., 2010). Furthermore, fats and oils are added to livestock diets in effort to increase palatability and decrease dust (Wiseman \& Garnsworthy, 1997). Lipids sourced from plants and animals, in the form of storage and structural lipids, are utilized for feedstuffs (Rossi et a., 2010). Livestock diets in the United States traditionally utilize corn and soybean meal to meet the nutritional needs of livestock (Toomer et al., 2020). Diet becomes a target of producers for the application of alternative feedstuffs that can make diets more cost effect, while eliciting comparable performance (Shircliff, 2016). At times, novel feedstuffs provide the possibility of promoting positive outcomes in either the live animal model and/or within the finial products produced from livestock. Recent research has shown the value of utilizing diet as a vehicle for manipulating the fatty acid composition of meat products (Wood and Enser, 2017; Mir et al, 2017). 
Changes in animal performance, carcass composition, and the impacts on meat quality, as a result of altering the dietary supply of fatty acids have been well documented (Wood and Enser, 2017).

\section{IMPACT OF FATTY ACID MANIPULATION ON PIG PERFORMANCE, CARCASS COMPOSTION, AND MEAT QUALITY}

\section{Pig Performance}

Consideration must be given regarding the impact on animal performance with the inclusion of alternative and novel feed ingredients that have fatty acid profiles that deviate from those normally found in livestock diets. Manipulation of ingredients within livestock diets presents the opportunity to improve animal performance, while not impacting the quality of animal products produced downstream. On the other hand, manipulating ingredients within the diet may be the result of trying to influence characteristics of end products from an animal, with the goal of not having a deleterious effect on animal performance along the way. After feeding pigs a variety of animal and plant fat/oil sources, Apple et al. (2009a) concluded that ADG, feed intake, and feed efficiency did not changes based on the dietary fat an animal received. Performance results from Duran-Montge et al. (2010) showed no significant difference in ADG, feed intake, and final live weight for pigs fed diets with different fat sources. However, an absence of dietary fat did have a negative impact on the feed to gain ratio compared to pigs receiving diets with a positive energy balance (Duran-Montge et al., 2010). Results from Kellner et al. (2014) reinforce the conclusion made by Apple et al. (2009a), as they 
too concluded that the type of fat supplied through the diet had no impact on the ADG and feed efficiency.

\section{Pork Carcass Composition}

A majority of pork is primarily priced and marketed on a lean yield basis. Thus, consideration must be given to the potential downstream effects of diet modification on lean muscle yield in pork carcasses. The addition of five percent of a variety of animal and plant fat sources had no measurable impact on carcass primal yields, or the percentage of lean and fat from those primal cuts (Apple et al., 2009b). Furthermore, adding beef tallow, soybean oil, or a 50:50 combination of the two at a dietary inclusion rate of four percent had showed no impact across treatments on the hot carcass weight, loin eye area, and percent yield of pigs (Stephenson et al., 2016). While fat source appears not to have an impact on lean carcass yield, the same cannot be said for the amount of fat include in the diet. The potential exists for altering carcass composition when increasing the amount of fat supplied through the diet, regardless of source, has the potential to increase backfat and reduce the percent lean of carcasses (Stephenson et al., 2016).

\section{Pork Meat Quality}

Defining meat quality becomes a rather difficult feat once an individual begins to consider the vast properties that can be included. Purslow (2017) defines meat quality as, "a set of properties that together identify what we appreciate about meat when we purchase it, eat it, or select it for use as a raw material for processing into meat products." Properties of meat quality can be categorized into intrinsic and extrinsic parameters (Purslow, 2017). Extrinsic parameters are those associated with how meat is produced, 
covering areas such as animal welfare, sustainability of production systems, and the nutritional value of meat (Purslow, 2017). Intrinsic parameters of meat quality are those tangible properties of meat we can see, feel, taste, and smell; including color, flavor, texture/tenderness, juiciness, and odor (Purslow, 2017). The following discussion will center on how manipulation of dietary fatty acids can alter the intrinsic parameters of meat quality.

Visual appearance is a driving force behind consumer purchasing of meat products, thus color is critical factor used to assess meat quality (England et al. 2017; King et al., 2018). The color of fresh pork can be evaluated utilizing either subjective color scores and/or objective instrumental color. When it comes to using instrumental color to evaluate differences in fresh pork color, $\mathrm{L}^{*}$ and a* account for approximately 69 percent of the changes in fresh pork color (Mancini and Hunt, 2005). L* value indicates the lightness to darkness and $\mathrm{a}^{*}$ value measures the red to green within a sample (American Meat Science Association, 2012). Mas et al. (2010) report that loin chops from Pietrain-cross pigs fed high oleic peanut meal had comparable $\mathrm{L}^{*}$ and $\mathrm{a}^{*}$ values to loin chops from Pietrain-cross pigs fed a more traditional corn-soy diet. Feeding the same diets, but to Yorkshire-cross pigs, Mas et al. (2011) supported the findings for L* and $\mathrm{a}^{*}$ values from Mas et al. (2010) for loin chop samples.

Intramuscular fat, better known as marbling, is the flecks of fat visible to the human, found within a muscle between the perimysium of the muscle fiber bundles (Warner et al., 2010). Visual appraisal of this fat depot has been utilized as another factor in the consideration of the quality and potential eating experience of a meat product. Past research has indicated a correlation between greater amounts of marbling 
and perceived improvements in tenderness, juiciness, and flavor (Warner et al., 2010). It is important to note that just as the composition of the dietary fatty acid profile plays a role in the quality and nutritional properties of a meat product, so does the quantity of fat (Wood and Enser, 2017). Pigs receiving a low protein diet with lower amounts of lysine and other essential amino acids had a greater amount of intramuscular fat within the longissimus dorsi, compared to control pigs receiving a diet balanced to meet protein and amino acid requirements (Wood et al., 2013).

Altering the fatty acid composition of muscle and fat issues within livestock can be a double-edged sword when it comes to impacting the quality of meat products procured. For pork processors, a condition known as "soft fat" becomes an issue in pork products containing high proportions of linoleic acid (Wood and Enser, 2017). A high level of linoleic acid leading to the development of soft fat, occurs when the fatty acid profile of a pork product contains 15 percent, or more, of linoleic acid (Wood, 1984). Feeding pigs diets containing increased levels of PUFAs may increase the risk of yielding bellies with undesirable processing characteristics from soft fat. In bacon process, the reduced firmness found in soft bellies presents a challenge for adequate slicing, thus reducing the overall yield and quality of bacon slices (Apple et al., 2010). This leads to a reduction in both processor profitability and consumer acceptability (Apple et al., 2010). 


\section{IMPACT OF FATTY ACID MANIPULATION ON BROILER PERFORMANCE, CARCASS YIELD, AND MEAT QUALITY}

\section{Broiler Performance}

Dietary supply of fatty acids can impact broiler growth performance, as a reduction in incoming essential fatty acids can lead to depressed growth (Zollitsch et al., 1993). Thus, producers, feed manufacturers and researchers must be aware of the potential outcomes in broiler performance when altering the dietary fatty acid supply. A study comparing the effect of feeding broilers diets containing differing fat sources of plant, animal, and blended origins, found differences between in the feed to gain ratio in broilers (Zollitsch et al., 1997). Broilers fed diets containing fats of plant origin showed improved feed to gain ratios compared to their counterparts receiving diets with animalbased fats (Zollitsch et al., 1997). The increase in feed efficiency in broilers receiving diets with plant sourced oils may be a result of the increased content of polyunsaturated fatty acids in the oils of plant origin, which have a higher digestibility compared to saturated fatty acids (Kirchgessner et al., 1993).

Research by Hsieh et al. (2002) showed broilers fed diets containing high levels of monounsaturated fatty acids from the addition of olive oil had similar growth performance and feed efficiency to broilers that received a diet containing beef tallow. While studying the effect of increased dietary content of omega-3 polyunsaturated fatty acids sourced from linseed oil in broilers, Haug et al. (2014) also found the increase in dietary supply of omega-3 fatty acids did not impact the final body weight. Moreover, replacement of lard with perilla seed oil, which is similar to linseed oil in fatty acid composition, within the diet of yellow-feathered had no impact on animal growth, or feed 
intake (Cui et al., 2019). Toomer et al., (2020) found feeding broilers high oleic peanuts had no impact on feed efficiency, or final body weight. Based on the above, the potential exists to modified dietary fatty acid composition without negatively impacting broiler efficiency and growth.

\section{Broiler Carcass Yield}

The ability of a broiler to reach its potential carcass and individual part yield is highly dependent on the nutrients supplied through the diet (Zollitsch et al., 1993). Broilers fed different diets containing differing plant, animal, and blended fat oil sources produced carcasses with similar dressing percentages (Zollitsch et al., 1997). Furthermore, results from the same study showed similar yield percentages for breast meat, leg meat, and adnominal fat pads (Zollitsch et al., 1997). Crespo and EsteveGarcia (2001) reported that feeding broilers a diet with increased amounts of polyunsaturated fatty acids reduced the rate of abdominal fat deposition in broilers. Recent work by Toomer et al. (2020) found that broilers fed high oleic peanuts exhibited lighter carcasses and yielded smaller portions of breast meat, than broilers fed a more conventional corn-soy diet. As sales of chicken meat have shifted from a whole carcass basis to individual parts and pieces, it is critical producers and processors continuously monitor changes in part/portion yield (Toomer et al., 2020).

\section{Broiler Meat Quality}

Advancements in genetics and production practices have provided the poultry industry to continually reach new heights in broiler meat yields. Achievement of increased outputs has led to a shift in consideration of improving broiler meat quality (Mir et al., 2017). As previously stated, meat quality is a complex term for describing the 
multiple intrinsic and extrinsic factors that drive consumer appreciation of a meat product (Purslow, 2017). Meat quality of fresh poultry has largely centered around visual appearance (i.e. confirmation, color, presence of bruising) with some attention directed towards texture and flavor (Mir et al., 2017).

The appearance of raw poultry meat is considered one of the most important indicators of quality, as consumers will associate what they see with the products quality and freshness (Mir et al., 2017). Color is a driving factor in visual appraisal of fresh poultry, with the ideal color of raw chicken breast meat being a pale pink color (Mir et al., 2017). Pre-slaughter factors, including diet, genetics, and environmental stress, can impact the final color of fresh chicken meat (Froning, 1995, Mir et al., 2017). Consumers tend to shy away from fresh poultry that shows signs of bruising, bone darkening, and extremely pale or dark color (Mir et al., 2017). Azcona et al. (2008) found that replacing soybeans with ground linseed and high oleic sunflower seeds had no impact on the objective color of breast and leg meat in Argentinean "Camperos" chickens.

With fat playing a key role in the development of flavor (Mir et al., 2017), it is important to understand how changes in the physical properties of a meat product, as a result of dietary fatty acid manipulation, influence consumer perceptions of that product. Palatability is a key determining factor that consumers use for product acceptance and leads to repeat purchase (Webb \& O’Neill, 2008). Sensory panels can be utilized to engage the end consumer of a meat product, with the means to better understand if consumers are able to detect any differences in organoleptic properties of a product, based on dietary manipulation. As for the influence of altering fatty acid supply on the organoleptic properties of broiler breast meat, Zollitsch et al. (1993) reported no 
difference in the perceived taste, juiciness, and tenderness between breast meat samples from broilers receiving diets containing oils from differing sources. The addition of oil sources high in omega-3 polyunsaturated fatty acids, such as fish oil and linseed oil, have shown the potential to negatively impact the odor and flavor of fresh broiler meat, as a result of their increased oxidative potential and volatile aromatic compounds (Lopez et al, 2001).

Shifting the fatty acid composition of poultry meat and fat has the potential to both slow and accelerate the rate of lipid oxidation within fresh poultry meat. In general, increased levels of polyunsaturated fatty acids can induce "soft fat" (Mir et al., 2001), which is more susceptible to lipid oxidation and leads to a reduction in the shelf-life of fresh poultry meat. Broilers fed diets containing olive oil as the main fat source (monounsaturated fatty acids) yielded thighs with lower beginning and ending levels of TBA (thiobarbituric acid) for a seven-day shelf life evaluation, compared to thighs from broilers receiving a diet with tallow and soybean oil as the fat sources (Hsieh et al., 2002).

\section{ALTERING FATTY ACID PROFILES IN MONOGASTRICS}

Differences exist in the composition of fatty acid profiles of meat between major meat producing species (Webb \& O'Neill, 2008). In general, it is widely accepted that dietary supply of fatty acids can influence the fatty acid composition of animal tissues (Wood et al., 2008). However, due to their role in energy metabolism fat depots are in a constant state of flux, thus they may not always reflect the dietary supply of fatty acids (Carroll, 1965; Martin et al., 1972). Furthermore, fatty acid composition of tissue is as 
influenced by the internal supply of fatty acid from de novo synthesis (Wiseman and Agunbiade, 1998). Nonetheless, shifting the composition of fatty acid profiles in monogastrics can be used to improve the nutritional profile of meat products from these animals (Wood and Enser, 2017; Cui et al., 2019). Due to increased rates of inclusion in the human diet, the pig and chicken models have the best potential for use as a tool in affecting positive dietary change in humans through the creation functional foods (Corine et al., 2014; Mir et al., 2017).

\section{Pigs}

When pigs are provided a diet containing a positive balance of energy, the composition of the dietary fatty acid profile can have a strong impact on the fatty acid content of pork carcasses (Duran-Montge et al., 2010). Realini et al. (2010) found similar results when evaluating the impact of animal and plant fat sources on pork carcass fatty acid composition. Pigs fed diets containing increased levels of oleic acid exhibited carcasses with fatty acid profiles that had greater proportions of monounsaturated fatty acids, compared to carcasses from pigs receiving diets with tallow and linseed oil (Realini et al., 2010). Mas et al. (2010) demonstrated that the addition of olive byproducts to the diets of Pietrain-cross pigs could increase the amount of monounsaturated fatty acids in subcutaneous and intramuscular fat depots, while decreasing the amount of polyunsaturated fatty acids. Similar results would be seen in Yorkshire-cross pigs in a follow up study by Mas et al. in 2011, where pigs fed olive by-products showed increased amounts of monounsaturated fatty acids in subcutaneous fat. Fatty acid composition of tissues has also been shown to be influenced by changes in tissue fat content, as a result of changes in the diet (Wood et al., 2013). Wood et al. (2013) showed an increase in the 
amount of oleic acid within the fatty acid profile of intramuscular fat within the longissimus dorsi for the low protein fed pigs mirrored the increase in intramuscular fat content (Wood et al., 2013).

\section{Broilers}

Analysis has shown that the major fatty acids found in chicken meat include oleic acid, palmitic acid, linoleic acid, stearic acid, and arachidonic acid (Zhao et al., 2011; Amorim et al., 2016). The fatty acid profile of poultry meat contains a greater proportion of polyunsaturated fatty acids compared to pork, beef, and lamb. In their analysis of abdominal fat pads and thigh from broilers, Zollitsch et al. (1993) concluded the fatty acid profile of both tissues mirrored the fatty acid profile of the corresponding diet a broiler received. Replacing beef tallow with olive oil in the diet of broilers significantly increased the amount of monounsaturated fatty acids, specifically oleic acid, in samples of breast meat (Hsieh et al., 2002). This increase in monounsaturated fatty acids came with the decrease in the levels of saturated fatty acids (Hsieh et al., 2002).

Azcona et al. (2008) found that breast and leg meat from Argentinean "Camperos" male chickens fed a diet containing ground linseed and high oleic sunflower seeds had a greater proportion of omega-9 monounsaturated fatty acids and omega-3 polyunsaturated fatty acids, compared to birds receiving a more traditional corn/soybean diet. This shift in the fatty acid profile led to an improvement in the omega-6/omega-3 ratio to 4:1, compared to 9:1 in samples from the control birds (Azcona et al., 2008). As a point of reference, 5:1, or less, is considered the ideal omega-6/omega-3 ratio (Raes et al., 2004). 
Linseed oil has become a key feed ingredient in the process of creating functional foods, due to its high content of heart healthy omega-3 (Haug et al., 2014). Haug et al. (2014) increased the omega-3 content of breast meat by replacing soybean oil with linseed oil as the fat source in broiler diets. Toomer et al. (2020) explored the use of high oleic peanuts, another novel feed ingredient, in the diets of broilers. Breast meat from broilers fed high oleic peanuts had an increase in the proportion of monosaturated fatty acids to 55 percent, compared to just 35 percent found in breast meat from birds receiving a more traditional corn-soy diet (Toomer et al., 2020). This increase in monounsaturated fatty acids came with a decrease in the amount of both the pools of saturated and polyunsaturated fatty acids (Toomer et al., 2020). Recent results by Toomer et al. (2020), adds to the foundation of knowledge supporting the idea that dietary fatty acid composition is positively correlated to the fatty acid composition with the meat of monogastrics (Tuunaien et al., 2016; Semogerere et al., 2016).

\section{ROLE OF HIGH OLEIC OILS}

The topic of high oleic oils in the food and feed industries has had a resurgence in recent years, as a result of policy changes from the United State of America Food and Drug Administration (FDA). The FDA removed the status of "Generally Recognized as Safe" from partially hydrogenated oil and banned them for use in human food production in June of 2015 (FDA, 2015). This decision came as an effort to reduce the deleterious effects of dietary trans-fats on human health from partially hydrogenated oils used in food production, as research by the FDA declared these oils to be the primary source of dietary trans-fats for humans (FDA, 2015). Trans-fats have been shown to increase LDL 
cholesterol, or "bad" cholesterol, levels, thus promoting concern over their negative effects on human health.

The FDA listed a final compliance date of June 18, 2018 for trans-fats to be removed from human food products (FDA, 2015). According to the United Soybean Board, this decision by the FDA could lead to a loss of 1.5 billion pounds of soybean oil demand from U.S. food companies on top of the 4 billion pounds of annual soybean demand due to previous trans-fat labeling requirements by the FDA (United Soybean Board, 2017). To fill this void, entities have both created high oleic (C18:1) oil soybean varieties to source a more stable, heart healthier oil product, compared to biohydrogenated soybean oil.

Developments within the fields of plant breeding and gene technology have provided novel oilseeds that present a modified composition, which offers increase functional and nutritional properties (Kris-Etherton \& Etherton, 2003). Prior to the Food and Drug Administration's ban of partially hydrogenated oils, Kris-Etherton \& Etherton (2003) discussed how the food industry's use of hydrogenated oils was decreasing leading up to the ban, as a means to reduce the supply of trans-fatty acids. This began the use of oils with increased contents of oleic acid within alternative oils to provide similar functionality to their hydogenated counterparts (Liu et al., 2002). Kris-Etherton \& Etherton (2003) expressed the importance of keeping track of the nutritional composition of novel oilseeds and their products, as a means of ensuring that accurate nutritional data is available. 


\section{RATIONALE}

The FDA ban on the use of partially hydrogenated oils in food processing has led to a search for stable alternative oil sources for use in the food industry. With its increased proportion of oleic acid, high oleic soybean oil has the ability to serve as a stable oil source in human food processing. Consideration must be given to the scenario in which demand for this new oil source by the food industry is met, causing excess supply to spill over into the livestock feed industry. With the possibility use of this oil in the livestock feed sector, it is necessary to understand the effect of this novel oil and meal source on livestock growth and performance, along with the yield and quality parameters surrounding the meats produced from those animals. Due to increased malleability, monogastric species, such as pigs and poultry, show the greatest potential for positive and negative changes in muscle and adipose tissue composition. This lends them to be ideal models for evaluating the potential effects from uptake of soybean-sourced high oleic acid. 


\title{
CHAPTER 2
}

\section{EVALUATING DIETARY INCLUSION OF MISSOURI HIGH OLEIC SOYBEAN OIL AND MEAL ON BROILER PERFORMANCE AND LIPID QUALITY}

\begin{abstract}
The banning of partially hydrogenated oils in food processing by the FDA has led to a search for alternative oil sources with a decreased potential for oxidation. High oleic soybean oil has the ability to serve as an oil source for both livestock feed and in human food production. The objective of this experiment was to evaluate the effect of dietary inclusion of high oleic soybean meal and oil on broiler performance and lipid quality of broiler meat. Male Ross 308 broiler chicks $(n=160)$ were sorted by weight and randomly assigned to one of two treatments containing 10 replicate pens with 8 broilers each. Treatment groups consisted of a control corn-soy diet that included commodity soybean meal and oil (CON) and a corn-soy diet containing high oleic soybean meal and oil (MOS). Broilers received, ad libitum, a two-phase diet consisting of starter (d0-21) containing $5 \%$ oil and grower $(\mathrm{d} 21-42)$ containing $3 \%$ oil. Body weight $(\mathrm{BW})$ and feed intake (FI) were recorded on days 0,21 , and 42 and used to calculate feed to gain ratio (F:G). Broilers were slaughtered on $\mathrm{d} 42$, after which carcasses were weighed and fabricated. Weights of fabricated parts were recorded for carcass yield. Samples of boneless, skinless breast and thigh meat were taken for fatty acid profile analysis. To
\end{abstract}


measure lipid oxidation, boneless, skinless breast halves chosen randomly from each pen were placed on Styrofoam trays and overwrapped with oxygen permeable, polyvinyl chloride and placed in retail storage $\left(4^{\circ} \mathrm{C}\right)$ and used for collection of thiobarbituric acid reactive substances (TBARS) on day 1, 3, and 5 of storage. Data were analyzed using PROC GLM procedure in SAS, with level of significance set at $\mathrm{P} \leq 0.05$. CON pens had a greater $(\mathrm{P}=0.002)$ change in weight $(2.90 \mathrm{~kg}$ vs $2.72 \mathrm{~kg})$, however, the CON treatment had an increase in FI $(\mathrm{P}=0.002)$ compared to the MOS treatment (2647.61 g vs. 2451.67 g). Thus, there was no difference in F:G between treatments. While there was no difference in percent carcass yield or boneless, skinless breast yield, the CON treatment had a greater $(\mathrm{P}=0.01)$ percent thigh yield compared to the MOS treatment $(16.36 \%$ vs 15.86\%). Results of lipid oxidation demonstrated an effect of day ( $\mathrm{P}<0.001)$, but no treatment or interaction effects were observed. Diet changed $(\mathrm{P}<0.001)$ the proportion of SFA, MUFA, and PUFA in breast and thigh meat. MOS treatment increased the proportion of MUFA and decreased the proportion of PUFA and SFA in both boneless, skinless breast and thigh meat. Both boneless, skinless breast and thigh samples from the MOS treatment had increased $(\mathrm{P}<0.001)$ proportions of $\mathrm{C} 18: 1 \mathrm{n} 9$ and decreased proportions of C18:2n6 compared to the control. Inclusion of MOS soybean meal and oil in broiler diets resulted in increased uptake of MUFA (C18:1) and decreased PUFA (C18:2) in both boneless, skinless breast and thigh meat, while having no impact on broiler feed efficiency. Pull through effect of MOS acid seen in fatty acid analysis of broiler meat, shows the ability to serve as a mechanism to increase oleic acid inclusion in human diets.

\section{INTRODUCTION}


Poultry meat is known to have a fatty acid profile weighted heavier with PUFAs compared to pork, beef, and lamb, resulting in an increased rate of lipid oxidation in fresh poultry (Aberle et al., 2012). This causes fresh poultry products to have a shorter shelflife and decreases margins for retailers due to having to mark down the prices of these products sooner or through a shorter time spent in the retail case. The fatty acid profile of poultry can be manipulated by feed ingredients added to the diet, however any changes made to the diet can yield unexpected outcomes on growth and efficiency. The recent FDA ban on partially hydrogenated oils has driven entities to produce high oleic soybean oil alternatives. The potential exists for these new oil sources to enter the feed supply chain (FDA, 2015). Currently little is known regarding the effect of this oil source on broiler performance, as well as its ability to assimilate into broiler muscle and adipose tissues. The purpose of this study was to evaluate the effect of dietary inclusion of Missouri high oleic soybean meal and oil on broiler performance and carcass quality of male Ross 308 broilers. Based on this purpose, the researcher generated the following objectives and hypotheses:

1. Describe the bird weight, feed intake, and feed to gain ratio of male Ross 308 broilers consuming a diet containing commodity soybean meal and oil.

2. Describe the bird weight, feed intake, and feed to gain ratio of male Ross 308 broilers consuming a diet containing Missouri high oleic soybean meal and oil.

3. Compare the bird weight, feed intake, and feed to gain ratio of male Ross 308 broilers consuming a diet containing commodity soybean meal and oil, to male Ross 308 broilers consuming a diet contain Missouri high oleic soybean meal and oil. 
To address objective 3, the following null and alternative hypotheses were generated:

Ho: No statistically significant $(\mathrm{p}>0.05)$ difference exists between bird weight for male Ross 308 broilers consuming a diet containing commodity soybean meal and oil, when compared to male Ross 308 broilers consuming a diet of Missouri high oleic soybean meal and oil.

H1. A statistically significant $(\mathrm{p} \leq 0.05)$ difference exists between bird weight for male Ross 308 broilers consuming a diet containing commodity soybean meal and oil, when compared to male Ross 308 broilers consuming a diet of Missouri high oleic soybean meal and oil.

Ho: No statistically significant $(\mathrm{p}>0.05)$ difference exists between feed intake for male Ross 308 broilers consuming a diet containing commodity soybean meal and oil, when compared to male Ross 308 broilers consuming a diet of Missouri high oleic soybean meal and oil.

H2. A statistically significant $(p \leq 0.05)$ difference exists between feed intake for male Ross 308 broilers consuming a diet containing commodity soybean meal and oil, when compared to male Ross 308 broilers consuming a diet of Missouri high oleic soybean meal and oil.

Ho: No statistically significant $(p>0.05)$ difference exists between feed:gain ratio for male Ross 308 broilers consuming a diet containing commodity soybean meal and oil, when compared to male Ross 308 broilers consuming a diet of Missouri high oleic soybean meal and oil. 
H3. A statistically significant $(\mathrm{p} \leq 0.05)$ difference exists between feed:gain ratio for male Ross 308 broilers consuming a diet containing commodity soybean meal and oil, when compared to male Ross 308 broilers consuming a diet of Missouri high oleic soybean meal and oil.

4. Describe the carcass weight, carcass yield, boneless, skinless breast and thigh fatty acid profile, breast lipid oxidation, and breast and thigh fat and moisture content of male Ross 308 broilers consuming a diet containing commodity soybean meal and oil.

5. Describe the carcass weight, carcass yield, boneless, skinless breast and thigh fatty acid profile, breast lipid oxidation, and breast and thigh fat and moisture content of male Ross 308 broilers consuming a diet containing Missouri high oleic soybean meal and oil.

6. Compare the carcass weight, carcass yield, boneless, skinless breast and thigh fatty acid profile, breast lipid oxidation, and breast and thigh fat and moisture content of male Ross 308 broilers consuming a diet containing commodity soybean meal and oil to male Ross 308 broilers consuming a diet containing Missouri high oleic soybean meal and oil.

To address objective 6 . the following null and alternative hypotheses were generated:

Ho: No statistically significant $(\mathrm{p}>0.05)$ difference exists between carcass weight for male Ross 308 broilers consuming a diet containing commodity soybean meal 
and oil, when compared to male Ross 308 broilers consuming a diet of Missouri high oleic soybean meal and oil.

H4. A statistically significant $(\mathrm{p} \leq 0.05)$ difference exists between carcass weight for male Ross 308 broilers consuming a diet containing commodity soybean meal and oil, when compared to male Ross 308 broilers consuming a diet of Missouri high oleic soybean meal and oil.

Ho: No statistically significant $(\mathrm{p}>0.05)$ difference exists between carcass yield for male Ross 308 broilers consuming a diet containing commodity soybean meal and oil, when compared to male Ross 308 broilers consuming a diet of Missouri high oleic soybean meal and oil.

H5. A statistically significant $(\mathrm{p} \leq 0.05)$ difference exists between carcass yield for male Ross 308 broilers consuming a diet containing commodity soybean meal and oil, when compared to male Ross 308 broilers consuming a diet of Missouri high oleic soybean meal and oil.

Ho: No statistically significant $(\mathrm{p}>0.05)$ difference exists between boneless, skinless breast and thigh fatty acid profile for male Ross 308 broilers consuming a diet containing commodity soybean meal and oil, when compared to male Ross 308 broilers consuming a diet of Missouri high oleic soybean meal and oil.

H6. A statistically significant $(\mathrm{p} \leq 0.05)$ difference exists between boneless, skinless breast and thigh fatty acid profile for male Ross 308 broilers consuming a diet containing commodity soybean meal and oil, when compared to male Ross 308 broilers consuming a diet of Missouri high oleic soybean meal and oil. 
Ho: No statistically significant $(\mathrm{p}>0.05)$ difference exists between boneless, skinless breast lipid oxidation for male Ross 308 broilers consuming a diet containing commodity soybean meal and oil, when compared to male Ross 308 broilers consuming a diet of Missouri high oleic soybean meal and oil.

H7. A statistically significant $(\mathrm{p} \leq 0.05)$ difference exists between boneless, skinless breast lipid oxidation for male Ross 308 broilers consuming a diet containing commodity soybean meal and oil, when compared to male Ross 308 broilers consuming a diet of Missouri high oleic soybean meal and oil.

Ho: No statistically significant $(\mathrm{p}>0.05)$ difference exists between boneless, skinless breast and thigh moisture content for male Ross 308 broilers consuming a diet containing commodity soybean meal and oil, when compared to male Ross 308 broilers consuming a diet of Missouri high oleic soybean meal and oil.

H8. A statistically significant $(\mathrm{p} \leq 0.05)$ difference exists between boneless, skinless breast and thigh moisture content for male Ross 308 broilers consuming a diet containing commodity soybean meal and oil, when compared to male Ross 308 broilers consuming a diet of Missouri high oleic soybean meal and oil.

Ho: No statistically significant $(\mathrm{p}>0.05)$ difference exists between boneless, skinless breast and thigh fat content for male Ross 308 broilers consuming a diet containing commodity soybean meal and oil, when compared to male Ross 308 broilers consuming a diet of Missouri high oleic soybean meal and oil.

H9. A statistically significant $(\mathrm{p} \leq 0.05)$ difference exists between boneless, skinless breast and thigh fat content for male Ross 308 broilers consuming a diet 
containing commodity soybean meal and oil, when compared to male Ross 308 broilers consuming a diet of Missouri high oleic soybean meal and oil. 


\section{MATERIALS AND METHODS}

The University of Missouri Animal Care and Use Committee approved animal care and experimental protocols prior to initiation of this experiment (\#EX-10094).

\section{Experimental Design}

Male Ross 308 broiler chicks ( $n=160)$ were sorted by weight and then randomly assigned to one of two treatment groups, that contained 10 replicate pens with 8 broilers each. Broilers were housed in a climate-controlled facility, that allowed for the temperature to be adjusted to meet the birds' requirements throughout the growing period.

The two treatment groups consisted of a control corn-soy diet that included conventional commodity soybean meal and oil $(\mathrm{CON})$ and a corn-soy diet containing Missouri high oleic soybean meal and oil (MOS). The commodity soybean oil had an oleic acid content of $21.80 \%$, compared to $81 \%$ oleic acid within the Missouri high oleic soybean oil. Commodity soybean oil was utilized as the control in this experiment due to its use as the preferred oil source in poultry diets (Okur, 2020). Broilers received a twostage diet consisting of a starter diet (d0-21) and a grower diet (d21-42). All diets (Table 2.1) were formulated and balanced to meet energy requirements using the Brill diet formulation software. All animals were provided water and feed ad libitum. Feed was added to pens as needed, with the total weight of feed added used to calculate the total feed consumption of each pen.

Broilers were humanely slaughtered at 7 weeks of age (42 days) following standard and sanitary U.S. poultry industry practices and USDA/FSIS inspection criteria, 
at the University of Missouri Poultry Processing Facility. The abdominal fat pad was collected from each bird during the evisceration process and then weighed. Abdominal fat pads were then placed in labeled Whirlpack bags and frozen until analysis. A boneless, skinless breast portion and a boneless, skinless thigh were collected from each chilled carcass to be used for further analysis. Samples were sealed in Whirlpack bags, labeled and frozen until sample analysis.

\section{Data Collection}

Growth performance. The body weight and feed consumption of all pens was recorded from the start of the study to the final day before the broilers were processed. Body weights were recorded on days 0,21 , and 42 . All pens started with a known amount of feed and any additional feed needed per pen was weighed and recorded before being added. Feeder weights were recorded on days 21 and 42 to measure the residual feed at the end of the starter and grower periods. Bird mortality records were used to adjust feed intake based on calculating bird days on feed. Measurements recorded were used to calculate changes in body weight (BW), feed intake (FI), and feed to gain ratio $(F: G)$ for each treatment.

Carcass weight and breakdown. Broilers were weighed individually prior to slaughter, thus allowing for the dressing percentage of each bird to be calculated. The hot carcass and chilled carcass weight of each bird was recorded. Dressing percentage was calculated by dividing the hot carcass weight by the live weight and multiplying the value by 100. Carcasses were then chilled in an ice water bath for 1 hour, after which a chilled carcass weight was recorded for each carcass. One half of each carcass was 
fabricated in a major, minor, wing, thigh, and leg. The weight of each piece was recorded and used to calculate the percent carcass yield.

Fatty acid analysis. Fatty acid profiles of boneless, skinless breast and thigh samples were determined according to modified methodologies by Folch et al. (1957) and Morrison and Smith (1964). Approximately $100 \mathrm{mg}$ of tissue was homogenized in chloroform:methanol $\left(\mathrm{CHCl}_{3}: \mathrm{CH}_{3} \mathrm{OH}, 2: 1\right.$, v/v) in a glass tube to extract lipids. Dehydrated samples were filtered through a sintered glass funnel fitted with a Whatman $2.4 \mathrm{~cm} \mathrm{GF} / \mathrm{C}$ filter.

A volume of $8 \mathrm{ml}$ of $0.74 \% \mathrm{KCl}$ was added to each sample and after two hours, two distinct layers formed. The upper phase was removed and discarded while the lower phase was evaporated to dryness with nitrogen in a water bath. At the point of dryness, 1 $\mathrm{ml}$ of $0.5 \mathrm{~N} \mathrm{KOH}$ was added to each tube and heated for $10 \mathrm{~min}$. in a $70^{\circ} \mathrm{C}$ water bath. The addition of $\mathrm{KOH}$ initiates the saponification reaction, which hydrolyzes fatty acids from a triglyceride molecule. Following this, $1 \mathrm{ml}$ of $14 \% \mathrm{BF}_{3}$ in $\mathrm{MeOH}$ was added, samples were flushed with nitrogen and heated in the water bath for $30 \mathrm{~min}$. Boron trifluoride is highly volatile and acts as an acid catalyst in the transesterification reaction that methylates the acid group on free fatty acids removing the net negative charge. The remaining molecule is known as a fatty acid methyl ester (FAME).

FAMEs are liquefied by adding $2 \mathrm{ml}$ of HPLC grade hexane and $2 \mathrm{ml}$ of $\mathrm{NaCl}$. Two distinct layers are formed; the upper layer is removed and added to $\sim 800 \mathrm{mg}$ of $\mathrm{Na}_{2} \mathrm{SO}_{4}$ to remove any moisture in the sample. At this point, 2 more $\mathrm{ml}$ of hexane was added to the tube containing $\mathrm{NaCl}$ and once more, the upper layer was removed and added to the tube containing $\mathrm{Na}_{2} \mathrm{SO}_{4}$. The hexane portion was removed from the salt and 
added to a labeled scintillation vial. The salt was rinsed once more with $1 \mathrm{ml}$ of hexane and the liquid was added to the vial. Samples were evaporated to dryness in a water bath at $70^{\circ} \mathrm{C}$ under nitrogen flow. Lastly, samples were reconstituted with $1 \mathrm{ml} \mathrm{HPLC}$ grade hexane and transferred to gas chromatograph vials.

The stable FAMEs were loaded into a Varian 3,800 gas chromatographer (Varion, Pala Alto, CA) to determine fatty acid profiles. The column utilized was a fused silica capillary column (SPTM - 2,560; $100 \mathrm{~m}$ x $0.25 \mathrm{~mm}$ x $0.2 \mu \mathrm{m}$ film thickness; Supelco, Bellefonte, PA). Temperature of the injector was held constant at $240^{\circ} \mathrm{C}$ and temperature of the flame-ionizer detector was held at $260^{\circ} \mathrm{C}$. The oven operated at $140^{\circ} \mathrm{C}$ for $5 \mathrm{~min}$ (temperature programmed $2.5^{\circ} \mathrm{C} / \mathrm{min}$ to $240^{\circ} \mathrm{C}$ and held for $16 \mathrm{~min}$ ). Helium, the carrier gas, was maintained at a constant pressure of $37 \mathrm{psi}$. Individual fatty acids were expressed as a percentage of the total area under the peaks.

Total saturated fatty acid (SFA), monounsaturated fatty acids (MUFA) and polyunsaturated fatty acid (PUFA) contents were calculated according to the following equations: $\mathrm{SFA}=(\mathrm{C} 10: 0+\mathrm{C} 12: 0+\mathrm{C} 14: 0+\mathrm{C} 15: 0+\mathrm{C} 16: 0+\mathrm{C} 17: 0+\mathrm{C} 18: 0+\mathrm{C} 20: 0+$ $\mathrm{C} 22: 0+\mathrm{C} 23: 0) ;$ MUFA $=(\mathrm{C} 14: 1+\mathrm{C} 15: 1+\mathrm{C} 16: 1+\mathrm{C} 17: 1+\mathrm{C} 18: \ln 9 \mathrm{t}+\mathrm{C} 18: 1 \mathrm{n} 9 \mathrm{c}+$ $\mathrm{C} 18: 1 \mathrm{n} 7+\mathrm{C} 20: 1+\mathrm{C} 22: 1 \mathrm{n} 9+\mathrm{C} 24: 1) ;$ PUFA $=(\mathrm{C} 18: 2 \mathrm{n} 6 \mathrm{t}+\mathrm{C} 18: 2 \mathrm{n} 6 \mathrm{c}+\mathrm{C} 18: 3 \mathrm{n} 6+$ $\mathrm{C} 18: 3 \mathrm{n} 3+\mathrm{C} 18: 9 \mathrm{c} 11 \mathrm{t}+\mathrm{C} 18: 10 \mathrm{t} 12 \mathrm{c}+\mathrm{C} 18: 9 \mathrm{c} 11 \mathrm{c}+\mathrm{C} 18: 9 \mathrm{t} 11 \mathrm{t}+\mathrm{C} 20: 2+\mathrm{C} 20: 3 \mathrm{n} 6+$ $\mathrm{C} 20: 3 \mathrm{n} 3+\mathrm{C} 20: 4 \mathrm{n} 6+\mathrm{C} 22: 5 \mathrm{n} 3+\mathrm{C} 22: 6 \mathrm{n} 3)$. The ratio between PUFAs and SFAs was calculated using the equation: $[(\mathrm{C} 18: 2 \mathrm{n} 6 \mathrm{c})+(\mathrm{C} 18: 3 \mathrm{n} 3)] /[(\mathrm{C} 14: 0+\mathrm{C} 16: 0+\mathrm{C} 18: 0)]$. The following equations were used to calculated total omega 3 and omega 6 fatty acid content: total omega $3=\mathrm{C} 18: 3 \mathrm{n} 3+\mathrm{C} 20: 3 \mathrm{n} 3+\mathrm{C} 22: 5 \mathrm{n} 3+\mathrm{C} 22: 6 \mathrm{n} 3)$; total omega $6=$ $(\mathrm{C} 18: 3 \mathrm{n} 6+\mathrm{C} 20: 3 \mathrm{n} 6+\mathrm{C} 20: 4 \mathrm{n} 6)$. 
Lipid oxidation (TBARS). Lipid oxidation of boneless breast, thigh meat, and fresh pork sausage will be measured using the method described by Tarladgis et al. (1960) with modifications from Fernando et al. (2003). Malonaldehyde, a by-product of oxidation, was measured to indicate the rate of oxidation that had occurred in each sample over a specified time period. Four boneless, skinless chicken breast samples from each pen were placed on Styrofoam trays and overwrapped with polyvinyl chloride (PVC), then randomly and stored to one of two retail display cases for 7 days. The conditions within each retail display case were as follows, temperature of $4^{\circ} \mathrm{C}$ and high florescent light source. One sample breast for each pen was removed to be measured on day $1,3,5$, and 7 of the shelf-life study. Duplicate 5 -gram samples of each hanging tender were blended for 2 minutes with $25 \mathrm{ml}$ of distilled water using a Hamilton Beach hand blender. Following homogenization, the cup containing the sample was rinsed with an additional $25 \mathrm{ml}$ of distilled water and transferred into a Kjeldahl flask. $2.5 \mathrm{ml}$ of $\mathrm{HCl}$ was added to the flask to balance the $\mathrm{pH}$ between 1.5 and 1.6 along with two drops of antifoam solution. $25 \mathrm{ml}$ of each sample was distilled through a water-cooled distillation apparatus. Following distillation, $5 \mathrm{ml}$ of each sample was pipetted into a glass tube followed by $5 \mathrm{ml}$ of TBA ( $0.02 \mathrm{M}$ thiobarbituric acid in $90 \%$ acetic acid) reagent. Samples were then placed in a boiling water bath for 35 minutes and then immediately transferred to an ice bath for 10 minutes to stop the chemical reaction. Color absorbance was measured at $538 \mathrm{~nm}$ using a Spectronic 20 (Bausch \& Lomb, Rochester, NY) spectrophotometer. Values of each reading were recorded and averaged for further calculation. Lipid oxidation was expressed in $\mathrm{mg} / \mathrm{kg}$ of malonaldehyde recovered and calculated using the recorded spectrophotometer averages and the give equation below. 


\section{$\mathrm{mg} / \mathrm{kg}$ of malonaldehyde $=7.8 *$ spectrophotometer reading}

Fat and moisture content analysis. Fat and moisture content analysis was performed according to Keeton et al. (2003). A CEM Moisture/Solids Analyzer and Smart Trac Rapid Fat Analysis system (CEM Corp., Matthews, NC, U.S.A.) was used to analyze the samples. Briefly, the moisture percentage was determined by weight using the CEM moisture/solids analyzer and the fat percentage was determined on dry basis using nuclear magnetic resonance and converted to wet basis. Each sample for analysis was performed in triplicate as described by Dow et al. (2011).

\section{Statistical Analysis}

Data were analyzed using the PROC GLM procedure of SAS (SAS Inst., Cary, NC) with pen serving as the experimental unit. The statistical model included the fixed effects of dietary treatment (control corn-soy diet using conventional soybean oil and meal or corn-soy diet using Missouri high oleic soybean oil and meal). The least squares means and standard errors were estimated. Level of significance was set at $\mathrm{P} \leq 0.05$.

\section{RESULTS}

\section{Growth Performance}

Table 2.2 provides a detailed breakdown of the results for broiler growth and performance. Pens receiving the $\mathrm{CON}$ diet showed a significantly greater $(\mathrm{P}=0.002)$ final live weight compared to the pens fed the MOS diet $(2.90 \mathrm{~kg}$ vs $2.72 \mathrm{~kg})$. However, the pens fed the CON treatment diet had an increase in feed intake $(\mathrm{P}=0.002)$ compared 
to the MOS treatment (2647.61 g vs $2451.67 \mathrm{~g})$. Therefore, no significant difference $(\mathrm{P}=$ 0.220) in F:G between treatments was found.

\section{Carcass Weight and Breakdown}

Results for carcass weight and yield can be found in Table 2.3. Pens fed the CON diet produced significantly heavier $\mathrm{HCW}(\mathrm{P}=0.002 ; 2.13 \mathrm{~kg}$ vs $2.01 \mathrm{~kg})$ and $\mathrm{CCW}(\mathrm{P}=$ $0.007 ; 2.23 \mathrm{~kg}$ vs $2.19 \mathrm{~kg}$ ) compared to the pens receiving the MOS diet. However, there was no difference found for dressing percentage and percent carcass yield between treatments. A significant difference between treatments for weight of individual parts and corresponding percent of carcass weight was only seen for liver weight $(\mathrm{P}=0.049)$, leg weight $(\mathrm{P}<0.001)$, thigh weight $(\mathrm{P}<0.001)$, and thigh \% $(\mathrm{P}=0.011)$. Compared to the pens receiving the MOS diet, pens fed the CON diet had heavier livers (45.17 $\mathrm{g}$ vs. $42.50 \mathrm{~g})$, leg portions (156.16 g vs $145.50 \mathrm{~g})$, and thighs (182.20 g vs $166.39 \mathrm{~g})$ Moreover, pens fed the CON treatment had a higher percent thigh yield compared to the MOS treatment (16.36\% vs $15.86 \%)$.

\section{Fatty Acid Analysis}

The fatty acid profile of boneless, skinless breast meat samples can be found in Table 2.6. Diet had a significant impact $(\mathrm{P}<0.001)$ on the proportion of saturated fatty acids (SFA), monounsaturated fatty acids (MUFA), and polyunsaturated fatty acids (PUFA) in broiler boneless, skinless breast meat. Breast samples from pens fed the MOS treatment diet had an increase in the proportion of MUFA, with a decrease in the proportion of PUFA and SFA compared to their counterparts receiving the CON diet. Results for the impact of diet on the level of C18:n9 in boneless, skinless breast meat, show a significantly higher amount $(\mathrm{P}<0.001)$ of $\mathrm{C} 18: 1 \mathrm{n} 9$, combined with a lower $(\mathrm{P}$ 
$<0.001$ ) amount of $\mathrm{C} 18: 2 \mathrm{n} 6$, in boneless, skinless breast meat from pens receiving the MOS treatment compared to CON. However, boneless, skinless breast meat from pens fed the MOS treatment had significantly lower levels $(\mathrm{P}<0.001)$ of $\mathrm{n}-6$ fatty acids compared to the CON pens.

Results for the fatty acid profile of broiler thigh meat (Table 2.7) indicate that diet had a significant impact $(\mathrm{P}<0.0001)$ on the proportion of SFA, MUFA, and PUFA in broiler thigh meat. Similar to the results for the breast samples, pens fed the MOS diet had an increase in the proportion of MUFA, combined with decreased levels of PUFA and SFA in thigh meat. Thigh samples from pens fed the MOS treatment had increased $(\mathrm{P}<0.001)$ levels of $\mathrm{C} 18: 1 \mathrm{n} 9$, as well as decreased $(\mathrm{P}<0.001)$ amounts of $\mathrm{C} 18: 2 \mathrm{n} 6$ and n- 6 fatty acids compared to the control.

\section{Lipid Oxidation (TBARS)}

Table 2.5 outlines the lipid oxidation results from the stimulated retail storage of boneless, skinless breast meat. There was no interaction effect found between treatment and day. Further analysis indicated that while there was also no significant treatment effect on the rate of lipid oxidation of boneless, skinless breast meat, boneless, skinless breast meat from MOS pens showed a tendency $(\mathrm{P}=0.074)$ for a lower average amount of malonaldehyde (0.217 vs. 0.313$)$. Results did show a significant effect of day (P $<0.0001$ ) on the rate of lipid oxidation, with the amount of malonaldehyde remaining similar from day 1 to $3(0.138 \mathrm{mg} / \mathrm{kg}$ and $0.113 \mathrm{mg} / \mathrm{kg})$ and drastically increasing on day $5(0.546 \mathrm{mg} / \mathrm{kg})$.

\section{Fat and Moisture Content Analysis}


Results for the moisture and fat percentage of broiler boneless, skinless breast and thigh meat can be found in Table 2.4. The effect of dietary treatment showed no significant difference $(\mathrm{P}=0.200)$ for the fat percentage found in broiler boneless, skinless breast meat. However, while not significant based on the established $p$-value of $\leq 0.05$, a tendency $(\mathrm{P}=0.093)$ was observed for difference in moisture content of broiler boneless, skinless breast meat. Boneless, skinless breast meat from MOS broilers contained $0.42 \%$ more moisture compared to CON birds ( $74.95 \%$ vs. $74.53 \%$ ). Additionally, no significant difference was observed between samples of thigh meat for either moisture ( $\mathrm{P}$ $=0.419)$ or fat $(\mathrm{P}=0.310)$ content, as a result of dietary treatment.

\section{DISCUSSION}

While birds fed the CON diet were significantly heavier in final live weight compared to the MOS pens, this increase in final live weight came at the cost of increased feed intake to acquire the increase gains in body weight. Thus, broiler efficiency, as measured by F:G, shows no benefit due to one treatment effect versus another. Studies by Hsieh et al. (2002) and Toomer et al. (2020) also found that inclusion of high oleic ingredients in broiler diets did not alter the F:G ratios from those of the control treatments. However, Toomer et al. (2020) reported no difference in final body weight as a result of feeding high oleic peanuts, compared to a corn-soy diet. The decrease in feed intake by the MOS pens could be a result of the slightly greater fat percentage within the diet compared to the CON treatment. Increasing the energy concentration within the diet can lead to a decline in feed intake (Averette Gatlin et al., 2002). 
The increase shown by the CON birds in live weight translated to increased HCW and CCW compared to that of pens fed MOS. The increase in weight found in CON pens, compared to MOS pens, appears to be the result of added weight found in the leg and thigh portions from carcass breakdown. These results conflict with those by Zollitsch et al. (1997), who saw no difference in part yield based on dietary fat source. Strong competition and narrow margins between competitors within the poultry industry make any in loss in carcass yield a questionable outcome. Based on the value of whole chicken roasters from the USDA, the loss in value based on reduced carcass weight would be the following:

$(2.90 \mathrm{~kg}$. for CON x $\$ 3.06 / \mathrm{kg})-.(2.72 \mathrm{~kg}$. for MOS x $\$ 3.06 / \mathrm{kg})=.\$ 0.55$ loss per bird. However, the use of niche, health-focused markets and labeling may provide the potential for placing a premium value on poultry meat containing measurable changes in fatty acids that could be of benefit to human health, as a means to offset a decrease in carcass weight. One example being the "Whole Omega-3 Roaster" chicken product offered by the Texas-based company, Slanker Grass-Fed Meat, which sells for $\$ 6.99$ per pound (Slanker Grass-Fed Meat, N.D.). Comparatively, commodity whole roaster chickens are priced at $\$ 1.39$ per pound (USDA, 2020). Utilizing the premium price established by Slanker Grass-Fed Meats for a poultry product enriched with a specific fatty acid, the potential value difference for a whole bird becomes: $(2.90 \mathrm{~kg}$. for CON x $\$ 3.06 / \mathrm{kg}$. $)$ - $(2.72 \mathrm{~kg}$. for MOS x $\$ 15.38 / \mathrm{kg}$. $)=\$ 32.96$ gain per bird. The drastic gain in value offered through premium niche markets targeting health conscious consumer, may be a more ideal outlet for marketing poultry fed diets containing high oleic soybean oil. 
A measurable difference was observed in liver weights between treatments, with broilers receiving a diet with commodity soybean meal and oil having heavier livers $(\mathrm{P}=$ 0.049) compared to broilers being fed Missouri high oleic soybean meal and oil. As CON birds had heavier live weights, this increase in liver weight is most likely the result of greater physiological need required by the heavier CON birds compared to their lighter MOS counterparts. Research has shown a moderate, positive correlation exists between liver weight and day 42 body weight in broilers (Gaya et al., 2006).

The increase in the carcass weight of CON birds was driven by an increase in the weight of the leg and thigh portions. However, it is not confirmed if the increase in weight of thigh and leg portion of birds fed CON diet, compared to MOS birds, is the result of an increase in muscle tissue, or bone. When combined with the lack of difference in the moisture and fat content of the thighs, it can be suggested that the increase in leg and thigh weights of CON treatment birds may be the result of added bone mass. An increase in lean muscle mass can be potentially ruled out, as thighs of both treatments had similar moisture contents. With the greatest portion of muscle being water, then it can be suggested that if there was an increase in the muscle mass of thighs from the $\mathrm{CON}$ treatment, there should be a corresponding increase in the moisture content of CON thighs. With an observed increase in live weight in CON broilers, one would suspect a corresponding increase in leg bone mass to support the increase in weight.

Fatty acid analysis of boneless, skinless breast and thigh meat revealed that birds from the MOS treatment showed greater inclusion of dietary MUFA (C18:1) in muscle tissues. This increase in the proportion of MUFA came with a corresponding decrease in 
the amount of PUFA and SFA, specifically C18:2 and C16:0, in breast and thigh meat. Similar results for breast and thigh fatty acid profiles indicate the shifts in total portions of fatty acids between SFA, MUFA, and PUFA are not muscle specific. Thus, when a MOS carcass is parted out, all individual parts should have the potential for providing increased proportions of MUFA. Studies by Hsieh et al. (2002), Azcona et al. (2008), and Toomer et al. (2020) all showed significant increases in the levels of MUFA of breast and thigh meat from broilers receiving diets with ingredients high in MUFA. These results add further confirmation to the ability of monogastric species to assimilate dietary fatty acids into tissues and the potential to use this ability to customize the supply of fatty acids that are deposited into broiler muscle and adipose tissue (Wood et al., 2008; Wood and Enser, 2017; Cui et al., 2019).

While not statistically significant, boneless, skinless breasts from MOS fed pens had a tendency $(\mathrm{P}=0.074)$ for decreased lipid oxidation after 5 days of storage in a retail display, compared to breast fillets from CON fed pens. This tendency may be the result of the increase in the proportion of C18:1 in boneless, skinless breast meat of MOS fed birds. Hsieh et al. (2002) also reported a reduction in the rate of lipid oxidation of thigh meat from broilers that received a diet high in monounsaturated fatty acids from olive oil. Shifting the fatty acid profile of poultry meat to have a decreased amount of polyunsaturated fatty acids, can reduce the susceptibility of fresh poultry meat to lipid oxidation and increase product shelf life (Mir et al., 2001). After five-days of retail storage, boneless, skinless breast samples from MOS broilers had a 20 percent lower accumulation of the lipid oxidation byproduct malonaldehyde, compared to CON broiler boneless, skinless breast meat. This numerical difference in lipid oxidation rate has the 
potential for real-world benefits for both retailers and consumers of poultry meat. In 2010 , approximately $\$ 15.4$ billion worth of poultry meat products were discarded at the retail and consumer levels as a result of overstocked shelves, spoilage, and undesirable product appearance (Buzby et al., 2014). The 20 percent improvement in lipid oxidation over a five-day period for MOS boneless, skinless breast meat represents an additional day of shelf-life, compared to CON breast meat.

\section{IMPLICATIONS}

Overall, the inclusion of Missouri high oleic soybean oil and meal in the diets of broilers had no impact on broiler feed efficiency, compared to broilers fed a diet containing traditional commodity soybean oil and meal. Furthermore, results from this experiment show that the increased supply of oleic acid via Missouri high oleic soybean meal and oil in broiler diets resulted in a shift in the fatty acid profile in both boneless, skinless breast and thigh meat to significantly increase the portion of MUFA, while decreasing the proportion of PUFA. Thus, offering the potential to create a broiler meat product containing high levels of MUFA, while at the same time potentially improving the balance of product healthiness and shelf-life. 
Table 2.1. Composition of treatment diets comparing commodity and Missouri high oleic soybean oil and meal.

\begin{tabular}{|c|c|c|c|c|}
\hline \multirow[b]{3}{*}{ Ingredient (kg) } & \multicolumn{4}{|c|}{ Treatment Diets $^{1}$} \\
\hline & \multicolumn{2}{|c|}{ Starter } & \multicolumn{2}{|c|}{ Grower } \\
\hline & $\mathrm{CON}$ & MOS & $\mathrm{CON}$ & MOS \\
\hline Corn & 483.05 & 516.35 & 571.91 & 606.96 \\
\hline SBM 48 & 344.40 & - & 273.81 & - \\
\hline MO High Oleic SBM & - & 310.03 & - & 241.46 \\
\hline Commodity Soybean Oil & 45.87 & - & 33.30 & - \\
\hline MO High Oleic Soybean Oil & - & 45.87 & - & 29.50 \\
\hline Dical Phosphate & 15.59 & 16.04 & 11.23 & 11.46 \\
\hline Limestone & 11.35 & 11.49 & 12.17 & 12.24 \\
\hline Salt & 4.20 & 4.24 & 3.03 & 3.03 \\
\hline NB 3000 Vitamin Premix & 2.27 & 2.27 & 2.27 & 2.27 \\
\hline Methionine & 1.69 & 2.08 & 0.69 & 1.03 \\
\hline Coban 60 & 0.68 & 0.68 & 0.68 & 0.68 \\
\hline \multirow[t]{2}{*}{ Lysine } & - & - & - & 0.46 \\
\hline & 909.09 & 909.09 & 909.09 & 909.09 \\
\hline Crude Protein, \% & 23.99 & 23.65 & 18.15 & 16.96 \\
\hline Crude Fat, \% & 4.80 & 7.25 & 3.73 & 5.12 \\
\hline Crude Fiber, \% & 2.22 & 2.08 & 2.39 & 3.11 \\
\hline Moisture, $\%$ & 11.54 & 10.11 & 12.04 & 11.12 \\
\hline Ash, $\%$ & 5.20 & 5.96 & 5.15 & 4.06 \\
\hline
\end{tabular}

${ }^{1} \mathrm{CON}=$ Control, $\mathrm{MOS}=$ Missouri high oleic soybean oil and meal 
Table 2.2. Growth Performance least squares means of broilers fed commodity soybean oil and meal and Missouri high oleic soybean oil and meal.

\begin{tabular}{lcccc}
\hline & \multicolumn{4}{c}{ Treatments $^{1}$} \\
\cline { 2 - 5 } Item $^{\mathrm{A}}$ & $\mathrm{CON}$ & MOS & SEM & P-value \\
\hline Final Live Weight, $\mathrm{kg}$ & $2.90^{\mathrm{a}}$ & $2.72^{\mathrm{b}}$ & 0.03 & 0.002 \\
Feed Intake, g & $2647.61^{\mathrm{a}}$ & $2451.67^{\mathrm{b}}$ & 46.98 & 0.002 \\
F:G, kg & 1.27 & 1.25 & 0.01 & 0.220 \\
\hline
\end{tabular}

${ }^{\mathrm{A}} \mathrm{LS}$ means within a row without superscripts do not differ at $\mathrm{P} \leq 0.05$.

${ }^{1} \mathrm{CON}=$ Control, $\mathrm{MOS}=$ Missouri high oleic soybean oil and meal 
Table 2.3. Carcass yield least squares means of broilers fed commodity soybean oil and meal and Missouri high oleic soybean oil and meal.

\begin{tabular}{|c|c|c|c|c|}
\hline \multirow[b]{2}{*}{ Item $^{\mathrm{A}}$} & \multicolumn{4}{|c|}{ Treatments $^{1}$} \\
\hline & $\mathrm{CON}$ & MOS & SEM & P-value \\
\hline $\mathrm{HCW}, \mathrm{kg}$ & 2.13 & 2.01 & 325.60 & 0.002 \\
\hline $\mathrm{CCW}, \mathrm{kg}$ & 2.23 & 2.10 & 0.03 & 0.007 \\
\hline Dressing Percent, \% & 76.87 & 77.10 & 0.16 & 0.299 \\
\hline Carcass Yield, \% & 72.05 & 73.09 & 0.84 & 0.387 \\
\hline Fat Pad, g & 42.00 & 39.13 & 1.35 & 0.133 \\
\hline Fat Pad, \% & 1.87 & 1.88 & 0.06 & 0.975 \\
\hline Liver, $\mathrm{g}$ & 45.17 & 42.50 & 0.95 & 0.049 \\
\hline Liver, \% & 2.12 & 2.12 & 0.03 & 0.911 \\
\hline Major, $\mathrm{g}$ & 296.72 & 283.02 & 6.41 & 0.133 \\
\hline Major, \% & 26.48 & 26.62 & 0.27 & 0.708 \\
\hline Minor, g & 52.97 & 51.44 & 1.06 & 0.309 \\
\hline Minor, $\%$ & 4.76 & 4.89 & 0.07 & 0.202 \\
\hline Leg, g & 156.16 & 145.50 & 2.00 & $<0.001$ \\
\hline Leg, \% & 14.05 & 13.94 & 0.12 & 0.484 \\
\hline Thigh, $\mathrm{g}$ & 182.20 & 166.39 & 2.78 & $<0.001$ \\
\hline Thigh, \% & 16.36 & 15.86 & 0.14 & 0.011 \\
\hline Wing, $g$ & 115.56 & 125.70 & 10.78 & 0.507 \\
\hline Wing, \% & 10.41 & 11.78 & 0.83 & 0.242 \\
\hline
\end{tabular}

${ }^{\mathrm{A}} \mathrm{LS}$ means within a row without superscripts do not differ at $\mathrm{P} \leq 0.05$.

${ }^{1} \mathrm{CON}=$ Control, $\mathrm{MOS}=$ Missouri high oleic soybean oil and meal 
Table 2.4. CEM moisture and fat percentages of boneless, skinless breast and thigh meat from broilers fed commodity soybean oil and meal and Missouri high oleic soybean oil and meal.

\begin{tabular}{lcccc}
\hline & \multicolumn{4}{c}{ Treatments $^{1}$} \\
\cline { 2 - 5 } Item $^{\mathrm{A}}$ & CON & MOS & SEM & P-value \\
\hline Breast Moisture, \% & 74.53 & 74.95 & 0.17 & 0.093 \\
Breast Fat, \% & 3.25 & 2.93 & 0.17 & 0.200 \\
Thigh Moisture, \% & 74.50 & 74.30 & 0.17 & 0.419 \\
Thigh Fat, \% & 5.77 & 6.05 & 0.19 & 0.310 \\
\hline
\end{tabular}

${ }^{\mathrm{A}} \mathrm{LS}$ means within a row without superscripts do not differ at $\mathrm{P} \leq 0.05$.

${ }^{1} \mathrm{CON}=$ Control, $\mathrm{MOS}=$ Missouri high oleic soybean oil and meal 
Table 2.5. Influence of High Oleic Soybean Oil and Meal on Lipid Oxidation of Boneless, Skinless Breast Meat.

\begin{tabular}{|c|c|c|c|}
\hline \multirow[b]{2}{*}{ Item $^{\mathrm{A}}$} & \multicolumn{3}{|c|}{ Treatments $^{1}$} \\
\hline & Malonaldehyde, g/kg & SEM & P-value \\
\hline \multicolumn{4}{|l|}{ Treatment } \\
\hline $\mathrm{CON}$ & 0.313 & \multirow{2}{*}{0.17} & \multirow{2}{*}{0.074} \\
\hline MOS & 0.217 & & \\
\hline \multicolumn{4}{|l|}{ Day } \\
\hline 1 & $0.138^{\mathrm{a}}$ & \multirow{3}{*}{0.05} & \multirow{3}{*}{$<.001$} \\
\hline 3 & $0.113^{\mathrm{a}}$ & & \\
\hline 5 & $0.546^{\mathrm{b}}$ & & \\
\hline
\end{tabular}


Table 2.6. Fatty acid profile of broiler boneless, skinless breast meat from broilers fed commodity soybean oil and meal and Missouri high oleic soybean oil and meal.

\begin{tabular}{lcccc}
\hline & \multicolumn{3}{c}{ Treatments $^{1}$} \\
\cline { 2 - 5 } Item $^{\mathrm{A}}$ & CON & MOS & SEM & P-value \\
\hline C16:0 (Palmitic acid), \% & $20.64^{\mathrm{b}}$ & $18.95^{\mathrm{a}}$ & 0.16 & $<.0001$ \\
C16:1 (Palmitoleic acid), \% & $3.31^{\mathrm{a}}$ & $3.91^{\mathrm{b}}$ & 0.06 & $<.0001$ \\
C18:0 (Stearic acid), \% & $7.05^{\mathrm{b}}$ & $6.03^{\mathrm{a}}$ & 0.09 & $<.0001$ \\
C18:1n9 (Oleic acid), \% & $34.07^{\mathrm{a}}$ & $54.30^{\mathrm{b}}$ & 0.25 & $<.0001$ \\
C18:2n6 (Linoleic acid), \% & $28.97^{\mathrm{b}}$ & $11.90^{\mathrm{a}}$ & 0.20 & $<.0001$ \\
C20:4n6 (Arachidonic acid), \% & $2.18^{\mathrm{b}}$ & $0.73^{\mathrm{a}}$ & 0.03 & $<.0001$ \\
Total SFA, \% & $28.92^{\mathrm{b}}$ & $26.05^{\mathrm{a}}$ & 0.25 & $<.0001$ \\
Total MUFA, \% & $39.27^{\mathrm{a}}$ & $60.52^{\mathrm{b}}$ & 0.20 & $<.0001$ \\
Total PUFA, \% & $31.44^{\mathrm{b}}$ & $12.87^{\mathrm{a}}$ & 0.23 & $<.0001$ \\
Omega-6, \% & $31.15^{\mathrm{b}}$ & $12.56^{\mathrm{a}}$ & 0.22 & $<.0001$ \\
Omega-3, \% & 0.24 & 0.28 & 0.05 & 0.594 \\
\hline
\end{tabular}

${ }^{\mathrm{A}} \mathrm{LS}$ means within a row without superscripts do not differ at $\mathrm{P} \leq 0.05$.

${ }^{1} \mathrm{CON}=$ Control, $\mathrm{MOS}=$ Missouri high oleic soybean oil and meal 
Table 2.7. Fatty acid profile of broiler thigh meat from broilers fed commodity soybean oil and meal and Missouri high oleic soybean oil and meal.

\begin{tabular}{lcccc}
\hline & \multicolumn{3}{c}{ Treatments $^{1}$} \\
\cline { 2 - 5 } Item $^{\mathrm{A}}$ & CON & MOS & SEM & P-value \\
\hline C16:0 (Palmitic acid), \% & $19.78^{\mathrm{b}}$ & $18.01^{\mathrm{a}}$ & 0.17 & $<.001$ \\
C16:1 (Palmitoleic acid), \% & $3.57^{\mathrm{a}}$ & $4.14^{\mathrm{b}}$ & 0.10 & $<.001$ \\
C18:0 (Stearic acid), \% & $6.54^{\mathrm{b}}$ & $5.43^{\mathrm{a}}$ & 0.08 & $<.001$ \\
C18:1n9 (Oleic acid), \% & $33.68^{\mathrm{a}}$ & $55.02^{\mathrm{b}}$ & 0.13 & $<.001$ \\
C18:2n6 (Linoleic acid), \% & $29.42^{\mathrm{b}}$ & $11.97^{\mathrm{a}}$ & 0.13 & $<.001$ \\
C20:4n6 (Arachidonic acid), \% & $2.24^{\mathrm{b}}$ & $0.75^{\mathrm{a}}$ & 0.02 & $<.001$ \\
Total SFA, \% & $27.60^{\mathrm{b}}$ & $24.22^{\mathrm{a}}$ & 0.28 & $<.001$ \\
Total MUFA, \% & $38.95^{\mathrm{a}}$ & $60.31^{\mathrm{b}}$ & 0.58 & $<.001$ \\
Total PUFA, \% & $32.84^{\mathrm{b}}$ & $13.46^{\mathrm{a}}$ & 0.19 & $<.001$ \\
Omega-6, \% & $31.67^{\mathrm{b}}$ & $12.56^{\mathrm{a}}$ & 0.16 & $<.001$ \\
Omega-3, \% & $1.11^{\mathrm{b}}$ & $0.85^{\mathrm{a}}$ & 0.05 & 0.004
\end{tabular}

${ }^{\mathrm{A}} \mathrm{LS}$ means within a row without superscripts do not differ at $\mathrm{P} \leq 0.05$.

${ }^{1} \mathrm{CON}=$ Control, $\mathrm{MOS}=$ Missouri high oleic soybean oil and meal 


\title{
CHAPTER 3
}

\section{EFFECT OF DIETARY INCULSION OF PLENISH HIGH OLEIC SOYBEAN OIL ON THE GROWTH PERFORMANCE AND FATTY ACID PROFILE OF BROILERS}

\begin{abstract}
Plenish ${ }^{\circledR}$ is a novel high oleic soybean oil product that has been developed, as a result of the FDA banning of partially hydrogenated oils in the food processing industry. While marketed and founded for use in the food industry, it is only a matter of time before this oil source makes its way into the livestock feed sector. The objective of this experiment was to evaluate the effects of replacing commodity soybean oil in the diets of broilers with Plenish, at two levels of inclusion, on broiler performance and tissue fatty acid composition. Cobb 500 as-hatched broiler chicks $(n=1344)$ were sorted by weight and then randomly assigned to one of four treatment groups, containing 12 replicate pens with 28 broilers each. Diets consisted of two control corn-soy diets with commodity soybean oil at 2.5\% (C2.5) and 5.0\% (C5) and two corn-soy diets containing Plenish ${ }^{\circledR}$ (high oleic soybean oil) at 2.5\% (P2.5) and 5.0\% (P5). Pens and feed were weighed and recorded to calculate changes in body weight (BW), average daily gain (ADG), feed intake $(\mathrm{FI})$, and feed to gain ratio $(\mathrm{F}: \mathrm{G})$ for each treatment. Broilers were slaughter on d49, after which carcasses were weighed and fabricated. A breast fillet was removed and weighed for yield. Breast meat samples were collected by pen and used for moisture and
\end{abstract}


fat analysis. Furthermore, samples of breast meat and abdominal fat pads were lotted by pen and used for fatty acid analysis. Data were analyzed using the PROC GLM procedure in SAS 9.4, with level of significance set at $\mathrm{P} \leq 0.05$. C2.5 pens had the heaviest final live weights $(\mathrm{P}=0.016)$ and the greatest amount of weight gain $(\mathrm{P}=0.016)$ compared to the other treatments, which were all similar $(\mathrm{P}>0.05)$ in final live weight and weight gain. Furthermore, broilers receiving a diet with $2.5 \%$ commodity soybean oil consumed a greater amount $(\mathrm{P}=0.003)$ of feed compared to the other treatment pens. However, there was no significant difference between treatments for $\mathrm{F}: \mathrm{G}(\mathrm{P}=0.202)$, or dressing percentage $(\mathrm{P}=0.435)$. Fatty acid analysis of boneless, skinless breast meat and fat pads suggests broilers receiving diets with Plenish ${ }^{\circledR}$ had greater portions of MUFA, specifically $\mathrm{C} 18: \ln 9$ and a decrease in PUFA, specifically C18:2n6 (linoleic acid) and C20:4n6 (arachidonic acid). Replacement of commodity soybean oil with Plenish ${ }^{\circledR}$ can successfully shift the fatty acid profile of broiler meat to have a greater proportion of MUFA, without having a deleterious effect on broiler feed efficiency. 


\section{INTRODUCTION}

The 2015 ban on partially hydrogenated oils by the FDA has resulted in a search for alternative sources of stable oil for use in the food industry (FDA, 2015). Plenish $®$ is one of a couple of new oil alternatives that has come from this search. Plenish ${ }^{\circledR}$ is in a high oleic soybean oil offered by Corteva and contains approximate 75 percent oleic acid (Corteva agriscience, N. D.). While marketed and founded for use in the food industry, it is only a matter of time before this oil source makes its way into the livestock feed sector. This may happen as a result of increased supply spilling over into the livestock industry, or as the result of trying to expand the market for this new product. At this time, little work exists on the potential impact of this oil source on animal performance and its ability to influence the fatty acid profile of animal tissues. The purpose of this study was to evaluate the effect of dietary inclusion of Plenish ${ }^{\circledR}$ high oleic soybean meal and oil on broiler performance and carcass quality of as-hatched Cobb 500 broilers. Based on this purpose, the researcher generated the following objectives and hypotheses:

1. Describe the bird weight, feed intake, average daily gain, and feed to gain ratio of as-hatched Cobb 500 broilers consuming a diet containing commodity soybean meal and oil.

2. Describe the bird weight, feed intake, average daily gain, and feed to gain ratio of as-hatched Cobb 500 broilers consuming a diet containing Plenish ${ }^{\circledR}$ high oleic soybean oil.

3. Compare the bird weight, feed intake, average daily gain, and feed to gain ratio of as-hatched Cobb 500 broilers consuming a diet containing commodity soybean 
meal and oil, to as-hatched Cobb 500 broilers consuming a diet contain Plenish ${ }$ high oleic soybean oil.

To address objective 3 , the following null and alternative hypotheses were generated:

Ho: No statistically significant $(\mathrm{p}>0.05)$ difference exists between bird weight for as-hatched Cobb 500 broilers consuming a diet containing commodity soybean meal and oil, when compared to as-hatched Cobb 500 broilers consuming a diet of Plenish ${ }^{\circledR}$ high oleic soybean oil.

H1. A statistically significant $(\mathrm{p} \leq 0.05)$ difference exists between bird weight for ashatched Cobb 500 broilers consuming a diet containing commodity soybean meal and oil, when compared to as-hatched Cobb 500 broilers consuming a diet of Plenish $®$ high oleic soybean oil.

Ho: No statistically significant $(p>0.05)$ difference exists between feed intake for as-hatched Cobb 500 broilers consuming a diet containing commodity soybean meal and oil, when compared to as-hatched Cobb 500 broilers consuming a diet of Plenish ${ }^{\circledR}$ high oleic soybean oil.

H2. A statistically significant $(p \leq 0.05)$ difference exists between feed intake for ashatched Cobb 500 broilers consuming a diet containing commodity soybean meal and oil, when compared to as-hatched Cobb 500 broilers consuming a diet of Plenish ${ }^{\circledR}$ high oleic soybean oil.

Ho: No statistically significant $(\mathrm{p}>0.05)$ difference exists between average daily gain for as-hatched Cobb 500 broilers consuming a diet containing commodity 
soybean meal and oil, when compared to as-hatched Cobb 500 broilers consuming a diet of Plenish ${ }^{\circledR}$ high oleic soybean oil.

H3. A statistically significant $(p \leq 0.05)$ difference exists between average daily gain for as-hatched Cobb 500 broilers consuming a diet containing commodity soybean meal and oil, when compared to as-hatched Cobb 500 broilers consuming a diet of Plenish® high oleic soybean oil.

Ho: No statistically significant $(p>0.05)$ difference exists between feed:gain ratio for as-hatched Cobb 500 broilers consuming a diet containing commodity soybean meal and oil, when compared to as-hatched Cobb 500 broilers consuming a diet of Plenish ${ }^{\circledR}$ high oleic soybean oil.

H4. A statistically significant $(\mathrm{p} \leq 0.05)$ difference exists between feed:gain ratio for as-hatched Cobb 500 broilers consuming a diet containing commodity soybean meal and oil, when compared to as-hatched Cobb 500 broilers consuming a diet of Plenish ${ }^{\circledR}$ high oleic soybean oil.

4. Describe the carcass weight, carcass yield, breast and abdominal fat pad fatty acid profile, and breast fat and moisture content of as-hatched Cobb 500 broilers consuming a diet containing commodity soybean meal and oil.

5. Describe the carcass weight, carcass yield, breast and abdominal fat pad fatty acid profile, and breast fat and moisture content of as-hatched Cobb 500 broilers consuming a diet containing Plenish ${ }^{\circledR}$ high oleic soybean oil.

6. Compare the carcass weight, carcass yield, boneless, skinless breast and abdominal fat pad fatty acid profile, and boneless, skinless breast fat and moisture 
content of as-hatched Cobb 500 broilers consuming a diet containing commodity soybean meal and oil to as-hatched Cobb 500 broilers consuming a diet containing Plenish ${ }^{\circledR}$ high oleic soybean oil.

To address objective 6 . the following null and alternative hypotheses were generated:

Ho: No statistically significant $(\mathrm{p}>0.05)$ difference exists between carcass weight for as-hatched Cobb 500 broilers consuming a diet containing commodity soybean meal and oil, when compared to as-hatched Cobb 500 broilers consuming a diet of Plenish ${ }^{\circledR}$ high oleic soybean oil.

H5. A statistically significant $(p \leq 0.05)$ difference exists between carcass weight for as-hatched Cobb 500 broilers consuming a diet containing commodity soybean meal and oil, when compared to as-hatched Cobb 500 broilers consuming a diet of Plenish ${ }^{\circledR}$ high oleic soybean oil.

Ho: No statistically significant $(\mathrm{p}>0.05)$ difference exists between carcass yield for as-hatched Cobb 500 broilers consuming a diet containing commodity soybean meal and oil, when compared to as-hatched Cobb 500 broilers consuming a diet of Plenish ${ }^{\circledR}$ high oleic soybean oil.

H6. A statistically significant $(\mathrm{p} \leq 0.05)$ difference exists between carcass yield for as-hatched Cobb 500 broilers consuming a diet containing commodity soybean meal and oil, when compared to as-hatched Cobb 500 broilers consuming a diet of Plenish ${ }^{\circledR}$ high oleic soybean oil. 
Ho: No statistically significant $(\mathrm{p}>0.05)$ difference exists between boneless, skinless breast and thigh fatty acid profile for as-hatched Cobb 500 broilers consuming a diet containing commodity soybean meal and oil, when compared to as-hatched Cobb 500 broilers consuming a diet of Plenish ${ }^{\circledR}$ high oleic soybean oil.

H7. A statistically significant $(p \leq 0.05)$ difference exists between boneless, skinless breast and abdominal fat pad fatty acid profile for as-hatched Cobb 500 broilers consuming a diet containing commodity soybean meal and oil, when compared to as-hatched Cobb 500 broilers consuming a diet of Plenish ${ }^{\circledR}$ high oleic soybean oil.

Ho: No statistically significant $(\mathrm{p}>0.05)$ difference exists between boneless, skinless breast moisture content for as-hatched Cobb 500 broilers consuming a diet containing commodity soybean meal and oil, when compared to as-hatched Cobb 500 broilers consuming a diet of Plenish ${ }^{\circledR}$ high oleic soybean oil.

H8. A statistically significant $(\mathrm{p} \leq 0.05)$ difference exists between boneless, skinless breast moisture content for as-hatched Cobb 500 broilers consuming a diet containing commodity soybean meal and oil, when compared to as-hatched Cobb 500 broilers consuming a diet of Plenish ${ }^{\circledR}$ high oleic soybean oil.

Ho: No statistically significant $(\mathrm{p}>0.05)$ difference exists between boneless, skinless breast fat content for as-hatched Cobb 500 broilers consuming a diet containing commodity soybean meal and oil, when compared to as-hatched Cobb 500 broilers consuming a diet of Plenish ${ }^{\circledR}$ high oleic soybean oil. 
H9. A statistically significant $(\mathrm{p} \leq 0.05)$ difference exists between boneless, skinless breast fat content for as-hatched Cobb 500 broilers consuming a diet containing commodity soybean meal and oil, when compared to as-hatched Cobb 500 broilers consuming a diet of Plenish ${ }^{\circledR}$ high oleic soybean oil. 


\section{MATERIALS AND METHODS}

The University of Missouri Animal Care and Use Committee approved animal care and experimental protocols prior to initiation of this experiment (\#EX-10094).

\section{Experimental Design}

Cobb 500 as-hatched broiler chicks $(n=1344)$ were sorted by weight and then randomly assigned to one of four treatment groups, containing 12 replicate pens with 28 broilers each. Broilers were housed in a climate-controlled facility, that allowed for the temperature to be adjusted to meet the birds' requirements throughout the experimental period.

The four treatment diets consisted of two control diet corn-soy diet that included conventional soybean oil at levels of 2.5\% (C2.5) and 5.0\% (C5) and two corn-soy diets containing Plenish ${ }^{\circledR}$ (high oleic soybean oil) at 2.5\% (P2.5) and 5.0\% (P5). Commodity soybean oil was utilized as the control in this experiment to compare Plenish ${ }^{\circledR}$ to, due to its use as the preferred oil source in poultry diets (Okur, 2020). Rate of oil inclusion of $2.5 \%$ and $5 \%$ for both oils was used to observe the effect of increased rate of inclusion of Plenish ${ }^{\circledR}$ on broiler performance and fatty acid profile of broiler tissues. Broilers received a three-stage diet consisting of a starter diet (d0-17), grower diet (d17-31), and finisher diet (d31-49) (Tables 3.1, 3.2, 3.3). All diets were formulated and balanced to meet NRC nutritional requirements (NRC, 1994). All animals were provided water and

feed ad libitum. Feed was added to pens as needed, with the total weight of feed added recorded to use to calculate the total feed consumption of each pen. 
Broilers were humanely slaughtered at 8 weeks of age (49 days) following standard and sanitary U.S. poultry industry practices and USDA/FSIS inspection criteria, at Central Illinois Poultry Processing, LLC in Arthur, Illinois. Abdominal fat pads were collected from each bird during the evisceration process, lotted by pen, then frozen for further fatty acid analysis. Whole carcasses were individually packaged, weighed, and stored under refrigeration for further sample retrieval. Approximately 24 hours postmortem a boneless, skinless breast portion and a boneless, skinless thigh were collected from each chilled carcass and packaged for storage by pen in Whirlpack bags, labeled, and frozen for further analysis.

\section{Data Collection}

Growth performance. The body weight and feed consumption of all pens was recorded from the start of the study to the final day before the all broilers were processed. Pen weights were recorded on days $0,17,31$, and 49 . All pens started with a known amount of feed and any additional feed needed per pen was weighed and recorded before being added. Feeder weights were recorded on days 17, 31, and 49 to measure the residual feed at the end of each production period. Bird mortality records were used to adjust feed intake based on calculating bird days on feed. Recorded measurements were used to calculate changes in body weight (BW), average daily gain (ADG), feed intake (FI), and feed to gain ratio $(\mathrm{F}: \mathrm{G})$ for each treatment.

Carcass weight and dressing percentage. Pen weights prior to slaughter were used in conjunction with carcass weights for each pen to calculate the average dressing percentage of each pen and treatment. Dressing percentage was calculated by dividing 
the chilled carcass weight by the live weight and multiplying the value by 100 . One boneless, skinless breast half was fabricated from each carcass of each pen, then individually weighed and recorded by pen. The average breast half weight for each pen was then calculated.

Fatty acid analysis. Fatty acid profiles of both a combined pen fat pad sample and a combined pen boneless, skinless breast meat sample were determined according to modified methodologies by Folch et al. (1957) and Morrison and Smith (1964). Approximately $100 \mathrm{mg}$ of sample was homogenized in chloroform:methanol $\left(\mathrm{CHCl}_{3}: \mathrm{CH}_{3} \mathrm{OH}, 2: 1, \mathrm{v} / \mathrm{v}\right)$ in a glass tube to extract lipids. Dehydrated samples were filtered through a sintered glass funnel fitted with a Whatman $2.4 \mathrm{~cm} \mathrm{GF/C} \mathrm{filter.}$

A volume of $8 \mathrm{ml}$ of $0.74 \% \mathrm{KCl}$ was added to each sample and after two hours, two distinct layers formed. The upper phase was removed and discarded while the lower phase was evaporated to dryness with nitrogen in a water bath. At the point of dryness, 1 $\mathrm{ml}$ of $0.5 \mathrm{~N} \mathrm{KOH}$ was added to each tube and heated for $10 \mathrm{~min}$. in a $70^{\circ} \mathrm{C}$ water bath. The addition of $\mathrm{KOH}$ initiates the saponification reaction, which hydrolyzes fatty acids from a triglyceride molecule. Following this, $1 \mathrm{ml}$ of $14 \% \mathrm{BF}_{3}$ in $\mathrm{MeOH}$ was added, samples were flushed with nitrogen and heated in the water bath for $30 \mathrm{~min}$. Boron trifluoride is highly volatile and acts as an acid catalyst in the transesterification reaction that methylates the acid group on free fatty acids removing the net negative charge. The remaining molecule is known as a fatty acid methyl ester (FAME).

FAMEs are liquefied by adding $2 \mathrm{ml}$ of HPLC grade hexane and $2 \mathrm{ml}$ of $\mathrm{NaCl}$. Two distinct layers are formed; the upper layer is removed and added to $\sim 800 \mathrm{mg}$ of $\mathrm{Na}_{2} \mathrm{SO}_{4}$ to remove any moisture in the sample. At this point, 2 more $\mathrm{ml}$ of hexane was 
added to the tube containing $\mathrm{NaCl}$ and once more, the upper layer was removed and added to the tube containing $\mathrm{Na}_{2} \mathrm{SO}_{4}$. The hexane portion was removed from the salt and added to a labeled scintillation vial. The salt was rinsed once more with $1 \mathrm{ml}$ of hexane and the liquid was added to the vial. Samples were evaporated to dryness in a water bath at $70^{\circ} \mathrm{C}$ under nitrogen flow. Lastly, samples were reconstituted with $1 \mathrm{ml} \mathrm{HPLC}$ grade hexane and transferred to gas chromatograph vials.

The stable FAMEs were loaded into a Varian 3,800 gas chromatographer (Varion, Pala Alto, CA) to determine fatty acid profiles. The column utilized was a fused silica capillary column (SPTM - 2,560; $100 \mathrm{~m}$ x $0.25 \mathrm{~mm}$ x $0.2 \mu \mathrm{m}$ film thickness; Supelco, Bellefonte, PA). Temperature of the injector was held constant at $240^{\circ} \mathrm{C}$ and temperature of the flame-ionizer detector was held at $260^{\circ} \mathrm{C}$. The oven operated at $140^{\circ} \mathrm{C}$ for $5 \mathrm{~min}$ (temperature programmed $2.5^{\circ} \mathrm{C} / \mathrm{min}$ to $240^{\circ} \mathrm{C}$ and held for $16 \mathrm{~min}$ ). Helium, the carrier gas, was maintained at a constant pressure of 37 psi. Individual fatty acids were expressed as a percentage of the total area under the peaks.

Total saturated fatty acid (SFA), monounsaturated fatty acids (MUFA) and polyunsaturated fatty acid (PUFA) contents were calculated according to the following equations: $\mathrm{SFA}=(\mathrm{C} 10: 0+\mathrm{C} 12: 0+\mathrm{C} 14: 0+\mathrm{C} 15: 0+\mathrm{C} 16: 0+\mathrm{C} 17: 0+\mathrm{C} 18: 0+\mathrm{C} 20: 0+$ $\mathrm{C} 22: 0+\mathrm{C} 23: 0) ; \mathrm{MUFA}=(\mathrm{C} 14: 1+\mathrm{C} 15: 1+\mathrm{C} 16: 1+\mathrm{C} 17: 1+\mathrm{C} 18: \ln 9 \mathrm{t}+\mathrm{C} 18: \ln 9 \mathrm{c}+$ $\mathrm{C} 18: 1 \mathrm{n} 7+\mathrm{C} 20: 1+\mathrm{C} 22: 1 \mathrm{n} 9+\mathrm{C} 24: 1) ;$ PUFA $=(\mathrm{C} 18: 2 \mathrm{n} 6 \mathrm{t}+\mathrm{C} 18: 2 \mathrm{n} 6 \mathrm{c}+\mathrm{C} 18: 3 \mathrm{n} 6+$ $\mathrm{C} 18: 3 \mathrm{n} 3+\mathrm{C} 18: 9 \mathrm{c} 11 \mathrm{t}+\mathrm{C} 18: 10 \mathrm{t} 12 \mathrm{c}+\mathrm{C} 18: 9 \mathrm{c} 11 \mathrm{c}+\mathrm{C} 18: 9 \mathrm{t} 11 \mathrm{t}+\mathrm{C} 20: 2+\mathrm{C} 20: 3 \mathrm{n} 6+$ $\mathrm{C} 20: 3 \mathrm{n} 3+\mathrm{C} 20: 4 \mathrm{n} 6+\mathrm{C} 22: 5 \mathrm{n} 3+\mathrm{C} 22: 6 \mathrm{n} 3)$. The ratio between PUFAs and SFAs was calculated using the equation: $[(\mathrm{C} 18: 2 \mathrm{n} 6 \mathrm{c})+(\mathrm{C} 18: 3 \mathrm{n} 3)] /[(\mathrm{C} 14: 0+\mathrm{C} 16: 0+\mathrm{C} 18: 0)]$. The following equations were used to calculated total omega 3 and omega 6 fatty acid 
content: total omega $3=\mathrm{C} 18: 3 \mathrm{n} 3+\mathrm{C} 20: 3 \mathrm{n} 3+\mathrm{C} 22: 5 \mathrm{n} 3+\mathrm{C} 22: 6 \mathrm{n} 3)$; total omega $6=$ $(\mathrm{C} 18: 3 \mathrm{n} 6+\mathrm{C} 20: 3 \mathrm{n} 6+\mathrm{C} 20: 4 \mathrm{n} 6)$.

Fat and moisture content analysis. Fat and moisture content analysis of boneless, skinless breast meat samples from each pen were performed according to Keeton et al. (2003). A CEM Moisture/Solids Analyzer and Smart Trac Rapid Fat Analysis system (CEM Corp., Matthews, NC, U.S.A.) was used to analyze the samples. Briefly, the moisture percentage was determined by weight using the CEM moisture/solids analyzer and the fat percentage was determined on dry basis using nuclear magnetic resonance and converted to wet basis. Each sample for analysis was performed in triplicate as described by Dow et al. (2011).

\section{Statistical Analysis}

Data were analyzed using SAS 9.4 (SAS Inst., Cary, NC). Pen served as the experimental unit and the statistical model included the fixed effect of dietary treatment. The least squares mean and standard error were determined for variable according to treatment. An analysis of variance of least squares means of treatments was conducted using PROC GLM, with a pairwise comparison used to detect potential differences between treatments. Level of significance was set at $\mathrm{P} \leq 0.05$.

\section{RESULTS}

\section{Growth performance}

Results for growth performance are outlined in Table 3.4. Broilers receiving a diet with $2.5 \%$ commodity soybean oil consumed a greater amount $(\mathrm{P}=0.003)$ of feed compared to the other treatment pens. On an average per bird basis, $\mathrm{C} 2.5$ pens consumed 
3933.49 grams compared to 3558.87 grams for C5 pens, 3501.56 grams for P2.5 pens, and 3380.53 grams for P5 pens. At the same time, birds from the C2.5 pens had the heaviest final live weights $(\mathrm{P}=0.016)$ and the greatest amount of weight gain $(\mathrm{P}=0.016)$ compared the to the other treatments, which were all similar $(\mathrm{P}>0.05)$ in final live weight and weight gain. The final live weight for each treatment based on individual bird average were $2.45 \mathrm{~kg}$ for $\mathrm{C} 2.5,2.34 \mathrm{~kg}$ for P5, $2.29 \mathrm{~kg}$ for C5, and $2.24 \mathrm{~kg}$ for P2.5. Pens receiving the $\mathrm{C} 2.5$ diet again outperformed the other treatment pens with a greater $\mathrm{ADG}$ $(\mathrm{P}=0.014)$. The ADG per bird for $\mathrm{C} 2.5$ pens was $0.049 \mathrm{~kg} / \mathrm{d}$, with the other three treatments being similar in ADG at $0.046 \mathrm{~kg} / \mathrm{d}$ for C5, $0.046 \mathrm{~kg} / \mathrm{d}$ for P2.5, and 0.045 $\mathrm{kg} / \mathrm{d}$ for P5. However, when it came to efficiency there was no significant difference between treatments for $F: G(P=0.202)$.

\section{Carcass weight and dressing percentage}

The benefits of increased live weight carried over into the carcass yield parameters (Table 3.5), with significant differences observed in carcass weight $(\mathrm{P}=$ 0.005). The $\mathrm{C} 2.5$ treatment yielded the significantly heaviest carcass weights at $1.79 \mathrm{~kg}$, followed by similar weights for C5 and P2.5 (1.70 kg; $1.68 \mathrm{~kg})$, with P5 being significantly smaller at $1.60 \mathrm{~kg}$. However, dietary treatment did not impact dressing percentage $(\mathrm{P}=0.435)$ and boneless, skinless breast portion yield $(\mathrm{P}=0.118)$.

\section{Fatty acid analysis}

Analysis of the fatty acid profile of boneless, skinless breast meat samples (Table 3.7) showed significant differences $(\mathrm{P}<.0001)$ between treatments for the following individual fatty acids: C16:0, C16:1, C18:0, C18:1n9, C18:2n6, and C20:4n6. C2.5 had the greatest amount of $\mathrm{C} 16: 0$ at 22.35, with P5 having the least at 17.62. The 2.5 fat 
percentage groups showed a greater amount of $\mathrm{C} 16: 1$ compared to the 5 fat percentage groups. The control groups had more C18:0 compared to the Plenish ${ }^{\circledR}$ groups. However, within the Plenish ${ }^{\circledR}$ groups, P2.5 had more C18:0, than P5. When it came to the amount of $\mathrm{C} 18: \ln 9$, the treatments stair-stepped in the order of most to least as follows, P5, P2.5, C2.5, and C5. Results were the same for C18:2n6 and C20:4n6, with C2.5 having the most and P5 having the least amount. Furthermore, measurable differences were present $(\mathrm{P}<.0001)$ for total SFA, total MUFA, total PUFA, and Omega- 6 fatty acids in fatty acid profiles of boneless, skinless breast meat samples. The C2.5 treatment had the greatest proportion of SFA, while the P5 had the least. For the proportion of PUFA, the treatments stair-stepped from most to least in the order of P5, P2.5, C2.5, and C5.0. C5 had the greatest proportion of PUFA, followed by C2.5, with the Plenish ${ }^{\circledR}$ treatments be similar to each other, but distant from the C2.5 group. The control groups had a greater amount of Omega- 6 fatty acids, compared to the Plenish ${ }^{\circledR}$ groups. However, within the groups $\mathrm{C} 5$ had more than $\mathrm{C} 2.5$, while there was no difference between the Plenish ${ }^{\circledR}$ groups.

Results for the fatty acid composition of abdominal fat pads (Table 3.8) showed significant differences in individual fatty acids for $\mathrm{C} 18: \ln 9(\mathrm{P}=0.05), \mathrm{C} 18: 2 \mathrm{n} 6(\mathrm{P}=$ 0.026), and $\mathrm{C} 20: 4 \mathrm{n} 6(\mathrm{P}=0.045) . \mathrm{P} 5, \mathrm{P} 2.5$, and $\mathrm{C} 5$ had a greater amount of $\mathrm{C} 18: 1 \mathrm{n} 9$, compared to $\mathrm{C} 2.5$. It was just the opposite for $\mathrm{C} 18: 2 \mathrm{n} 6$, with $\mathrm{C} 2.5$ having significantly more, than the P5, P2.5, and C5 treatment groups. Results for $\mathrm{C} 20: 4 \mathrm{n} 6$ showed the $\mathrm{C} 2.5$ group with the greatest amount at 2.05 and the P2.5 with the least at 1.27 . Looking at the proportion of groups of fatty acids, significant differences were observed for total MUFA $(\mathrm{P}=0.049)$, total PUFA $(\mathrm{P}=0.026)$, and Omega-6 fatty acids $(\mathrm{P}=0.026)$. Looking at 
the total amount of MUFA, the Plenish ${ }^{\circledR}$ groups had significantly more MUFA (50.73 and 50.52), compared the $\mathrm{C} 2.5$ group which had the least at 40.14 . However, the $\mathrm{C} 2.5$ group had significantly more PUFA compared to all other treatment groups. The same results were observed with the amount of Omega- 6 fatty acids, with the C2.5 group having significantly more than all other treatments.

\section{Fat and moisture content analysis}

Analysis of moisture and fat content of boneless, skinless breast meat samples showed no significant difference for either moisture percentage $(P=0.759)$, or fat percentage $(\mathrm{P}=0.501)$ based on treatment. Complete results for fat and moisture content of boneless, skinless breast meat can be found in Table 3.6.

\section{DISCUSSION}

Broilers from the $\mathrm{C} 2.5$ treatment excelled over the other treatment groups in terms of final live weight and ADG. It should be noted that the chicks received for this experiment started a lower weight, which appeared to carry through to the final live weights. Nonetheless, the added weight gain came as the result of increased feed intake. This led to all treatment groups performing equally for $\mathrm{F}: \mathrm{G}$ ratio. The experiment described in the previous chapter had a similar conclusion for feed efficiency when it comes to feeding high oleic soybean products, as this experiment also showed that dietary fat source had no impact on F:G. Other studies have yielded similar conclusions for feed efficiency in broilers receiving diets containing high oleic feed ingredients (Hsieh et al., 2002; Toomer et al., 2020). 
The heavier final live weights of the $\mathrm{C} 2.5$ birds, translated to the $\mathrm{C} 2.5$ birds yielding heavier carcass weights. While evaluating a different source of high oleic oil, similar results were observed in the differences in carcass weights between birds fed commodity soybean oil compared to Plenish ${ }^{\circledR}$ high oleic soybean oil. Thus, results for carcass weights again raise concern for the potential loss in value per bird. Using the value of whole chicken roasters from the USDA, the value based on carcass weight for each treatment would be the following:

Control 2.5\%: (1.79 kg. for CON x $\$ 3.06 / \mathrm{kg}.)=\$ 5.48$ per bird Control 5\%: (1.70 kg. for CON x $\$ 3.06 / \mathrm{kg}.)=\$ 5.20$ per bird Plenish ${ }^{\circledR} 2.5 \%$ : (1.68 kg. for CON x $\left.\$ 3.06 / \mathrm{kg}.\right)=\$ 5.14$ per bird Plenish ${ }^{\circledR}$ 5\%: (1.60 kg. for CON x $\$ 3.06 / \mathrm{kg}$. $)=\$ 4.90$ per bird This gives a price spread of $\$ 0.58$ across the treatments, with the control treatment carcasses having a greater value, compared to the Plenish ${ }^{\circledR}$ carcasses. However, as with the previous experiment, use of niche, health-focused markets and labeling may provide the potential for increasing the value of Plenish ${ }^{\circledR}$ fed chicken carcasses. Utilizing the premium price established by Slanker Grass-Fed Meats for a poultry product enriched with a specific fatty acid (Slanker Grass-Fed Meats, N.D.), the potential value difference for a whole bird, comparing $\mathrm{C} 2.5 \%$ to $\mathrm{P} 2.5 \%$, becomes:

$(1.79 \mathrm{~kg}$. for $\mathrm{C} 2.5 \%$ x $\$ 3.06 / \mathrm{kg}$. $)$ - (1.68 kg. for P2.5\% x $\$ 15.38 / \mathrm{kg}.)=\$ 20.36$ gain per bird.

The additional value offered through premium niche markets targeting health conscious consumer, again may be a more ideal outlet for marketing poultry fed diets containing high oleic soybean oil. 
However, the lack of significant difference between treatments for dressing percentage and breast portion yield show an increase in yield efficiency for the other treatment groups. Results for dressing percentage are again similar to those seen in the study from chapter 2, as well as supported by Zollitsch et al. (1997). The added benefit in live and carcass weight for the C2.5 group may be attributed to an increase in either viscera weight, gut fill, or a combination of the two. Furthermore, the resulting similar weights for boneless, skinless breast meat show Plenish ${ }^{\circledR}$ can replace traditional commodity soybean oil without having a deleterious effect on broiler meat yield.

The analysis of the fatty acid profiles of boneless, skinless breast meat and abdominal fat pads add further support to the idea that dietary fatty acid supply is positively correlated to the fatty acid composition in meat from monogastrics (Tuunaien et al., 2016; Semogerere et al, 2016). Results show that regardless of fat depot, broilers receiving diets with Plenish ${ }^{\circledR}$ had greater portions of monounsaturated fatty acids, specifically $\mathrm{C} 18: \ln 9$ (oleic acid). This shift in the fatty acid profile primarily came from the decrease in polyunsaturated fatty acids, specifically C18:2n6 (linoleic acid) and C20:4n6 (arachidonic acid). Previous work by the author, as well as other studies, support the measurable shift observed in the proportion of monounsaturated fatty acids, when broilers are provided increased proportions of oleic acid in the diet (Azcona et al., 2008, Toomer et al., 2020). As commodity soybean oil contains increased amounts of C18:2n6, it is expected that replacing commodity soybean oil with a high oleic alternative would decrease the amounts of C18:2n6. Furthermore, the differences in the amounts of Omega- 6 fatty acids correspond with the differences in the amount of C18:2n6, as C18:2n6 is the primary Omega-6 fatty acid. 
However, the fatty acid profiles showed different results for $\mathrm{C} 16: 0$, with the proportion of $\mathrm{C} 16: 0$ being significantly different in boneless, skinless breast meat, while not being different in abdominal fat pads. Previous research has shown that fat depots undergo different rates of metabolic activity comparatively (Martin et al., 1972). Moreover, the fatty acid metabolism of birds is different than that of mammals (Skrivan et al., 2018). Work by Skrivan et al. (2018) suggests the fatty acid profile of muscle tissue of broilers show greater influence from dietary fatty acid supply, compared to abdominal fat. Abdominal fat in broilers appears to be more resistant to the influence of dietary fatty acid supply (Skrivan et al., 2018).

\section{IMPLICATIONS}

This work further adds to the body of knowledge surrounding how the dietary fatty acid composition translates to the fatty acid composition of meat and adipose tissues of broiler chickens. Results from this study clearly show that Plenish ${ }^{\circledR}$ high oleic soybean oil can be a suitable replacement for commodity soybean oil, without impact the feed efficiency or carcass yield of broiler chickens. Moreover, replacement of commodity soybean oil with Plenish ${ }^{\circledR}$ can shift the fatty acid profile of broiler meat to have a greater proportion of MUFA. Further research should be conducted to evaluate the rate of lipid oxidation in meat from broilers raised on diets with Plenish $\AA$, as a means to evaluate any benefits that may come from the altered fatty acid profile. 
Table 3.1. Composition of broiler starter diets containing commodity soybean oil and Plenish $®$ high oleic soybean oil.

\begin{tabular}{lcccc}
\hline & \multicolumn{3}{c}{ Treatments $^{1}$} \\
\cline { 2 - 5 } Ingredients (kg.) & $\mathrm{C} 2.5$ & $\mathrm{C} 5.0$ & $\mathrm{P} 2.5$ & $\mathrm{P} 5.0$ \\
\hline Corn & 490.18 & 463.18 & 490.18 & 463.18 \\
SBM 48 & 276.14 & 280.41 & 276.14 & 280.41 \\
Corn Distillers Sol. & 90.91 & 90.91 & 90.91 & 90.91 \\
Commodity Soy Oil & 22.73 & 45.46 & - & - \\
Plenish ${ }^{-}$ & - & - & 22.73 & 45.46 \\
Dical & 9.09 & 10.06 & 9.09 & 10.06 \\
Limestone & 10.91 & 10.37 & 10.91 & 10.37 \\
Salt & 3.18 & 3.18 & 3.18 & 3.18 \\
L-Lysine & 1.27 & 1.21 & 1.27 & 1.21 \\
Methionine & 1.45 & 1.55 & 1.45 & 1.55 \\
Vitamin/Mineral Premix & 2.27 & 2.27 & 2.27 & 2.27 \\
Coban & 1.00 & 0.46 & 1.00 & 0.46 \\
\cline { 2 - 5 } & 909.09 & 909.09 & 909.09 & 909.09 \\
& & & & \\
Crude Protein, \% & 22.19 & 21.24 & 20.41 & 25.55 \\
Crude Fat, \% & 5.81 & 7.63 & 5.97 & 8.39 \\
Crude Fiber, \% & 3.01 & 3.17 & 3.19 & 2.98 \\
Moisture, \% & 10.14 & 9.50 & 9.52 & 8.56 \\
Ash, \% & 6.48 & 4.98 & 5.39 & 5.18 \\
Lysine, \% & 1.26 & 1.27 & 1.29 & 1.24 \\
Methionine, \% & 0.47 & 0.50 & 0.47 & 0.46 \\
Tryptophan, \% & 0.27 & 0.25 & 0.26 & 0.26 \\
\hline C2.5\%Con & & & \\
\hline
\end{tabular}

${ }^{1} \mathrm{C} 2.5=$ Control with $2.5 \%$ oil inclusion, $\mathrm{C} 5.0=$ Control with $5.0 \%$ oil inclusion, $\mathrm{P} 2.5=$ Plenish $\AA$ treatment with $2.5 \%$ oil inclusion, $\mathrm{P} 5.0=$ Plenish ${ }^{\circledR}$ treatment with 5.0 oil inclusion 
Table 3.2. Composition of broiler grower diets containing commodity soybean oil and Plenish $®$ high oleic soybean oil.

\begin{tabular}{|c|c|c|c|c|}
\hline \multirow[b]{2}{*}{ Ingredients (kg.) } & \multicolumn{4}{|c|}{ Treatment $^{1}$} \\
\hline & $\mathrm{C} 2.5$ & $\mathrm{C} 5.0$ & $\mathrm{P} 2.5$ & P5.0 \\
\hline Corn & 536.57 & 509.57 & 536.57 & 509.57 \\
\hline SBM 48 & 231.33 & 235.60 & 231.33 & 235.60 \\
\hline Corn Distillers Sol. & 90.91 & 90.91 & 90.91 & 90.91 \\
\hline Commodity Soy Oil & 22.73 & 45.46 & - & - \\
\hline 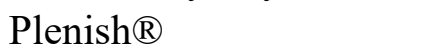 & - & - & 22.73 & 45.46 \\
\hline Dical & 8.89 & 8.96 & 8.89 & 8.96 \\
\hline Limestone & 10.01 & 9.96 & 10.01 & 9.96 \\
\hline Salt & 3.18 & 3.18 & 3.18 & 3.18 \\
\hline L-Lysine & 1.29 & 1.23 & 1.29 & 1.23 \\
\hline Methionine & 1.47 & 1.53 & 1.47 & 1.53 \\
\hline Vitamin/Mineral Premix & 2.27 & 2.27 & 2.27 & 2.27 \\
\hline \multirow[t]{2}{*}{ Coban } & 0.46 & 0.46 & 0.46 & 0.46 \\
\hline & 909.09 & 909.09 & 909.09 & 909.09 \\
\hline Crude Protein, \% & 16.29 & 18.50 & 17.54 & 19.70 \\
\hline Crude Fat, \% & 5.60 & 7.96 & 4.16 & 7.13 \\
\hline Crude Fiber, $\%$ & 2.62 & 3.02 & 3.65 & 2.72 \\
\hline Moisture, \% & 10.16 & 9.23 & 10.43 & 10.51 \\
\hline Ash, $\%$ & 5.29 & 5.30 & 5.06 & 4.62 \\
\hline Lysine, \% & 1.16 & 1.16 & 1.12 & 1.13 \\
\hline Methionine, \% & 0.50 & 0.41 & 0.43 & 0.47 \\
\hline Tryptophan, \% & 0.23 & 0.25 & 0.26 & 0.24 \\
\hline
\end{tabular}

${ }^{1} \mathrm{C} 2.5=$ Control with 2.5 oil inclusion, $\mathrm{C} 5.0=$ Control with 5.0 oil inclusion, $\mathrm{P} 2.5=$ Plenish ${ }^{\circledR}$ treatment with $2.5 \%$ oil inclusion, P5.0 $=$ Plenish ${ }^{\circledR}$ treatment with $5.0 \%$ oil inclusion 
Table 3.3. Composition of broiler finisher diets containing commodity soybean oil and Plenish $®$ high oleic soybean oil.

\begin{tabular}{lcccc}
\hline & \multicolumn{3}{c}{ Treatment $^{1}$} \\
\cline { 2 - 5 } Ingredients (kg.) & $\mathrm{C} 2.5$ & $\mathrm{C} 5.0$ & $\mathrm{P} 2.5$ & $\mathrm{P} 5.0$ \\
\hline Corn & 555.25 & 533.65 & 555.25 & 533.65 \\
SBM 48 & 211.69 & 215.11 & 211.69 & 215.11 \\
Corn Distillers Sol. & 90.91 & 90.91 & 90.91 & 90.91 \\
Commodity Soy Oil & 22.73 & 45.46 & - & - \\
Plenish ${ }^{\text {Dical }}$ & - & - & 22.73 & 45.46 \\
Limestone & 7.11 & 7.17 & 7.11 & 7.17 \\
Salt & 9.35 & 9.31 & 9.35 & 9.31 \\
L-Lysine & 3.18 & 3.18 & 3.18 & 3.18 \\
Methionine & 0.58 & 0.52 & 0.58 & 0.52 \\
Vitamin/Mineral Premix & 1.02 & 1.06 & 1.02 & 1.06 \\
Coban & 2.27 & 2.27 & 2.27 & 2.27 \\
& 0.46 & 0.45 & 0.46 & 0.45 \\
\cline { 2 - 5 } & 909.09 & 909.09 & 909.09 & 909.09 \\
Crude Protein, \% & & & & \\
Crude Fat, \% & 17.22 & 19.10 & 17.19 & 17.39 \\
Crude Fiber, \% & 4.12 & 6.29 & 4.94 & 6.71 \\
Moisture, \% & 2.54 & 2.39 & 2.52 & 2.72 \\
Ash, \% & 11.36 & 11.03 & 11.31 & 11.34 \\
Lysine, \% & 4.90 & 4.99 & 4.70 & 4.94 \\
Methionine, \% & 1.02 & 0.99 & 0.98 & 0.94 \\
Tryptophan, \% & 0.41 & 0.38 & 0.40 & 0.37 \\
\hline C2.5 Con & 0.21 & 0.21 & 0.20 & 0.21 \\
\hline
\end{tabular}

${ }^{1} \mathrm{C} 2.5=$ Control with $2.5 \%$ oil inclusion, $\mathrm{C} 5.0=$ Control with $5.0 \%$ oil inclusion, $\mathrm{P} 2.5=$ Plenish ${ }^{\circledR}$ treatment with $2.5 \%$ oil inclusion, P5.0 $=$ Plenish ${ }^{\circledR}$ treatment with $5.0 \%$ oil inclusion 
Table 3.4. Growth performance least squares means of broilers fed diets with commodity soybean oil and Plenish ${ }^{\circledR}$ high oleic soybean oil.

\begin{tabular}{lcccccc}
\hline & \multicolumn{5}{c}{ Treatments $^{1}$} \\
\cline { 2 - 7 } Item $^{\mathrm{A}}$ & $\mathrm{C} 2.5$ & $\mathrm{C} 5.0$ & $\mathrm{P} 2.5$ & P5.0 & SEM & P-value \\
\hline Total Intake, g. & $3933.49^{\mathrm{a}}$ & $3558.87^{\mathrm{b}}$ & $3501.56^{\mathrm{b}}$ & $3380.53^{\mathrm{b}}$ & 103.50 & 0.003 \\
Final Live Weight, kg. & $2.45^{\mathrm{a}}$ & $2.29^{\mathrm{b}}$ & $2.24^{\mathrm{b}}$ & $2.34^{\mathrm{b}}$ & 0.05 & 0.016 \\
Weight Gain, kg. & $2.41^{\mathrm{a}}$ & $2.25^{\mathrm{b}}$ & $2.20^{\mathrm{b}}$ & $2.19^{\mathrm{b}}$ & 0.05 & 0.016 \\
ADG, kg/d. & $0.049^{\mathrm{a}}$ & $0.046^{\mathrm{b}}$ & $0.045^{\mathrm{b}}$ & $0.045^{\mathrm{b}}$ & 0.001 & 0.014 \\
F:G, kg. & 1.64 & 1.59 & 1.59 & 1.54 & 0.03 & 0.202 \\
\hline
\end{tabular}

${ }^{\mathrm{A}} \mathrm{LS}$ means within a row without superscripts do not differ at $\mathrm{P} \leq 0.05$.

${ }^{1} \mathrm{C} 2.5=$ Control with $2.5 \%$ oil inclusion, $\mathrm{C} 5.0=$ Control with $5.0 \%$ oil inclusion, $\mathrm{P} 2.5=$ Plenish ${ }^{\circledR}$ treatment with $2.5 \%$ oil inclusion, P5.0 $=$ Plenish ${ }^{\circledR}$ treatment with $5.0 \%$ oil inclusion 
Table 3.5. Carcass yield least squares means of broilers fed diets with commodity soybean oil and Plenish ${ }^{\circledR}$ high oleic soybean oil.

\begin{tabular}{lcccccc}
\hline & \multicolumn{5}{c}{ Treatments $^{1}$} \\
\cline { 2 - 7 } Item $^{\mathrm{A}}$ & $\mathrm{C} 2.5$ & $\mathrm{C} 5.0$ & $\mathrm{P} 2.5$ & P5.0 & SEM & P-value \\
\hline Carcass Weight, kg. & $1.79^{\mathrm{a}}$ & $1.70^{\mathrm{ab}}$ & $1.68^{\mathrm{bc}}$ & $1.60^{\mathrm{c}}$ & 0.04 & 0.005 \\
Dressing Percent, \% & 73.13 & 74.44 & 74.77 & 71.67 & 1.47 & 0.435 \\
Breast portion, g. & 213.86 & 194.25 & 198.82 & 192.99 & 6.66 & 0.118 \\
\hline
\end{tabular}

${ }^{\mathrm{A}} \mathrm{LS}$ means within a row without superscripts do not differ at $\mathrm{P} \leq 0.05$.

${ }^{1} \mathrm{C} 2.5=$ Control with $2.5 \%$ oil inclusion, $\mathrm{C} 5.0=$ Control with $5.0 \%$ oil inclusion, $\mathrm{P} 2.5=$ Plenish ${ }^{\circledR}$ treatment with $2.5 \%$ oil inclusion, P5.0 $=$ Plenish ${ }^{\circledR}$ treatment with $5.0 \%$ oil inclusion 
Table 3.6. Moisture and fat content least squares means of breast meat from broilers fed diets with commodity soybean oil and Plenish ${ }^{\circledR}$ high oleic soybean oil.

\begin{tabular}{lcccccc}
\hline & \multicolumn{5}{c}{ Treatments $^{1}$} \\
\cline { 2 - 7 } Item $^{\mathrm{A}}$ & $\mathrm{C} 2.5$ & $\mathrm{C} 5.0$ & $\mathrm{P} 2.5$ & P5.0 & SEM & P-value \\
\hline Moisture Content, \% & 73.72 & 73.81 & 73.60 & 73.95 & 0.25 & 0.759 \\
Fat Content, \% & 2.84 & 3.07 & 3.33 & 3.06 & 0.25 & 0.501 \\
\hline
\end{tabular}

${ }^{\mathrm{A}} \mathrm{LS}$ means within a row without superscripts do not differ at $\mathrm{P} \leq 0.05$.

${ }^{1} \mathrm{C} 2.5=$ Control with $2.5 \%$ oil inclusion, $\mathrm{C} 5.0=$ Control with $5.0 \%$ oil inclusion, $\mathrm{P} 2.5=\mathrm{Plenish} \AA$ treatment with $2.5 \%$ oil inclusion, P5.0 $=$ Plenish ${ }^{\circledR}$ treatment with $5.0 \%$ oil inclusion 
Table 3.7. Fatty acid composition of breast meat from broilers fed diets with commodity soybean oil and Plenish ${ }^{\circledR}$ high oleic soybean oil.

\begin{tabular}{lcccccc}
\hline & \multicolumn{5}{c}{ Treatments $^{1}$} \\
\cline { 2 - 7 } Item $^{\mathrm{A}}$ & $\mathrm{C} 2.5$ & $\mathrm{C} 5.0$ & $\mathrm{P} 2.5$ & P5.0 & SEM & P-value \\
\hline C16:0 (Palmitic acid), \% & $22.35^{\mathrm{a}}$ & $20.21^{\mathrm{b}}$ & $20.16^{\mathrm{b}}$ & $17.26^{\mathrm{c}}$ & 0.30 & $<.0001$ \\
C16:1 (Palmitoleic acid), \% & $3.32^{\mathrm{a}}$ & $2.09^{\mathrm{b}}$ & $3.26^{\mathrm{a}}$ & $2.38^{\mathrm{b}}$ & 0.14 & $<.0001$ \\
C18:0 (Stearic acid), \% & $8.73^{\mathrm{a}}$ & $8.22^{\mathrm{a}}$ & $7.58^{\mathrm{b}}$ & $6.74^{\mathrm{c}}$ & 0.25 & $<.0001$ \\
C18:1n9 (Oleic acid), \% & $34.35^{\mathrm{c}}$ & $31.41^{\mathrm{d}}$ & $48.16^{\mathrm{b}}$ & $54.11^{\mathrm{a}}$ & 0.40 & $<.0001$ \\
C18:2n6 (Linoleic acid), \% & $28.83^{\mathrm{b}}$ & $35.01^{\mathrm{a}}$ & $18.26^{\mathrm{c}}$ & $16.94^{\mathrm{c}}$ & 0.51 & $<.0001$ \\
C20:4n6 (Arachidonic acid), \% & $1.72^{\mathrm{b}}$ & $2.37^{\mathrm{a}}$ & $1.09^{\mathrm{c}}$ & $1.17^{\mathrm{c}}$ & 0.10 & $<.0001$ \\
Total SFA, \% & $32.14^{\mathrm{a}}$ & $29.52^{\mathrm{b}}$ & $28.97^{\mathrm{b}}$ & $25.21^{\mathrm{c}}$ & 0.56 & $<.0001$ \\
Total MUFA, \% & $37.67^{\mathrm{c}}$ & $33.73^{\mathrm{d}}$ & $51.73^{\mathrm{b}}$ & $57.50^{\mathrm{a}}$ & 0.44 & $<.0001$ \\
Total PUFA, \% & $30.55^{\mathrm{b}}$ & $37.54^{\mathrm{a}}$ & $19.54^{\mathrm{c}}$ & $18.63^{\mathrm{c}}$ & 0.56 & $<.0001$ \\
Omega-6, \% & $30.55^{\mathrm{b}}$ & $37.42^{\mathrm{a}}$ & $19.50^{\mathrm{c}}$ & $18.55^{\mathrm{c}}$ & 0.56 & $<.0001$ \\
Omega-3, \% & ND $^{2}$ & 0.12 & $0.05^{2}$ & 0.08 & 0.05 & 0.258 \\
\hline
\end{tabular}

${ }^{\mathrm{A}}$ LS means within a row without superscripts do not differ at $\mathrm{P} \leq 0.05$.

${ }^{1} \mathrm{C} 2.5=$ Control with $2.5 \%$ oil inclusion, $\mathrm{C} 5.0=$ Control with $5.0 \%$ oil inclusion, $\mathrm{P} 2.5=$ Plenish ${ }^{\circledR}$ treatment with $2.5 \%$ oil inclusion, P5.0 $=$ Plenish ${ }^{\circledR}$ treatment with $5.0 \%$ oil inclusion

${ }^{2} \mathrm{ND}=$ Not Detectable 
Table 3.8. Fatty acid composition of abdominal fat pads from broilers fed diets with commodity soybean oil and Plenish ${ }^{\circledR}$ high oleic soybean oil.

\begin{tabular}{|c|c|c|c|c|c|c|}
\hline \multirow[b]{2}{*}{ Item $^{A}$} & \multicolumn{6}{|c|}{ Treatments $^{1}$} \\
\hline & $\mathrm{C} 2.5$ & C5.0 & $\mathrm{P} 2.5$ & P5.0 & SEM & P-value \\
\hline C16:0 (Palmitic acid), \% & 20.17 & 20.34 & 20.04 & 19.21 & 0.70 & 0.603 \\
\hline C16:1 (Palmitoleic acid), \% & 3.18 & 4.21 & 4.18 & 3.86 & 0.25 & 0.483 \\
\hline C18:0 (Stearic acid), \% & 6.08 & 5.71 & 5.92 & 5.53 & 0.19 & 0.160 \\
\hline C18:1n9 (Oleic acid), \% & $35.72^{\mathrm{b}}$ & $42.99^{\mathrm{a}}$ & $45.81^{\mathrm{a}}$ & $46.00^{\mathrm{a}}$ & 2.99 & 0.05 \\
\hline C18:2n6 (Linoleic acid), \% & $30.01^{\mathrm{a}}$ & $24.30^{\mathrm{b}}$ & $20.26^{\mathrm{b}}$ & $21.71^{\mathrm{b}}$ & 2.43 & 0.026 \\
\hline C18:3n3 ( $\alpha$-linolenic acid), $\%$ & 0.26 & 0.25 & 0.19 & 0.23 & 0.02 & 0.121 \\
\hline C20:4n6 (Arachidonic acid), \% & $2.05^{\mathrm{a}}$ & $1.66^{\mathrm{ab}}$ & $1.27^{\mathrm{b}}$ & $1.52^{\mathrm{ab}}$ & 0.20 & 0.045 \\
\hline Total SFA, \% & 27.20 & 27.03 & 27.08 & 25.57 & 0.86 & 0.478 \\
\hline Total MUFA, \% & $40.14^{\mathrm{b}}$ & $47.82^{\mathrm{ab}}$ & $50.73^{\mathrm{a}}$ & $50.52^{\mathrm{a}}$ & 3.03 & 0.049 \\
\hline Total PUFA, \% & $32.86^{\mathrm{a}}$ & $26.78^{b}$ & $22.34^{\mathrm{b}}$ & $24.01^{\mathrm{b}}$ & 2.63 & 0.027 \\
\hline Omega-6, \% & $30.26^{\mathrm{a}}$ & $24.65^{b}$ & $20.65^{b}$ & $22.09^{b}$ & 2.40 & 0.026 \\
\hline Omega-3, \% & 0.39 & 0.36 & 0.28 & 0.29 & 0.04 & 0.097 \\
\hline
\end{tabular}

${ }^{\mathrm{A}} \mathrm{LS}$ means within a row without superscripts do not differ at $\mathrm{P} \leq 0.05$.

${ }^{1} \mathrm{C} 2.5=$ Control with $2.5 \%$ oil inclusion, $\mathrm{C} 5.0=$ Control with $5.0 \%$ oil inclusion, $\mathrm{P} 2.5=$ Plenish ${ }^{\circledR}$

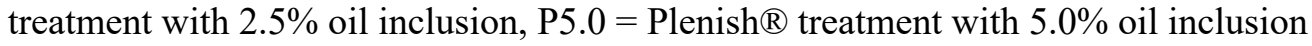




\title{
CHAPTER 4
}

\section{DETERMINING THE EFFECT OF TRADITIONAL AND NOVEL DIETARY OILS ON PERFORMANCE AND QUALITY OF FINISHING PIGS.}

\begin{abstract}
Novel feed ingredients and different feed ingredient processing methods can vary the fatty acid supply in diets. Thus, when formulating diets, due to the potential effects on animal performance and the downstream effects on fresh meat properties, nutritionists must consider possible alterations in the fatty acid profile of a diet. The objective of the experiment was to evaluate the impact of the inclusion of traditional and novel dietary oils in finishing pig diets on performance, carcass composition, and meat/lipid quality. Finisher pigs $(n=80)$ were weighed and randomly sorted into 8 treatment groups containing 10 individually housed pigs per treatment. Treatment diets included the follow oil sources, control (choice white grease), commodity soybean oil (CS), coconut oil (CO), control+Missouri high oleic soybean oil (C+MOS), Missouri High Oleic Soybean Oil (MOS), 4\% Missouri high oleic soybean oil (MOS4), Plenish ${ }^{\circledR}(\mathrm{P})$, and 4\% Plenish ${ }^{\circledR}$. Pig and feed weights were recorded on days 0,14 , and 28 and were used to determine ADG, feed intake, and F:G. Pigs were slaughtered under in two-groups on day 28 at a target-finished weight of $280 \mathrm{lbs}$. (127 kg.). Carcasses were weighed and chilled
\end{abstract}


for 24 hours, after which, carcass measurements of loin eye area, last rib and $10^{\text {th }}$ rib fat thickness, ham and loin $\mathrm{pH}$, objective color $\left(\mathrm{L}^{*}, \mathrm{a}^{*}, \mathrm{~b}^{*}\right)$, and subjective marbling and color scores were recorded. Carcasses were fabricated to obtain samples for further analysis. Loin chop sample was collected for CEM moisture and fat content. Bellies were fabricated and commercially processed into sliced bacon slabs for quality analysis. Finally, jowl, subcutaneous, intermuscular, intramuscular fat samples were obtained for fatty acid analysis. Data was analyzed using PROC GLM procedure in SAS, with level of significance set at $\mathrm{P} \leq 0.05$. Growth performance and feed efficiency was not affected $(P>0.05)$ by the source of dietary oil, with no differences observed for final body weight, feed consumption, ADG, and F:G. Furthermore, no treatment effect $(\mathrm{P}>0.05)$ was detected when looking at the predetermined indicators of pork carcass composition and pork carcass quality. Loin chop samples from yielded similar $(\mathrm{P}>0.05)$ moisture and fat percentages between treatments. Analysis of the bacon slice yield and quality data only showed a significant difference $(\mathrm{P}=0.003)$ for treatment effect in the yield of Number 1 slices. Bacon from pigs receiving the coconut oil diet had the greatest amount of number 1 slices at 25.30. The other treatments followed in the order of $\mathrm{P}$ at 21.44 slices, $\mathrm{CON}$ at 20.30 slices, $\mathrm{P} 4$ at 18.70 slices, $\mathrm{C}+\mathrm{MOS}$ at 18.56 slices, $\mathrm{CS}$ at 16.60 slices, MOS at 15 slices, and MOS4 at 10.90 slices. No significance difference $(\mathrm{P}>$ 0.05) was observed in the fatty acid profile of intramuscular fat samples between treatments. Analysis of intermuscular fat samples showed significant differences in the concentration of $\mathrm{C12}: 0(\mathrm{P}<.0001), \mathrm{C16}: 0(\mathrm{P}=0.028), \mathrm{C} 16: 1(\mathrm{P}=0.002), \mathrm{C} 18: 0(\mathrm{P}=$ 0.015), C18:1n9 ( $\mathrm{P}=<.0001)$, total SFA $(\mathrm{P}=0.005)$, and total MUFA $(\mathrm{P}=<.0001)$. These results suggest that traditional dietary oils can be replaced by novel high oleic 
soybean oils to shift the proportion of fatty acids in tissues, without causing deleterious effect on finishing pig performance, carcass composition, and fresh pork quality. 


\section{INTRODUCTION}

On June 17, 2015, the Food and Drug Administration (FDA) announced that it was removing the Generally Recognized as Safe (GRAS) status from partially hydrogenated oils (FDA, 2015). The FDA declared these oils to be the primary source of dietary trans-fats for humans (FDA, 2015). Trans-fats have been shown to increase LDL cholesterol, or "bad" cholesterol, levels, thus promoting concern over their negative effects on human health. The FDA listed a final compliance date of June 18, 2018 for trans-fats to be removed from human food products (FDA, 2015). According to the United Soybean Board, this decision by the FDA could lead to a loss of 1.5 billion pounds of soybean oil demand from U.S. food companies on top of the 4 billion pounds of annual soybean demand due to previous trans-fat labeling requirements by the FDA (United Soybean Board, 2017). To fill this void, entities have both created high oleic (C18:1) oil soybean varieties to source a more stable, heart healthier oil product, compared to bio-hydrogenated soybean oil.

Monounsaturated fatty acids have gained recognition from their prevalence in Mediterranean diets (Yang et al., 2017; Delgado et al., 2017). These diets traditionally contain greater amounts of olive oil, which is rich in MUFAs, primarily in the form of oleic acid (C18:1) (Yang et al., 2017; Delgado et al., 2017). Schwingshackl and Hoffmann (2014) reported that the consumption of diets rich in MUFAs have been linked to lower cardiovascular events and mortality, compared to diets rich in SFAs. Fat sources containing a greater proportion of MUFAs, primarily oleic acid, may yield a cooperative "middle ground". Studies have shown that dietary MUFA increase HDL cholesterol, decrease LDL cholesterol, and may even improve insulin sensitivity (FAO-WHO, 2008; 
Gillingham, Harris-Janz, \& Jones, 2011). On top of their health benefits, MUFAs have a lower oxidative potential compared to PUFAs due to only having one double bond. Meat scientists and food processors have long sought the ideal fatty acid profile of a raw meat product, which yields both an extended shelf life and human health benefits. High oleic soybean oil offers the potential of yielding that ideal fatty acid profile. While research has been conducted over the use of other feed ingredients that contain high levels of oleic acid, limited research has been done to understand how livestock models utilize this new source of high oleic acid and how it affects the quality of the final products from these livestock.

Other feed sources that contain increased levels of oleic acid have shown the ability to improve quality traits of pork products by altering the fatty acid profile. MUFAs not only can increase the firmness of pork fat when compared to PUFAs, but at the same time, oleic acid (C18:1) content has been positively correlated with organoleptic properties such as flavor, tenderness, juiciness, pork flavor, flavor liking and overall acceptability (Cameron \& Enser, 1991; Cameron et al., 2000; Tikk et al., 2007). With the emergence of this new soybean source of high oleic acid, little is known on its effect on the meat and lipid quality of pork and the retention rate of oleic acid within that final product. The purpose of this study was to evaluate the effect of dietary inclusion of high oleic soybean oil on finisher pig performance and carcass quality. Based on this purpose, the researcher generated the following objectives and hypotheses:

1. Describe the pig weight, feed intake, average daily gain, and feed to gain ratio of Duroc $\mathrm{x}$ Yorkshire barrows consuming a diet containing decreased amounts of oleic acid. 
2. Describe the pig weight, feed intake, average daily gain, and feed to gain ratio of Duroc $\mathrm{x}$ Yorkshire barrows consuming a diet containing increased amounts of oleic acid.

3. Compare the pig weight, feed intake, average daily gain, and feed to gain ratio of Duroc $\mathrm{x}$ Yorkshire barrows consuming a diet containing decreased amounts of oleic acid compared to Duroc x Yorkshire barrows consuming a diet containing increased amounts of oleic acid.

To address objective 3 , the following null and alternative hypotheses were generated:

Ho: No statistically significant $(p>0.05)$ difference exists between pig weight for Duroc $\mathrm{x}$ Yorkshire barrows consuming a diet containing decreased amounts of oleic acid compared to Duroc x Yorkshire barrows consuming a diet containing increased amounts of oleic acid.

H1. A statistically significant $(\mathrm{p} \leq 0.05)$ difference exists between pig weight for Duroc $\mathrm{x}$ Yorkshire barrows consuming a diet containing decreased amounts of oleic acid compared to Duroc $\mathrm{x}$ Yorkshire barrows consuming a diet containing increased amounts of oleic acid.

Ho: No statistically significant $(\mathrm{p}>0.05)$ difference exists between feed intake for Duroc $\mathrm{x}$ Yorkshire barrows consuming a diet containing decreased amounts of oleic acid compared to Duroc x Yorkshire barrows consuming a diet containing increased amounts of oleic acid.

H2. A statistically significant $(p \leq 0.05)$ difference exists between feed intake for Duroc $\mathrm{x}$ Yorkshire barrows consuming a diet containing decreased amounts of 
oleic acid compared to Duroc $\mathrm{x}$ Yorkshire barrows consuming a diet containing increased amounts of oleic acid.

Ho. No statistically significant $(\mathrm{p}>0.05)$ difference exists between average daily gain for Duroc x Yorkshire barrows consuming a diet containing decreased amounts of oleic acid compared to Duroc x Yorkshire barrows consuming a diet containing increased amounts of oleic acid.

H3. A statistically significant $(\mathrm{p} \leq 0.05)$ difference exists between average daily gain for Duroc x Yorkshire barrows consuming a diet containing decreased amounts of oleic acid compared to Duroc $\mathrm{x}$ Yorkshire barrows consuming a diet containing increased amounts of oleic acid.

Ho: No statistically significant $(\mathrm{p}>0.05)$ difference exists between feed:gain ratio for Duroc x Yorkshire barrows consuming a diet containing decreased amounts of oleic acid compared to Duroc $\mathrm{x}$ Yorkshire barrows consuming a diet containing increased amounts of oleic acid.

H4. A statistically significant $(\mathrm{p} \leq 0.05)$ difference exists between feed:gain ratio for Duroc $\mathrm{x}$ Yorkshire barrows consuming a diet containing decreased amounts of oleic acid compared to Duroc $\mathrm{x}$ Yorkshire barrows consuming a diet containing increased amounts of oleic acid.

4. Describe the pig weight, feed intake, average daily gain, and feed to gain ratio of Duroc $\mathrm{x}$ Yorkshire barrows consuming a diet containing increased amounts of SFA. 
5. Describe the pig weight, feed intake, average daily gain, and feed to gain ratio of Duroc $\mathrm{x}$ Yorkshire barrows consuming a diet containing increased amounts of USFA.

6. Compare the pig weight, feed intake, average daily gain, and feed to gain ratio of Duroc $\mathrm{x}$ Yorkshire barrows consuming a diet containing increased amounts of SFA compared to Duroc $\mathrm{x}$ Yorkshire barrows consuming a diet containing increased amounts of USFA.

To address objective 6 , the following null and alternative hypotheses were generated:

Ho: No statistically significant $(\mathrm{p}>0.05)$ difference exists between pig weight for Duroc $\mathrm{x}$ Yorkshire barrows consuming a diet containing increased amounts of SFA compared to Duroc $\mathrm{x}$ Yorkshire barrows consuming a diet containing increased amounts of USFA.

H5. A statistically significant $(\mathrm{p} \leq 0.05)$ difference exists between pig weight for Duroc $\mathrm{x}$ Yorkshire barrows consuming a diet containing increased amounts of SFA compared to Duroc $\mathrm{x}$ Yorkshire barrows consuming a diet containing increased amounts of USFA.

Ho: No statistically significant $(p>0.05)$ difference exists between feed intake for Duroc $\mathrm{x}$ Yorkshire barrows consuming a diet containing increased amounts of SFA compared to Duroc $\mathrm{x}$ Yorkshire barrows consuming a diet containing increased amounts of USFA. 
H6. A statistically significant $(\mathrm{p} \leq 0.05)$ difference exists between feed intake for Duroc $\mathrm{x}$ Yorkshire barrows consuming a diet containing increased amounts of SFA compared to Duroc $\mathrm{x}$ Yorkshire barrows consuming a diet containing increased amounts of USFA.

Ho. No statistically significant $(\mathrm{p}>0.05)$ difference exists between average daily gain for Duroc $\mathrm{x}$ Yorkshire barrows consuming a diet containing increased amounts of SFA compared to Duroc x Yorkshire barrows consuming a diet containing increased amounts of USFA.

H7. A statistically significant $(\mathrm{p} \leq 0.05)$ difference exists between average daily gain for Duroc x Yorkshire barrows consuming a diet containing increased amounts of SFA compared to Duroc x Yorkshire barrows consuming a diet containing increased amounts of USFA.

Ho: No statistically significant $(\mathrm{p}>0.05)$ difference exists between feed:gain ratio for Duroc x Yorkshire barrows consuming a diet containing increased amounts of SFA compared to Duroc x Yorkshire barrows consuming a diet containing increased amounts of USFA.

H8. A statistically significant $(\mathrm{p} \leq 0.05)$ difference exists between feed:gain ratio for Duroc x Yorkshire barrows consuming a diet containing increased amounts of SFA compared to Duroc $\mathrm{x}$ Yorkshire barrows consuming a diet containing increased amounts of USFA. 
7. Describe the carcass weight, carcass yield, carcass quality, intramuscular and intermuscular fatty acid profile, and loin chop fat and moisture content of Duroc x Yorkshire barrows consuming a diet containing decreased amounts of oleic acid.

8. Describe the carcass weight, carcass yield, carcass quality, intramuscular and intermuscular fatty acid profile, and loin chop fat and moisture content of Duroc x Yorkshire barrows consuming a diet containing increased amounts of oleic acid.

9. Compare the carcass weight, carcass yield, carcass quality, intramuscular and intermuscular fatty acid profile, and loin chop fat and moisture content of Duroc x Yorkshire barrows consuming a diet containing decreased amounts of oleic acid compared to Duroc x Yorkshire barrows consuming a diet containing increased amounts of oleic acid.

To address objective 9 , the following null and alternative hypotheses were generated:

Ho: No statistically significant $(\mathrm{p}>0.05)$ difference exists between carcass weight for Duroc x Yorkshire barrows consuming a diet containing decreased amounts of oleic acid compared to Duroc x Yorkshire barrows consuming a diet containing increased amounts of oleic acid.

H9. A statistically significant $(p \leq 0.05)$ difference exists between carcass weight for Duroc $\mathrm{x}$ Yorkshire barrows consuming a diet containing decreased amounts of oleic acid compared to Duroc x Yorkshire barrows consuming a diet containing increased amounts of oleic acid. 
Ho: No statistically significant $(\mathrm{p}>0.05)$ difference exists between carcass yield for Duroc $\mathrm{x}$ Yorkshire barrows consuming a diet containing decreased amounts of oleic acid compared to Duroc $\mathrm{x}$ Yorkshire barrows consuming a diet containing increased amounts of oleic acid.

H10. A statistically significant $(\mathrm{p} \leq 0.05)$ difference exists between carcass yield for Duroc $\mathrm{x}$ Yorkshire barrows consuming a diet containing decreased amounts of oleic acid compared to Duroc $\mathrm{x}$ Yorkshire barrows consuming a diet containing increased amounts of oleic acid.

Ho: No statistically significant $(\mathrm{p}>0.05)$ difference exists between intramuscular and intermuscular fatty acid profile for Duroc x Yorkshire barrows consuming a diet containing decreased amounts of oleic acid compared to Duroc x Yorkshire barrows consuming a diet containing increased amounts of oleic acid.

H11. A statistically significant $(p \leq 0.05)$ difference exists between intramuscular and intermuscular fatty acid profile for Duroc x Yorkshire barrows consuming a diet containing decreased amounts of oleic acid compared to Duroc x Yorkshire barrows consuming a diet containing increased amounts of oleic acid.

Ho: No statistically significant $(\mathrm{p}>0.05)$ difference exists between carcass quality for Duroc x Yorkshire barrows consuming a diet containing decreased amounts of oleic acid compared to Duroc x Yorkshire barrows consuming a diet containing increased amounts of oleic acid.

H12. A statistically significant $(\mathrm{p} \leq 0.05)$ difference exists between carcass quality for Duroc x Yorkshire barrows consuming a diet containing decreased amounts of 
oleic acid compared to Duroc $\mathrm{x}$ Yorkshire barrows consuming a diet containing increased amounts of oleic acid.

Ho: No statistically significant $(\mathrm{p}>0.05)$ difference exists between loin chop moisture content for Duroc x Yorkshire barrows consuming a diet containing decreased amounts of oleic acid compared to Duroc x Yorkshire barrows consuming a diet containing increased amounts of oleic acid.

H13. A statistically significant $(\mathrm{p} \leq 0.05)$ difference exists between loin chop moisture content for Duroc x Yorkshire barrows consuming a diet containing decreased amounts of oleic acid compared to Duroc x Yorkshire barrows consuming a diet containing increased amounts of oleic acid.

Ho: No statistically significant $(\mathrm{p}>0.05)$ difference exists between loin chop fat content for Duroc x Yorkshire barrows consuming a diet containing decreased amounts of oleic acid compared to Duroc x Yorkshire barrows consuming a diet containing increased amounts of oleic acid.

H14. A statistically significant $(p \leq 0.05)$ difference exists between loin chop fat content for Duroc x Yorkshire barrows consuming a diet containing decreased amounts of oleic acid compared to Duroc x Yorkshire barrows consuming a diet containing increased amounts of oleic acid.

10. Describe the carcass weight, carcass yield, carcass quality, intramuscular and intermuscular fatty acid profile, and loin chop fat and moisture content of Duroc $\mathrm{x}$ Yorkshire barrows consuming a diet containing increased amounts of SFA. 
11. Describe the carcass weight, carcass yield, carcass quality, intramuscular and intermuscular fatty acid profile, and loin chop fat and moisture content of Duroc $\mathrm{x}$ Yorkshire barrows consuming a diet containing increased amounts of USFA.

12. Compare the carcass weight, carcass yield, carcass quality, intramuscular and intermuscular fatty acid profile, and loin chop fat and moisture content of Duroc $\mathrm{x}$ Yorkshire barrows consuming a diet containing increased amounts of SFA compared to Duroc $\mathrm{x}$ Yorkshire barrows consuming a diet containing increased amounts of USFA.

To address objective 12, the following null and alternative hypotheses were generated:

Ho: No statistically significant $(\mathrm{p}>0.05)$ difference exists between carcass weight for Duroc x Yorkshire barrows consuming a diet containing increased amounts of SFA compared to Duroc $\mathrm{x}$ Yorkshire barrows consuming a diet containing increased amounts of USFA.

H15. A statistically significant $(\mathrm{p} \leq 0.05)$ difference exists between carcass weight for Duroc x Yorkshire barrows consuming a diet containing increase amounts of SFA compared to Duroc $\mathrm{x}$ Yorkshire barrows consuming a diet containing increased amounts of USFA.

Ho: No statistically significant $(\mathrm{p}>0.05)$ difference exists between carcass yield for Duroc $\mathrm{x}$ Yorkshire barrows consuming a diet containing increased amounts of SFA compared to Duroc $\mathrm{x}$ Yorkshire barrows consuming a diet containing increased amounts of USFA. 
H16. A statistically significant $(\mathrm{p} \leq 0.05)$ difference exists between carcass yield for Duroc $\mathrm{x}$ Yorkshire barrows consuming a diet containing increased amounts of SFA compared to Duroc x Yorkshire barrows consuming a diet containing increased amounts of USFA.

Ho: No statistically significant $(\mathrm{p}>0.05)$ difference exists between intramuscular and intermuscular fatty acid profile for Duroc x Yorkshire barrows consuming a diet containing increased amounts of SFA compared to Duroc x Yorkshire barrows consuming a diet containing increased amounts of USFA.

H17. A statistically significant $(\mathrm{p} \leq 0.05)$ difference exists between intramuscular and intermuscular fatty acid profile for Duroc $\mathrm{x}$ Yorkshire barrows consuming a diet containing increased amounts of SFA compared to Duroc x Yorkshire barrows consuming a diet containing increased amounts of USFA.

Ho: No statistically significant $(\mathrm{p}>0.05)$ difference exists between carcass quality for Duroc x Yorkshire barrows consuming a diet containing increased amounts of SFA compared to Duroc $\mathrm{x}$ Yorkshire barrows consuming a diet containing increased amounts of USFA.

H18. A statistically significant $(\mathrm{p} \leq 0.05)$ difference exists between carcass quality for Duroc x Yorkshire barrows consuming a diet containing increased amounts of SFA compared to Duroc $\mathrm{x}$ Yorkshire barrows consuming a diet containing increased amounts of USFA.

Ho: No statistically significant $(p>0.05)$ difference exists between loin chop moisture content for Duroc $\mathrm{x}$ Yorkshire barrows consuming a diet containing 
increased amounts of SFA compared to Duroc $\mathrm{x}$ Yorkshire barrows consuming a diet containing increased amounts of USFA.

H19. A statistically significant $(p \leq 0.05)$ difference exists between loin chop moisture content for Duroc $\mathrm{x}$ Yorkshire barrows consuming a diet containing increased amounts of SFA compared to Duroc x Yorkshire barrows consuming a diet containing increased amounts of USFA.

Ho: No statistically significant $(p>0.05)$ difference exists between loin chop fat content for Duroc x Yorkshire barrows consuming a diet containing increased amounts of SFA compared to Duroc x Yorkshire barrows consuming a diet containing increased amounts of USFA.

H20. A statistically significant $(p \leq 0.05)$ difference exists between loin chop fat content for Duroc x Yorkshire barrows consuming a diet containing increased amounts of SFA compared to Duroc x Yorkshire barrows consuming a diet containing increased amounts of USFA. 


\section{MATERIALS AND METHODS}

The University of Missouri Animal Care and Use Committee approved animal care and experimental protocols prior to initiation of this experiment (\#EX-10094).

\section{Experimental Design}

Finisher pigs $(n=80)$ were weighed and randomly sorted into 8 treatment groups containing 10 individually housed pigs per treatment. Pigs were housed in the Double L Building at the MU Swine Teaching Farm and under the same environmental conditions. Both groups were placed on treatment at approximately $150 \mathrm{lbs} .(68 \mathrm{~kg}$.$) . The treatment$ diets contained a variety of dietary oil sources at an inclusion rate of $3 \%$, unless otherwise stated. All diets (Table 4.1) were formulated based on the nutrition requirements of finishing pigs set forth in the Swine NRC. Treatment diets included the follow oil sources, control - choice white grease (CON), commodity soybean oil (CS), coconut oil (CO), control+Missouri high oleic soybean oil (C+MOS), Missouri High Oleic Soybean Oil (MOS), 4\% Missouri high oleic soybean oil (MOS4), Plenish ${ }^{(P)}$, and $4 \%$ Plenish ${ }^{\circledR}$. The use of commodity soybean oil and choice white grease as dietary treatment for comparison to novel high oleic soybean oils, was based on the fact that soybean oil and animal fats comprise the most common sources for added fat within the diets of swine (Feed Energy Company, 2018). Furthermore, soybean oil provides a plantbased oil source rich in PUFA for comparison, whereas, choice white grease provides an animal-source fat containing a greater portion of SFA and MUFA. Coconut oil was used as a plant source with a high proportion of SFA for comparisons. The individual oleic acid (C18:1n9) content of each dietary oil/fat source were as follows: choice white 
grease, $35.81 \%$; commodity soybean oil, $21.80 \%$; coconut oil, $6.00 \%$; Missouri high oleic soybean oil, 81.00\%; and Plenish ${ }^{\circledR}, 71.87 \%$ (Benz et al., 2011; Boateng et al., 2016; Seemamahannop et al., 2019).

All pigs were provided ad libitum access to feed and water until the time of slaughter. Pig weights and quantity of feed consumed by each animal were recorded on days 0,14 , and 28 . Recorded weights were used to determine average daily gain, feed intake, and feed to gain ratio. On day 28 , pigs were slaughtered under USDA inspection at a target finished weight of $280 \mathrm{lbs}$. (127 kg.). Carcasses were weighed, then chilled for 24 hours. After 24 hours, carcass measurements were recorded per the methods described below. After 48 hours, carcasses were fabricated to obtain the samples needed to analyze pork and fat quality using the methods outlined below.

\section{Data Collection}

Growth performance. The body weight and feed consumption of all pigs were recorded on days 0,14 , and 28 , with feed consumption calculated from recorded weights of feed in and residual feed. These measurements were then used to calculate average daily gain, total feed intake, and feed to gain.

Carcass measurements. Hot carcass weights ( $\mathrm{HCW})$ were recorded immediately after slaughter and used with the final live weight to calculate a dressing percentage for each animal. Loin eye area, backfat thickness at the tenth rib, and fat thickness at the last rib will be taken 24 hours postmortem from the right side of each carcass between the $10^{\text {th }}$ and $11^{\text {th }}$ ribs. Loin eye area was measured in square inches using a grid with which 20 dots equals 1 square inch. $10^{\text {th }}$ rib fat thickness was measured in tenths of an inch 
using a ruler probe at $3 / 4$ around the loin eye from the backbone on the ribbed surface. Last rib fat thickness was measured in tenths of an inch using a ruler probe and taken adjacent to the split surface of the backbone, next to the last rib.

Loin and ham $\mathbf{p H}$. A portable $\mathrm{pH}$ probe was utilized to collect $\mathrm{pH}$ readings from the loin and ham of the right side of each carcass. Measurements were taken at the same location and depth of the loin and ham. Ham $\mathrm{pH}$ readings were taken from the semimembranosus just above the aitch bone. Readings for loin $\mathrm{pH}$ were taken from the longissimus dorsi between the $9^{\text {th }}$ and $10^{\text {th }}$ vertebrae. A pH reading was recorded once the $\mathrm{pH}$ value reached a settling point.

Subjective marbling and color score. A subjective marbling score and color score will be determined for each animal by visual evaluation of marbling and color in the loin eye at the ribbed surface between the $10^{\text {th }}$ and $11^{\text {th }}$ ribs. Amounts of marbling and color observed within each loin eye (longissimus dorsi) were compared to marbling and color scorecards from the National Pork Board. This yielded a numerical score for marbling and color within the loin of each carcass.

Moisture and fat content analysis. Fat and moisture content analysis of loin chop samples were performed according to Keeton et al. (2003). A CEM Moisture/Solids Analyzer and Smart Trac Rapid Fat Analysis system (CEM Corp., Matthews, NC, U.S.A.) was used to analyze the samples. Briefly, the moisture percentage was determined by weight using the CEM moisture/solids analyzer and the fat percentage was determined on dry basis using nuclear magnetic resonance and converted to wet basis. Each sample for analysis was performed in triplicate as described by Dow et al. (2011). 
Fatty acid analysis. Fatty acid profiles of fat depot (jowl, subcutaneous, intermuscular, and intramuscular) samples were determined according to an adaptation of the methodologies described by Folch et al. (1957) and Morrison and Smith (1964). At the moment of analysis, approximately $1 \mathrm{~g}$ of sample is homogenized in $5 \mathrm{~mL}$ of chloroform:methanol $\left(\mathrm{CHCl}_{3}: \mathrm{CH}_{3} \mathrm{OH}, 2: 1, \mathrm{v} / \mathrm{v}\right)$ in a glass tube to extract lipids and samples are filtered through a sintered glass funnel fitted with a Whatman $2.4 \mathrm{~cm} \mathrm{GF/C}$ filter. A volume of $8 \mathrm{~mL}$ of $0.74 \% \mathrm{KCl}$ is added to each sample and after two hours of rest, two distinct phases formed. The upper phase is carefully removed and discarded while the lower phase was evaporated to dryness with nitrogen gas in a heated water bath at $70^{\circ} \mathrm{C}$. At the point of dryness, $1 \mathrm{~mL}$ of $0.5 \mathrm{~N} \mathrm{KOH}$ in $\mathrm{MeOH}$ is added to each tube and heated for 10 minutes in a $70^{\circ} \mathrm{C}$ water bath. Following this, $1 \mathrm{~mL}$ of $14 \%$ boron trifluoride $\left(\mathrm{BF}_{3}\right)$ in $\mathrm{MeOH}$ is added and samples are flushed with nitrogen and heated in the $70^{\circ} \mathrm{C}$ water bath for an additional 30 minutes in order to form fatty acid methyl esters (FAME). After cooling to room temperature, FAMEs are extracted by adding $2 \mathrm{~mL}$ of HPLC grade hexane and $2 \mathrm{~mL}$ of saturated $\mathrm{NaCl}$. Two distinct layers formed; the upper layer is removed and added to approximately $800 \mathrm{mg}$ of $\mathrm{Na}_{2} \mathrm{SO}_{4}$. At this point, an additional $2 \mathrm{~mL}$ of hexane are added to the tube containing $\mathrm{NaCl}$ and once more, the upper layer is removed and added to the tube containing $\mathrm{Na}_{2} \mathrm{SO}_{4}$. The hexane portion is removed from the salt and added to a labeled scintillation vial. The salt is rinsed a final time with $1 \mathrm{~mL}$ of hexane and the liquid was added to the vial. Samples are evaporated to dryness in a water bath at $70^{\circ} \mathrm{C}$ under nitrogen flow. Lastly, samples are reconstituted with $1 \mathrm{ml} \mathrm{HPLC}$ grade hexane and transferred to gas chromatograph vials. 
The stable FAMEs are loaded into a Varian 3800 gas chromatograph (Varian, Palo Alto, CA) to determine fatty acid profiles. The GC column utilized id a fused silica capillary column (SPTM - 2560; $100 \mathrm{~m}$ x $0.25 \mathrm{~mm}$ x $0.2 \mu \mathrm{m}$ film thickness; Supelco, Bellefonte, $\mathrm{PA}$ ). Temperature of the injector is held constant at $240^{\circ} \mathrm{C}$ and temperature of the flame-ionization detector is held at $260^{\circ} \mathrm{C}$. The oven operates at $140^{\circ} \mathrm{C}$ for $5 \mathrm{~min}$, then temperature programmed at $2.5^{\circ} \mathrm{C} / \mathrm{min}$ to $240^{\circ} \mathrm{C}$ and held for $16 \mathrm{~min}$. Helium, the carrier gas, is maintained at a constant pressure of $255.11 \mathrm{kPa}$. Individual fatty acid areas are normalized and so that the area under each peak represents a percentage of the total area. Total saturated fatty acid (SFA), monounsaturated fatty acids (MUFA) and polyunsaturated fatty acid (PUFA) contents are calculated according to the following equations: $\mathrm{SFA}=(\mathrm{C} 10: 0+\mathrm{C} 12: 0+\mathrm{C} 14: 0+\mathrm{C} 15: 0+\mathrm{C} 16: 0+\mathrm{C} 17: 0+\mathrm{C} 18: 0+\mathrm{C} 20: 0+$ $\mathrm{C} 22: 0+\mathrm{C} 23: 0) ; \mathrm{MUFA}=(\mathrm{C} 14: 1+\mathrm{C} 15: 1+\mathrm{C} 16: 1+\mathrm{C} 17: 1+\mathrm{C} 18: \ln 9 \mathrm{t}+\mathrm{C} 18: 1 \mathrm{n} 9 \mathrm{c}+$ $\mathrm{C} 18: 1 \mathrm{n} 7+\mathrm{C} 20: 1+\mathrm{C} 22: 1 \mathrm{n} 9+\mathrm{C} 24: 1) ;$ PUFA $=(\mathrm{C} 18: 2 \mathrm{n} 6 \mathrm{t}+\mathrm{C} 18: 2 \mathrm{n} 6 \mathrm{c}+\mathrm{C} 18: 3 \mathrm{n} 6+$ $\mathrm{C} 18: 3 \mathrm{n} 3+\mathrm{C} 18: 9 \mathrm{c} 11 \mathrm{t}+\mathrm{C} 18: 10 \mathrm{t} 12 \mathrm{c}+\mathrm{C} 18: 9 \mathrm{c} 11 \mathrm{c}+\mathrm{C} 18: 9 \mathrm{t} 11 \mathrm{t}+\mathrm{C} 20: 2+\mathrm{C} 20: 3 \mathrm{n} 6+$ $\mathrm{C} 20: 3 \mathrm{n} 3+\mathrm{C} 20: 4 \mathrm{n} 6+\mathrm{C} 22: 5 \mathrm{n} 3+\mathrm{C} 22: 6 \mathrm{n} 3)$. The ratio between PUFAs and SFAs is calculated using the equation: $[(\mathrm{C} 18: 2 \mathrm{n} 6 \mathrm{c})+(\mathrm{C} 18: 3 \mathrm{n} 3)] /[(\mathrm{C} 14: 0+\mathrm{C} 16: 0+\mathrm{C} 18: 0)]$. The following equations are used to calculated total omega 3 and omega 6 fatty acid content: total omega $3=\mathrm{C} 18: 3 \mathrm{n} 3+\mathrm{C} 20: 3 \mathrm{n} 3+\mathrm{C} 22: 5 \mathrm{n} 3+\mathrm{C} 22: 6 \mathrm{n} 3)$; total omega $6=$ $(\mathrm{C} 18: 3 \mathrm{n} 6+\mathrm{C} 20: 3 \mathrm{n} 6+\mathrm{C} 20: 4 \mathrm{n} 6)$.

\section{Bacon Slice Yield and Quality}

Green bellies that were vacuum sealed and frozen during fabrication were processed into slab bacon and sliced under commercial settings. Prior to analyzing each slab, 10 slices were removed from the shoulder and flank ends to account for end damage 
to slices from processing. Each slab of bacon was analyzed for the number of total slices, number one slices, number two slices, shattered slices, irregular slices, fishhook slices, and evidence of bone in slices.

\section{Statistical Analysis}

Collected data was analyzed using SAS 9.4. The least squares mean and standard error were determined for variable according to treatment. An analysis of variance of least squares means of treatments for pre-established variable was conducted using PROC GLM to determine if there was an effect of treatment, within each group. A pairwise comparison used to detect potential differences between treatments. Level of significance was set at $\mathrm{P} \leq 0.05$.

\section{RESULTS}

\section{Growth Performance}

A detailed list of data for growth performance and feed efficiency can be found in Table 4.2. Animal growth performance, as described by ADG and F:G, was not significantly affected by the source of dietary oil in either group of pigs. Furthermore, no differences were observed for final body weight $(\mathrm{P}=0.673)$ and feed consumption $(\mathrm{P}=$ $0.575)$ between treatments. Thus, treatment had no statistically significant effect on either ADG $(\mathrm{P}=0.327)$ or $\mathrm{F}: \mathrm{G}$ ratio $(\mathrm{P}=0.303)$.

\section{Carcass Yield and Quality Measurements}

A complete listing of carcass measurements of composition and quality are outlined in Table 4.3. Source of dietary oil included in the treatment diets showed no impact on carcass yield when it comes to $\mathrm{HCW}(\mathrm{P}=0.606)$, dressing percent $(\mathrm{P}=0.906)$, 
loin eye area $(\mathrm{P}=0.378)$, last rib fat thickness $(\mathrm{P}=0.737)$, and $10^{\text {th }}$ rib fat thickness $(\mathrm{P}=$ 0.505). Furthermore, when evaluating difference in pork carcass quality, no treatment effect was detected when looking at the quality indicators of subjective marbling score ( $\mathrm{P}$ $=0.922)$, subjective color score $(\mathrm{P}=0.313)$, loin $\mathrm{pH}(\mathrm{P}=0.243)$, and ham $\mathrm{pH}(\mathrm{P}=$ $0.116)$.

\section{Fat and Moisture Content}

The results for the moisture and fat content of loin chops can be found in Table 4.4. Analysis indicated no significant difference $(\mathrm{P}=0.684)$ across treatments for fat content of loin chop samples. However, while no statistically significant $(\mathrm{P} \leq 0.05)$, a tendency $(\mathrm{P}=0.08)$ existed for differences in moisture content between treatments, with a spread from top to bottom of $1.66 \%$.

\section{Bacon Slice Yield and Quality}

Bacon slice yield and quality measurements for treatments are outlined in Table 4.5. Analysis of the bacon slice yield and quality data only showed a significant difference $(\mathrm{P}=0.003)$ for treatment effect in the yield of Number 1 slices. Bacon from pigs receiving the coconut oil diet had the greatest amount of number 1 slices at 25.30. The other treatments followed in the order of $\mathrm{P}$ at 21.44 slices, CON at 20.30 slices, $\mathrm{P} 4$ at 18.70 slices, $\mathrm{C}+\mathrm{MOS}$ at 18.56 slices, $\mathrm{CS}$ at 16.60 slices, MOS at 15 slices, and MOS4 at 10.90 slices. No other significant differences $(\mathrm{P}>0.05)$ were observed between treatments for the remaining variables of bacon slice yield and quality.

\section{Fatty Acid Profile Analysis}

Full results for the fatty acid composition of intramuscular fat from the early finishing group can be found in Table 4.6. Treatment groups exhibited no significant 
differences $(\mathrm{P}>0.05)$ in fatty acid composition of intramuscular fat samples. Greater differences between treatments was observed for the fatty acid composition of intermuscular fat samples. Results for the fatty acid composition of intermuscular fat samples can be found in Table 4.7. Analysis of intermuscular fat samples showed significant differences $(\mathrm{P} \leq 0.05)$ in the concentration of $\mathrm{C} 12: 0, \mathrm{C} 16: 0, \mathrm{C} 16: 1, \mathrm{C} 18: 0$, $\mathrm{C} 18: 1 \mathrm{n} 9$, total SFA, and total MUFA. The $\mathrm{CO}$ treatment had a greater proportion $(\mathrm{P}<$ $.0001)$ of $\mathrm{C} 12: 0$, compared to all other treatment groups. Treatments containing an increased amount of SFA $(\mathrm{CO}, \mathrm{CON}, \mathrm{C}+\mathrm{MOS})$ showed an increase $(\mathrm{P}=0.028)$ in the proportion of C16:0, compared to the treatments with a greater amount of USFA (CS, MOS, MOS4, P, P4). Treatments CON, CS, CO, C+MOS, MOS, and $\mathrm{P}$ had a higher concentration $(\mathrm{P}=0.015)$ of $\mathrm{C} 18: 0$, compared to the MOS4 and $\mathrm{P} 4$ treatments. Samples of intermuscular fat from the $\mathrm{P} 4, \mathrm{P}, \mathrm{MOS} 4$, and MOS pigs exhibited a greater concentration $(\mathrm{P}<.0001)$ of $\mathrm{C} 18: 1 \mathrm{n} 9$ versus pigs from the $\mathrm{CS}$ and $\mathrm{CO}$ treatments. Looking at the total proportion of SFA, the $\mathrm{CO}$ and $\mathrm{C}+\mathrm{MOS}$ treatments had an increased $(\mathrm{P}=0.005)$ proportion of SFA compared to the CON, MOS, MOS4, $\mathrm{P}$, and $\mathrm{P} 4$ treatment groups. Additionally, the MOS, MOS4, P, and P4 treatments yielded intermuscular fat samples with a greater $(\mathrm{P}<.0001)$ total proportion of MUFA, compared to samples from pigs receiving the $\mathrm{CS}, \mathrm{CO}, \mathrm{CON}$, and $\mathrm{C}+\mathrm{MOS}$ diets. Finally, a tendency $(\mathrm{P}=0.086)$ was observed for a difference in the total PUFA, with the CS treatment group having a greater proportion of PUFA compared to the other treatment groups. 


\section{DISCUSSION}

The outcome of growth performance results is to be expected from animals consuming diets with similar energy and protein. As treatment diets were balanced for energy requirements, it can be expected that little to no difference would be seen in the resulting growth performance data, as all treatment received adequate energy supply regardless of source. No evidence of reduced feed intake, combined with similar average daily gain and final live weights, provide support to the idea that finisher pig diets can be reformulated to include novel high oleic soybean oil, regardless of source. These results for ADG and feed efficiency agree with results other studies, where dietary fat source had no effect on pig ADG, feed intake, and feed efficiency (Apple et al., 2009a; DuranMontge et al., 2020; Kellner et al., 2014).

Results from the analysis of carcass compositions and quality showed no significant effect of dietary oil source, or rate of inclusion on pork carcass composition and quality. Stephenson et al. (2016) saw no difference as a result of dietary fat source in $\mathrm{HCW}$, loin eye area, and percent yield in pigs. Results from the carcass analysis further supports the case that traditionally dietary oil sources can be replaced successfully with novel high oleic soybean oils, without resulting in deleterious effects on carcass weights and lean meat yields. Furthermore, the resulting lack of detectable differences in the analyzed variables of fresh meat quality, is evidence of little impact that dietary inclusion of novel high oleic soybean oil would have on the fresh pork supply chain.

While the majority of parameters of bacon slice yield and quality showed little difference as a result of dietary treatment, a significant difference was observed for treatment for the yield of number 1 slices. The increase in the number of number 1 slices 
from $\mathrm{CO}$ slabs is evidence of the potential for fatty acid profile of monogastrics to mirror that found in the diet, which has been supported by previous research from our lab. The greater proportion of saturated fatty acids found in the diet containing coconut oil, most likely provide the increase in potential for the increase in the quantity of number one slices. This would be the result of altering the fatty acid profile of the $\mathrm{CO}$ treatment bellies to include a greater proportion of saturated fatty acids, specifically $\mathrm{C} 12: 0, \mathrm{C} 16: 0$, and C18:0. This would result in firmer bellies that allow for easier fabrication, yielding a thicker and more uniform belly for bacon processing. The shift to a more saturated fatty acid profile found in the CO treatment bellies most likely overcame the "soft fat" effect caused by higher amounts of PUFA found in the diets containing oil/fat sources with increased proportions of USFA (Apple et al., 2010).

Interestingly, no significant differences were observed in the individual fatty acids and total fatty acid portion in the fatty acid profile of intramuscular fat. The lack of differences in individual fatty acids for intramuscular fat is most likely the result of the increased metabolic activity level of this fat depot. Intramuscular fat deposition is considered to be the last location for fat to be deposited, as a result of it increased metabolic activity (Wiegand et al., 2011; Shircliff, 2016). When evaluating the fatty acid profile results for intermuscular fat samples, differences were observed between treatment groups. Diets containing increased amounts of SFA produced a greater proportion of SFA in intermuscular fat samples. This increase in the proportion of SFA came as a result of increasing the concentrations of $\mathrm{C} 12: 0, \mathrm{C} 16: 0$, and C18:0. Pigs receiving diets with high oleic oil sources exhibited greater proportions of total MUFA, as a result of increases in the individual fatty acids $\mathrm{C} 16: 1$ and $\mathrm{C} 18: 1 \mathrm{n} 9$, compared to pigs 
receiving other oil sources. Studies by Realini et al. (2010), Mas et al. (2010), and Mas et al. (2011) concluded that pigs receiving diets with increased amounts of monounsaturated fatty acids yield tissues with increased concentration of monounsaturated fatty acids. The mirroring of the fatty acid profile of dietary fat sources observed in the fatty acid profile of intermuscular fatty acids, supports the conclusions by previous studies that tissue fatty acid composition mirrors the dietary fatty acid supply (Wood et al., 2008; Wood and Enser, 2017).

\section{IMPLICATIONS}

Overall, the results of this experiment highlight previous conclusions regarding the lack of differences in pig growth and performance, along with pork carcass composition and quality, as a result of manipulating the dietary fat source. However, as demonstrated in previous work in pigs and chickens, this experiment showed the pullthrough ability of the inclusion of novel high oleic soybean oil sources, to influence the fatty acid profile of tissues. These results suggest that traditional dietary oils can be replaced by novel high oleic soybean oils to shift the proportion of fatty acids in tissues, without causing deleterious effect on finishing pig performance, carcass composition, and fresh pork quality. Further, research should evaluate the rate of lipid oxidation in fresh pork cuts from pigs fed diets containing high oleic soybean oil, as the shift in the fatty acid composition suggests a potential to reduce lipid oxidation and improve shelf life. 


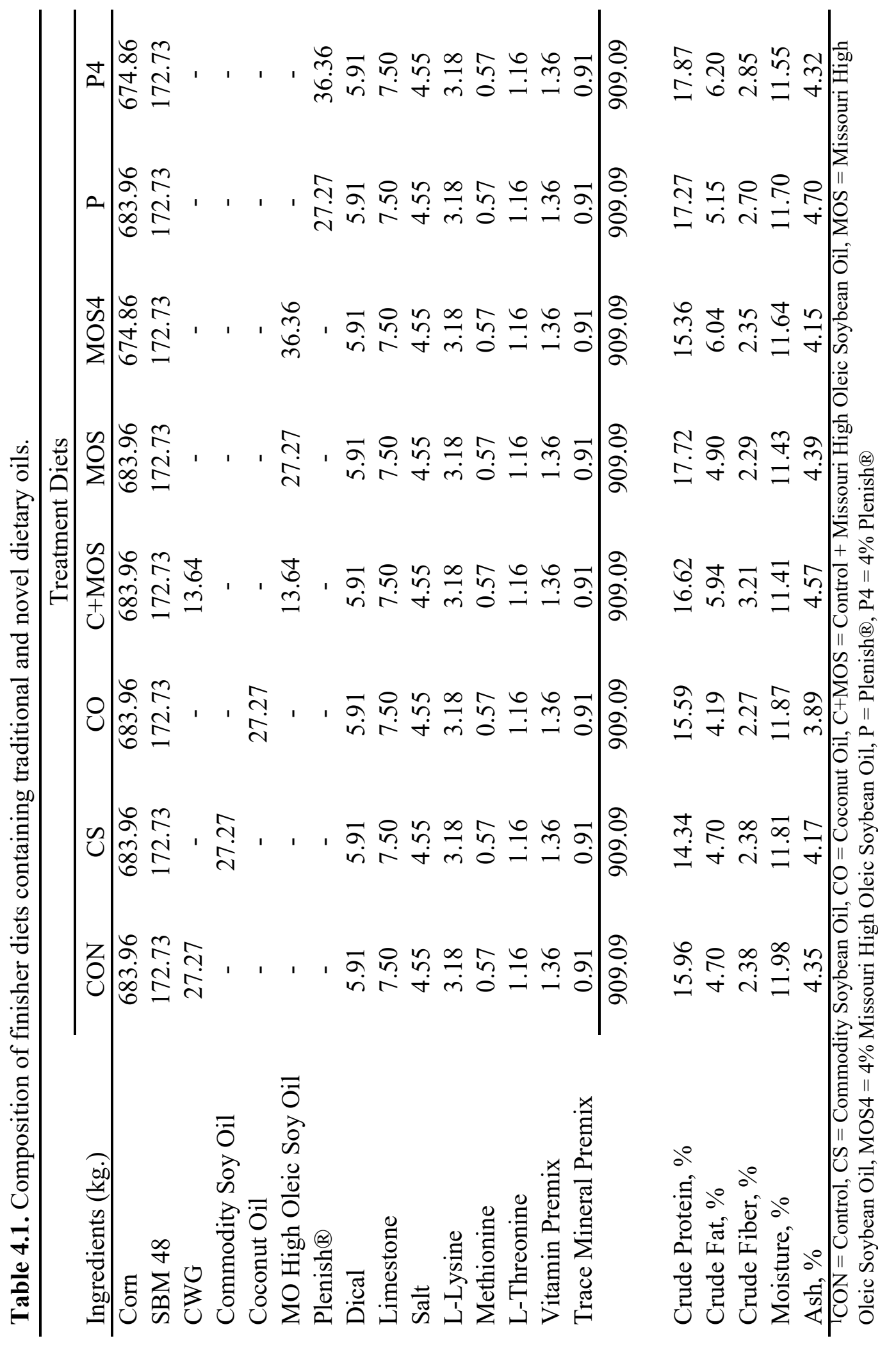




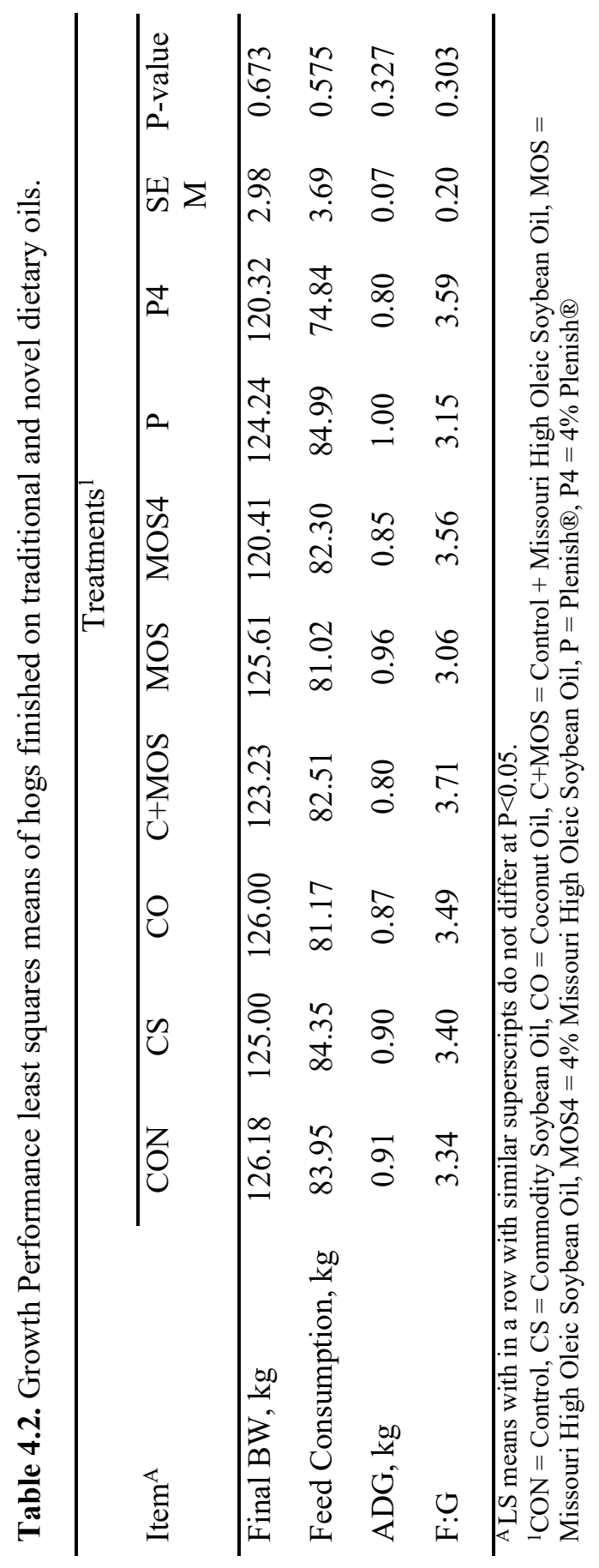




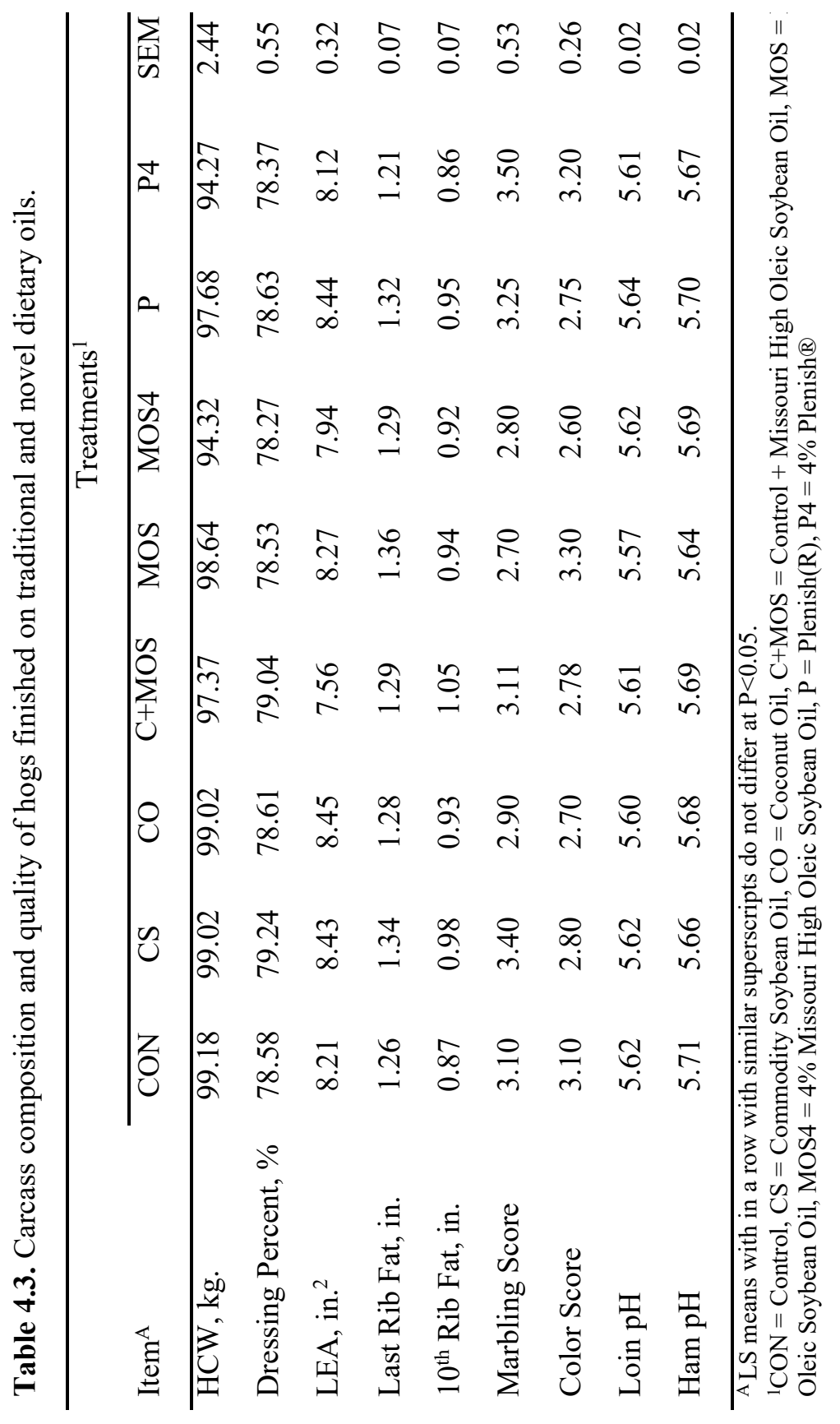




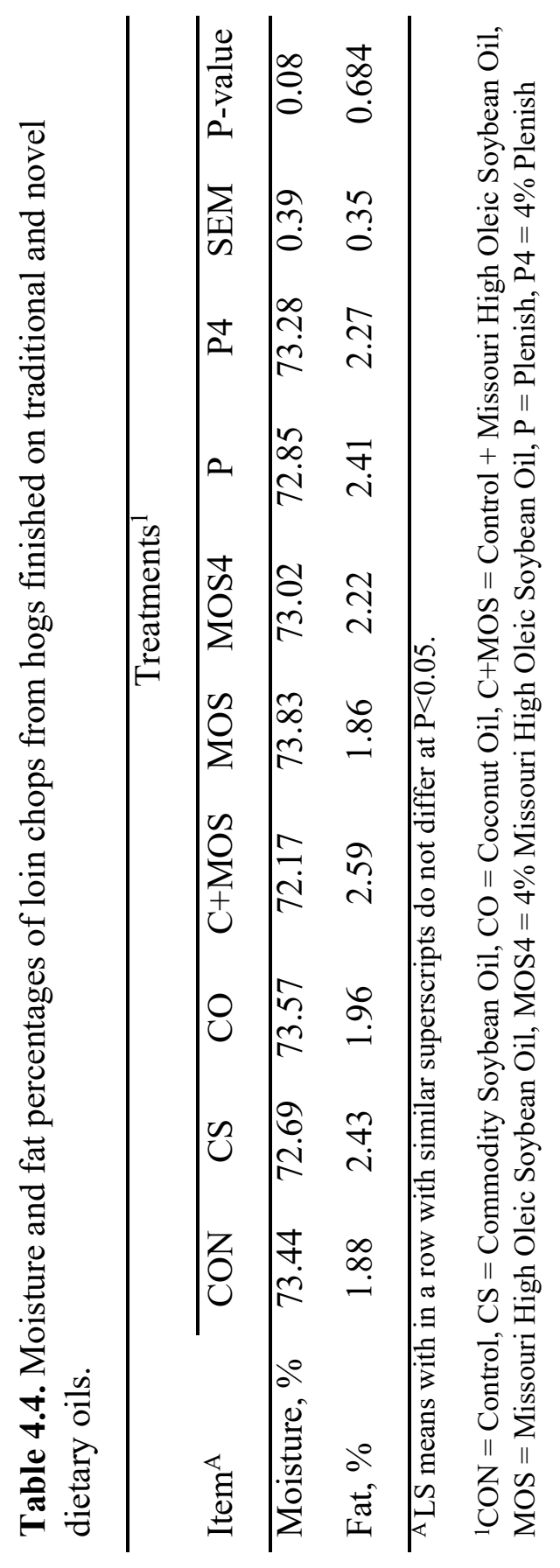




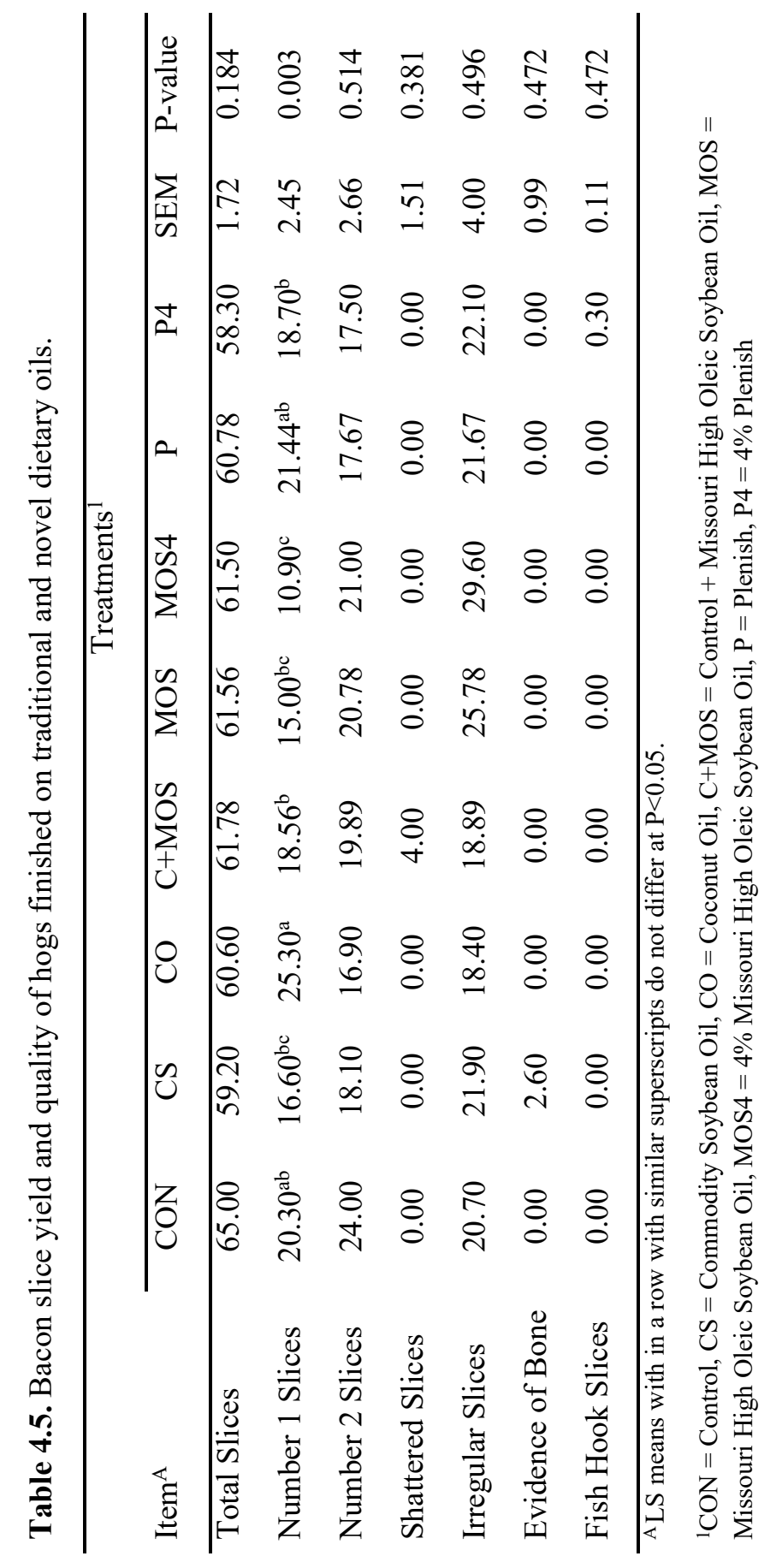




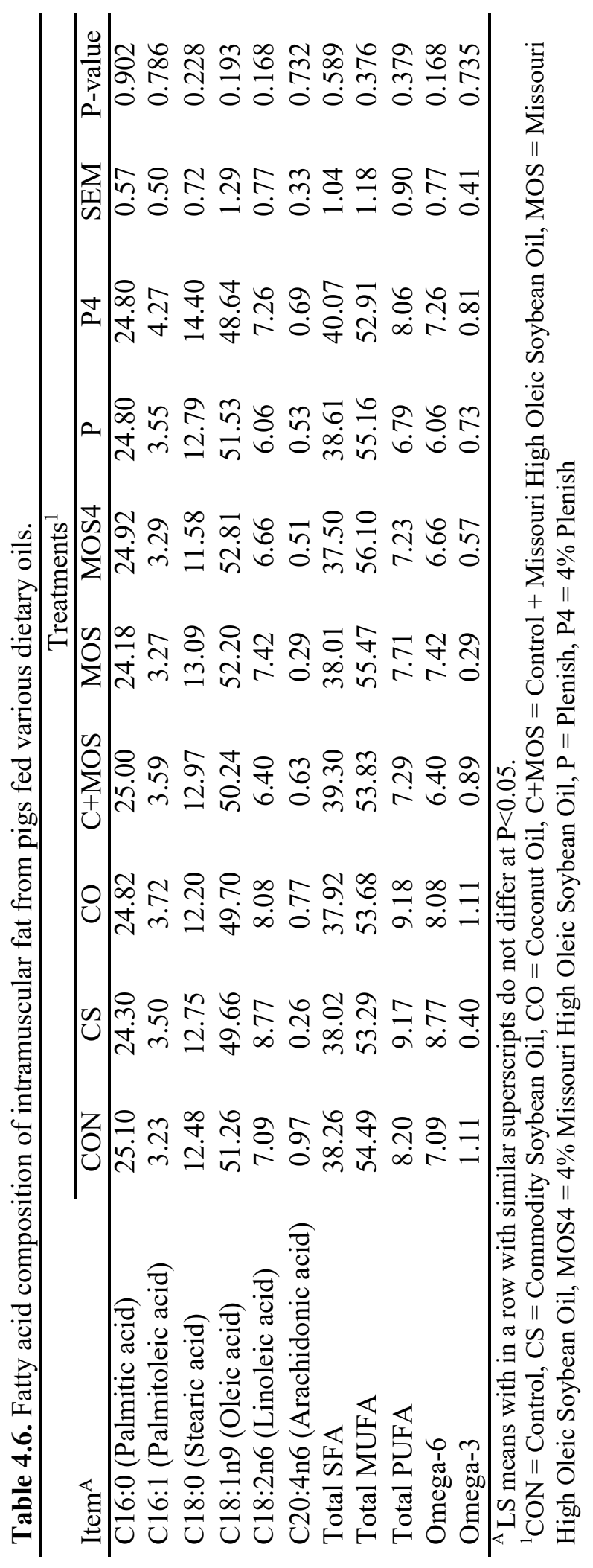




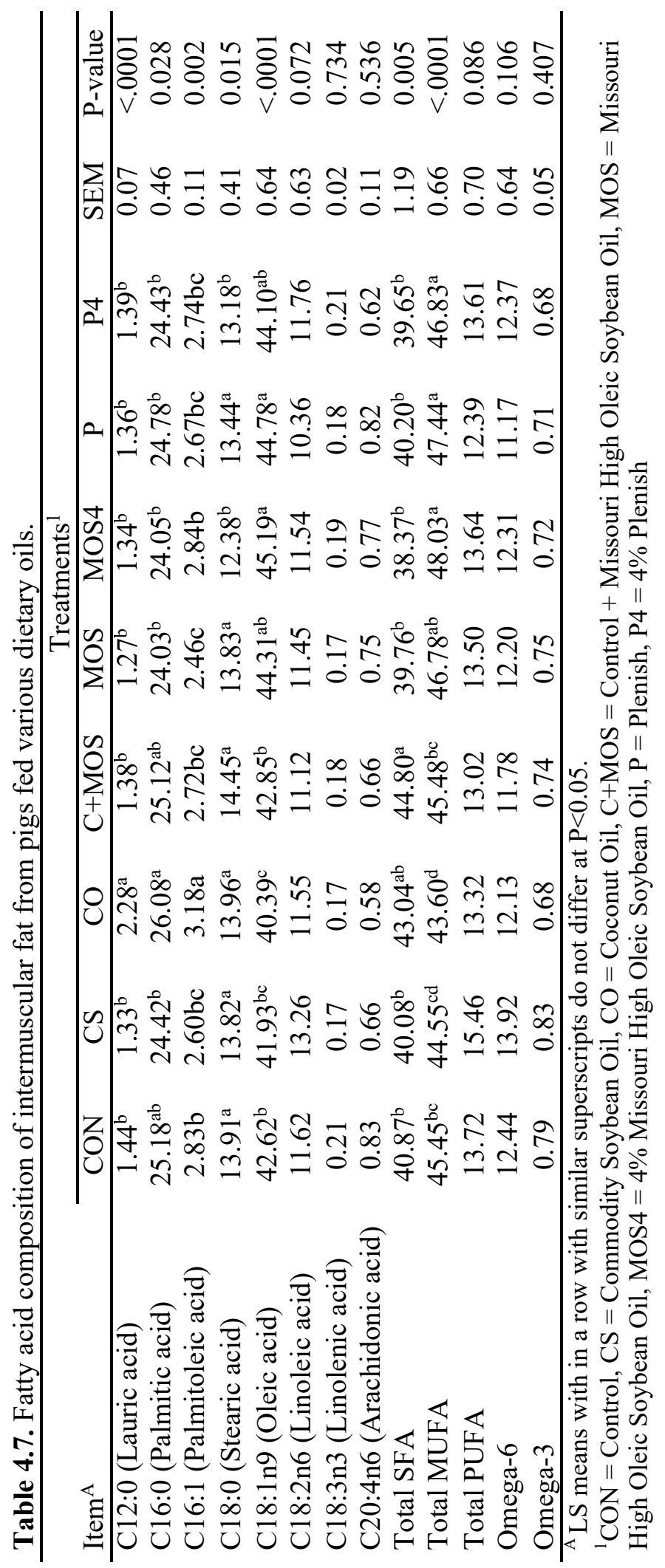




\section{LITERATURE CITED}

Aberle, E. D., Forrest, J. C., Gerrard, D. E., \& Mills, E. W. (2012). Principles of Meat Science. $5^{\text {th }}$ ed. Kendall Hunt Publishing Company, Des Moines, Iowa.

American Meat Science Association. (2012). AMSA Meat Color Measurement Guidelines. AMSA Meat Color Measurement Guidelines. American Meat Science Association, Champaign, IL.

Amorim, A., Rodrigues, S., Pereira, E., and Teixeira, A. (2016). Physiochemical composition and sensory quality evaluation of capon and rooster meat. Poultry Science, 95, $1211-1219$.

Apple, J. K., Maxwell, C.V., Galloway, D. L., Hutchinson, S., and Hamilton, C. R. (2009a). Interactive effects of dietary fat source and slaughter weight in growingfinishing swine: I. Growth performance and longissimus muscle fatty acid composition. Journal of Animal Science, 87, 1407 - 1422.

Apple, J. K., Maxwell, C.V., Galloway, D. L., Hamilton, C. R., and Yancy, J. W. S. (2009b). Interactive effects of dietary fat source and slaughter weight in growingfinishing swine: III. Carcass and fatty acid composition. Journal of Animal Science, 87, $1441-1454$.

Apple, J. K. (2010). Beyond Iodine Value: Measuring belly/fat firmness. $63^{\text {rd }}$ Annual Reciprocal Meats Conference, American Meat Science Association. Lubbock, TX.

Averette Gatlin, L., See, M. T., Hansen, J. A., Sutton, D., and Odle, J. (2002). The effects of dietary fat sources, levels, and feeding intervals on pork fatty acid composition. Journal of Animal Science, 80, 1606 - 1615.

Azcona, J. O. Garcia, P. T., Cossu, M. E., Iglesias, B. F., Picallo, A., Perez, C., Gallinger, C. I., Schang, M. J., and Canet, Z. E. (2008). Meat quality of Argentinean "Camperos" chicken enhanced in omega-3 and omega-9 fatty acids. Meat Science, 79, $437-443$.

Bellavia, A., Stilling, F., \& Wolk, A. (2016). High red meat intake and all-cause cardiovascular and cancer mortality: is the risk modified by fruit and vegetable intake? The American Journal of Clinical Nutrition, 104(4), 1137-1143. doi.org/10.3945/ajcn.116.135335

Benz, J. M., Tokach, M. D., Dritz, S. S., Nelssen, J. L., DeRouchey, J. M., Sulabo, R. C., and Goodband, R. D. (2011). Effects of choice white grease and soybean oil on growth performance, carcass characteristics, and carcass fat quality of growingfinishing pigs. Journal of Animal Science, 89, $404-413$. 
Boateng, L., Anson, R., Owusu, W. B., and Steiner-Asiedu, M. (2016). Coconut oil and palm oil's role in nutrition, health, and national development: A review. Ghana medical journal, 50(3), 189 - 196.

Bonanome, A., Pagnan, A., Biffanti, S., Opportuno, A., Sorgato, F., Mariorino, M., and Ursini, M. (1992). Effect of dietary monounsaturated and polyunsaturated fatty acids on the susceptibility of plasma low density lipoproteins to oxidative modification. Arterioscler. Thromb. 12, 529 - 533.

Buzby, J. C., Wells, H. F., and Hyman, F. (2014). The estimated amount, value, and calories of postharvest food losses at the retail and consumer levels in the United States. USDA, Economic Information Bulletin Number 121.

Cameron, N.D., and Enser, M.B. (1991). Fatty acid composition of lipid in Longissimus dorsi

muscle of Duroc and British Landrace pigs and its relationship with eating quality. Meat Science, 29(4), 295-307.

Cameron, N.D., Enser, M., Nute, G.R., Whittington, F.M., Penman, J.C., Fisken, A.C., Perry,

A.M., and Wood, J.D. (2000). Genotype with nutrition interaction on fatty acid composition of intramuscular fat and the relationship with flavour of pig meat. Meat Science, 55(2), 187-195.

Cardona, M., Gorriz, A., Barat, J. M., \& Fernández-Segovia, I. (2020). Perception of fat and other quality parameters in minced and burger meat from Spanish consumer studies. Meat Science. doi.org/10.1016/j.meatsci.2020.108138.

Carroll, K. K. (1965). Dietary fat and the fatty acid composition of tissue lipids. Journal of American Oil Chemistry Society, 42, 516 - 528.

Corteva Agriscience. (N.D.) Healthy Oils, Plenish® High Oleic Soybean Oil. https://www.healthyoils.corteva.com/about/plenish.html. Accessed November 2, 2020.

Crawford, M. A., Gale, M. M., Woodford, M. H., \& Casped, N. M. (1970). Comparative studies on fatty acid composition of wild and domestic meat. Int. J. Biochem. $1(3), 295-305$.

Crespo, N. and Esteve-Gracia, E. (2001). Dietary fatty acid profile modifies abdominal fat deposition in broiler chickens. Poultry Science, 80, $71-78$.

Cui, X., Gou, Z., Fan, Q., Li, L., Lin, X., Wang, Y., Jiang, S., \& Jiang, Z. (2019). Effects of dietary perilla seed oil supplementation on lipid metabolism, meat quality, and fatty acid profiles in Yellow-feathered chickens. Poultry Science, 98, 5714-5723. doi.org/10.3382/ps/pez358. 
Delgado, G. E., Kramer, B. K., Lorkowski, S., Marz, W., Schacky, C. V., and Kleber, M. E. (2017). Individual omega-9 monounsaturated fatty acids and mortality-The Ludwigshafen Risk and Cardiovascular Health Study. Journal of Clinical Lipidology, 11, 126-135.

Dow D. L., Wiegand, B. R., Ellersieck, M. R., and Lorenzen, C. L. (2011). Prediction of fat percentage within marbling score on beef longissimus muscle using 3 different fat determination methods. Journal of Animal Scence, 89, 1173-1179.

Duran-Montge, P., Realini, C. E., Barroeta, A. C., Lizardo, R. G., and Esteve-Garcia, E. (2010). De novo fatty acid synthesis and balance of fatty acids of pigs fed different fat sources. Livestock Science, 132, 157-164.

England, E. M., Matarneh, S. K., Scheffler, T. L., and Gerrard, D. E. (2017). Perimortal muscle metabolism and its effects on meat quality. New Aspects of Meat Quality: From Genes to Ethics.

FAO. (2014). Food and Agriculture Organization of the United Nations. http://faostat.fao.org/site/610/DesktopDefault.aspx?PageID=610\#ancorFAO.

FAO-WHO (2008). Interim summary of conclusions and dietary recommendations on total fat \& fatty acids. Retrieved from http://www.fao.org/ag/agn/nutrition/docs/ Fats $\% 20$ and $\% 20$ Fatty\%20Acids\%20Summary.pdf

FDA. (2015). Final Determination Regarding Partially Hydrogenated Oils. 80 FR 34650, 2015-14883, 34650-34670.

Feed Energy Company. (2018). Utilization of fatty acids in swine diets. https://www.feedenergy.com/wp-content/uploads/2018/04/utilization-of-fattyacids-in-swine-diets-41 ebcf89.pdf.

Fernando, L. N., Berg, E. P., and Gruen, I. U. (2003). Quantitation of hexanal by automated SPME for studying dietary influences on the oxidation of pork. Journal of Food Composition and Analysis, 16, 179-188.

Flanzy, J., François, A. C., and Rerat, A. (1970). Utilisation metabolique des acides gras chez le porc. Ann. Biol. anim. Bioch. Biophys., 10, 603-620.

Folch, J., M. Lees, and S. G. H. Stanley. (1957). A simple method for the isolation and purification of total lipids from animal tissues. J. Biol. Chem, 226, 497-509.

Forouhi, N. G., Krauss, R. M., Taubes, G., \& Willett, W. (2018). Dietary fat and cardiometabolic health: Evidence, controversies, and consensus for guidance. BMJ (Online). doi.org/10.1136/bmj.k2139.

Froning, G. W. (1995). Color of poultry meat. Poult Avain Biol Rev, 6(1), 173 - 181. 
Gaya, L. G., Ferraz, J. B., Rezende, F. M., Mourao, G. B., et al. (2006). Heritability and genetic correlation estimates for performance and carcass and body composition traits in a male broiler line. Poultry Science, 85, 837 - 843.

Gibney, M. J. (1999). Fish and the Mediterranean diet. Atherosclerosis, 144 (1), 170.

Gillingham, L.G., Harris-Janz, S., \& Jones, P.J.H. (2011). Dietary monounsaturated fatty acids are protective against metabolic syndrome and cardiovascular disease risk factors.

Lipids, 46(3), 209-228.

Guadalupe, G. A., Lerma-García, M. J., Fuentes, A., Barat, J. M., Bas, M. del C., \& Fernández-Segovia, I. (2019). Presence of palm oil in foodstuffs: consumers' perception. British Food Journal, 121, 2148-2162. doi.org/10.1108/BFJ-09-20180608 .

Haug, A., Nyquist, N. F., Thomassen, M., Hostmark, A. T., and Knutsdatter Ostbye, T. K. (2014). N-3 fatty acid intake altered fat content and fatty acid distribution in chicken breast muscle, but did not influence mRNA expression of lipid-related enzymes. Lipids in Health and Disease, 13, 92.

Henchion, M., McCarthy, M., Resconi, V. C., \& Troy, D. (2014). Meat consumption: Trends and quality matters. Meat Science, 98, 561-568. doi.org/10.1016/j.meatsci.2014.06.007.

Hsieh, H. F., Chiang, S. H., and Lu, M. Y. (2002). Effect of dietary monounsaturated/saturated fatty acid ratio on fatty acid composition and oxidative stability of tissues in broilers. Animal Feed Science and Technology, 95, 189 204.

Institute of Shortening Edible Oils (ISEO). (2006). Food Fats and Oils, $9^{\text {th }}$ ed, Available at: http://www.iseo.org/foodfats.htm.

Johnson, L. R. (2007). Digestion and Absorption. Gastrointestinal Physiology, $7^{\text {th }}$ Ed., Chapter 11, p. 107-125.

Keeton, J. T., Hafley, B. S., Eddy, S. M., Moser, C. R., McManus, B. J., and Leffler, T. P. (2003). Rapid determination of moisture and fat in meats by microwave and nuclear magnetic resonance analysis. J. of AOAC Int., 86, 1193-1202.

Kellner, T. A., Prusa, K. J., and Patience, J. F. (2014). Impact of dietary fat source and concentration and daily fatty acid intake on the composition of carcass fat and iodine value sampled in three regions of a pork carcass. Journal of Animal Science, 92, 5485 - 5495 . 
King, D. A., Shackelford, S. D., Schnell, T., Pierce, L., and Wheeler, T. L. (2018). Characterizing the ham halo condition: A color defect in fresh pork biceps femoris muscle. Meat and Muscle Biology, 2(1), 205 - 2013.

Kirchgessner, M., Ristic, M. Kreuzer, M., and Roth, F. X. (1993). Inclusion of fats with high quantities of free fatty acids in broiler diets. II: Growth as well as quality of carcass, meat and fat as affected by the stepwise substitution of saturated by unsaturated fatty acids. European poultry science, 57(6), 265 - 274.

Kris-Etherton, P. M., \& Etherton, T. D. (2003). The impact of the changing fatty acid profile of fats on diet assessment and health. Journal of Food Composition, 16, 373-378.

Larsson, S. C., \& Orsini, N. (2013). Red Meat and Processed Meat Consumption and AllCause Mortality: A Meta-Analysis. American Journal of Epidemiology, 179(3), 282-289. https://doi.org/10.1093/aje/kwt261.

Liu, Q., Singh, S., \& Green, A. (2002). High-oleic and high-stearic cottonseed oils: Nutritionally improved cooking oils developed using gene silencing. Journal of American College of Nutrition, 21, 205S-211S.

Lopez-Ferrer, M., Baucells, M. D., Barroeta, A. C., and Grashornt, M. A. (2001). N-3 enrichment of chicken meat. 1. Use of very long chain fatty acids in chicken diets and their influence on meat quality: Fish oil. Poultry Science, 80, 741 - 752.

Maixner, F., Turaev, D., Cazenave-Gassiot, A., Janko, M., Krause-Kyora, B., Hoopmann, M. R., Kusebauch, U., Sartain, M., Guerriero, G., O’Sullivan, N., Teasdale, M., Cipollini, G., Paladin, A., Mattiangeli, V., Samadelli, M., Tecchiati, U., Putzer, A., Palazoglu, M., Meissen, J., ... Zink, A. (2018). The Iceman's Last Meal Consisted of Fat, Wild Meat, and Cereals. Current Biology, 28(14), 23482355.e9. doi.org/10.1016/j.cub.2018.05.067.

Mancini, R. A., and Hunt, M. C. (2005). Current research in meat color. Meat Science, $71,100-121$.

Martin, A. H., Fredeen, H. T., Weiss, G. M., and Carson, R. B. (1972). Distribution and composition of porcine carcass fat. Journal of Animal Science, 35, 534 - 541.

Meade, B. \& Rosen, S. (2013). International Food Assessment, 2013-2023, GFA-24, U.S. Department of Agriculture. Economic Research Service. June 2013.

Mir, N. A., Rafiq, A., Kumar, F., and Singh, V. (2017). Determinants of broiler chicken meat quality and factors affecting them: a review. J Food Sci Technol, 54(10), 2997 - 3009. 
Morrison, W. R., and Smith, L. M. (1964). Preparation of fatty acid methyl esters and dimethylacetals from lipids with boron fluoride-methanol. J. Lipid Res, 5, 600608.

Nakamura, M. T. and Nara, T. Y. (2004). Structure, function, and dietary regulation of delta6, delta5, and delta9 desaturases. Annu Rev Nutr, 24, 345 - 376.

NAMI. 2014. The Meat Buyer's Guide, $8^{\text {th }}$ Edition. North American Meat Institute, Washington, DC.

Nelson, R. H. and Cox, M. M. (2013). Lehninger: Principles of Biochemistry. $6^{\text {th }}$ Edition. Worth Publishing, New York, NY.

NPB. (2014). Pork Stats. The National Pork Board, Des Moines, IA.

National Research Council (NRC). (1994). Nutrient Requirements of Poultry. $9^{\text {th }}$ Edition. The National Academies Press, Washington, D.C.

Ntambi, J. M. and Miyazaki, M. (2004). Regulation of stearoyl-CoA desaturases and role in metabolism. Prog Lipid Res, 43, 91 - 104.

OCED-FAO. (2013). Agricultural Outlook 2012-2021.

Okur, N. (2020). The effects of soy oil, poultry fat, and tallow with fixed energy: protein ratio on broiler performance. Archives Animal Breeding, 63(1), 91 - 101.

Pereira, P. C. \& Vicente, F. (2017). 'Meat Nutritive Value and Human Health'. in P. P. Purslow, New Aspects of Meat Quality: From Genes to Ethices. Cambridge: Elsevier; p. 465-477.

Purslow, P. (2017). New Aspects of Meat Quality: From Genes to Ethics. Woodhead Publishing.

Raes, K., De Smet, S., and Demeyer, D. (2004). Effect of dietary fatty acids on incorporation of long chain polyunsaturated fatty acids and conjugated linoleic acid in lamb, beef and pork meat: a review. Animal Feed Science and Technology, $113,199-221$.

Realini, C. E., Duran-Montge, P., Lizardo, R., Gispert, M., Oliver, M. A., and EsteveGarcia, E. (2010). Effect of source of dietary fat on pig performance, carcass characteristics, and carcass fat content, distribution and fatty acid composition. Meat Science, 85, $606-612$.

Rentfrow, G. T., Sauber, T. E., Allee, G. L., and Berg, E. P. (2003). The influence of diets containing either conventional corn, conventional corn with choice white grease, high corn oil, or high oil high oleic corn on belly/bacon quality. Meat Science, 64, 459-466. 
Rossi, R., Pastorelli, G., Cannata, S., \& Corino, C. (2010). Recent advances in the use of fatty acids as supplements in pig diets: A review. Animal Feed Science and Technology, 162, 1-11. doi.org/10.1016/j.anifeedsci.2010.08.013.

Schwingshackl, L., and Hoffmann, G. (2014). Monounsaturated fatty acids, olive oil and health status: a systematic review and meta-analysis of cohort studies. Lipids Health Dis. 13, 154.

Seemamahannop, R., Bilyeu, K., He., Y., Kapila, S., Tumiatti, V., and Pompili, M. (2019). Assessment of oxidative stability and physical properties of high oleic natural esters. Proceedings of the IEEE International Conference on Dielectric Liquids (2019, Roma, Italy), IEEE Computer Society, June 2019.

Semwogerere, F., Neethling, J., Muchenje, V., and Hoffman, C. (2019). Meat quality, fatty acid profile, and sensory attributes of spent laying hens fed expeller press canola meal or a conventional diet. Poultry Science, 98, 3557 - 3570.

Shircliff, K. E. (2016). Novel feed additives to improve lipid profiles in pigs.

Sinclair, L. A. and O'Dea, K. (1990). Fats in human diets throughout history: is the Western diet out of step? In: Wood, J. D., Fisher, A. V. (Eds.), Reducing Fat in Meat Animals. Elsevier Applied Science, London, pp. 1 - 47.

Simopoulos, A. P. (2009). Omega-6/Omega-3 essential fatty acids: biological effects. World Rev. Nutr. Diet., 99, $1-16$.

Skrivan, M., Marounek, M., Englmaierova, M., Cermak, L., Vlckova, J., and Skrivanova, E. (2018). Effect of dietary fat type on intestinal digestibility of fatty acids, fatty acid profiles of breast meat and abdominal fat, and mRNA expression of lipidrelated genes in broiler chickens. PLOS ONE 13(4), e0196035.

Slankers Grass-Fed Meats. (N.D.). Omega-3 Whole Chicken. https://www.texasgrassfedbeef.com/meat-store/products/category/omega-3chicken/omega-3-whole-chicken.

Stephenson, E. W., Vaughn, M. A., Burnett, D. D., Paulk, C. B., Tokach, M. D., Dritz, S. S., DeRouchey, J. M., Goodband, R. D., Woodworth, J. C., and Gonzalez, J. M. (2016). Influence of dietary fat source and feeding duration on finishing pig growth performance, carcass composition, and fat quality. Journal of Animal Science, 94, $2851-2866$.

Tarladgis, B. G. (1960). A distillation method for the quantitative determination of malonaldehyde in rancid foods.

Tikk, K., Tikk,M., Aaslyng, M.D., Karlsson, A.H., Lindahl, G., and Andersen, H.J. (2007). Significance of fat supplemented diets on pork quality - Connections between specific fatty acids and sensory attributes of pork. Meat Science, 77(2), 275-286. 
Toomer, O. T., Livingston, M., Wall, B., Sanders, E., Vu, T., Malhereiros, R. D., Livingston, K. A., Carvalho, L. V., Ferket, P. R., and Dean, L. L. (2020). Feeding high-oleic peanuts to meat-type broiler chickens enhances the fatty acid profile of the meat produced. Poultry Science, 99, $2236-2245$.

Tuunainen, P., Koivunen, E., Valaja, J., Valkonen, E., Hiidenhovi, J., Tupasela, T., and Hongisto, M. (2016). Effects of dietary rapeseed meal and peas on the performance and meat quality of broilers. Agr. Food Sci., 25, 22 - 33.

United Soybean Board. (2017). High Oleic Soybeans. Retrieved from http://unitedsoybean.org/media-center/issue-briefs/high-oleic-soybeans/. Accessed July 24, 2017.

United States Department of Agriculture (USDA). (2020). USDA National Retail Report - Chicken. https://www.ams.usda.gov/mnreports/pywretailchicken.pdf.

Vahmani, P., Ponnampalam, E. N., Kraft, J., Mapiye, C., Bermingham, E. N., Watkins, P. J., Proctor, S. D., \& Dugan, M. E. R. (2020). Bioactivity and health effects of ruminant meat lipids. Invited Review. In Meat Science. doi.org/10.1016/j.meatsci.2020.108114.

Voet, D. and Voet J. G. (1995.) Lipid Metabolism. Biochemistry, ${ }^{\text {th }}$ Ed., Chapter 23, p. 662-726.

Warner, R. D., Greenwood, P. I., Pethick, D. W., and Ferguson, D. M. (2010). Genetic and environmental effects on meat quality. Meat Science, 86, $171-183$.

Webb, E. C., \& O’Neill, H. A. (2008). The animal fat paradox and meat quality. Meat Science, 80, 28-36. https://doi.org/10.1016/j.meatsci.2008.05.029.

Wiegand, B. R., Hinson, R. B., Ritter, M. J., Carr, S. N., and Allee, G. L. (2011). Fatty acid profiles and iodine value correlations between four carcass fat depots from pigs fed varied combinations of ractopamine and energy. Journal of Animal Science, 89, $3580-3586$.

Wiseman, J. \& Garnsworthy, P. C. (1997). The role of lipids in animal feeds. In Gunstone, F. D., Padley, F. B. (Eds.), Lipid Technologies and Applications. Marcel Dekker, Inc., New York, USA.

Wiseman, J. and Agunbiade, J. A. (1998). The influence of changes in dietary fat and oils on fatty acid profiles of carcass fat in finishing pigs. Livestock Production Science, 54, $217-227$.

Wood, J. D. (1984). Fat deposition and the quality of fat tissue in meat animals. In: Wiseman, J. (Ed.), Fats in Animal Nutrition. Butterworths, London, pp. 407 435 . 
Wood, J. D. and Enser, M. (2017). Manipulating the Fatty Acid Composition of Meat to Improve Nutritional Value and Meat Quality. New Aspects of Meat Quality: From Genes to Ethics.

Wood, J. D., Richardson, R. I., Nute, G. R., Fisher, A. V., Campo, M. M., Kasapidou, E., Sheard, P. R., and Enser, M. (2003). Effects of fatty acids on meat quality: a review. Meat Science, 66, $21-32$.

Wood, J. D., Enser, M., Fisher, A. V., Nute, G. R., Sheard, P. R., Richardson, R. I., Hughes, S. I., and Whittington, F. M. (2008). Fat deposition, fatty acid composition, and meat quality: A review. Meat Science, 78, 343 - 358.

Yang, Z. H., Gordon, S. M., Sviridov, D., Wang, S., Danner, R. L., Pryor, M., Vaisman, B., Shichijo, Y., Doisaki, N., and Remaley, A. T. (2017). Dietary supplementation with long-chain monounsaturated fatty acid isomers decreases atherosclerosis and alters lipoprotein proteomes in LDLr-/- mice. Atherosclerosis, 262, 31-38.

Zhao, G. P., Cui, H. X., Liu, R. R., Zheng, M. Q., Chen, J. L., and Wen, J. (2011). Comparison of breast muscle meat quality in 2 broiler breeds. Poultry Science, $90,2355-2359$.

Zollitsch, W., Knaus, W., Aichinger, F., and Lettner, F. (1993). Effects of dietary fat sources on performance and carcass characteristics of broilers. Animal Feed Science Technology, 66, $63-73$. 


\section{VITA}

Tylan Earl Peckman was born in Harrisonville, Missouri in 1993. Raised on a cattle operation in western Vernon County, Missouri, a passion for agriculture was planted and nurtured throughout his formative years. As an active member of 4-H and FFA, Tylan developed his communication and leadership skills, alongside furthering his knowledge of the agriculture industry, both of which would be key to his academic and early career success.

Upon graduation from high school, Tylan attended the University of Missouri in Columbia, Missouri, where he earned a Bachelor of Science in Animal Sciences. During this time, Tylan took advantage of opportunities in undergraduate research, meats judging, and livestock judging. Towards the end of his time as an undergraduate, Tylan was approached with the opportunity to pursue a master's degree and help coach the University of Missouri Meats Judging Team. Tylan accepted and started on another adventure at Mizzou.

During his time as a master's student Ty travelled thousands of miles across the country with meats judging teams, during which time his teams experienced some success along the way. In the lab, he delved into the depth of meat science and further cemented his passion for applying the science behind production animal agriculture to improving the quality of meat products. Upon completion of his master's degree in December 2016, Tylan went to work as the HACCP Coordinator for Jennings Premium Meats in New Franklin, Missouri.

After a year of working in the industry, the itch to continue his education came back and prompted him to reach out to his master's advisor Dr. Wiegand about pursuing 
a $\mathrm{PhD}$ in meat science. Tylan returned to Mizzou in January 2017 to begin his doctoral program and again assist in coaching the University of Missouri Meats Judging team. Halfway through his $\mathrm{PhD}$ program, Tylan was approached with the opportunity to serve in a role with the state 4-H program for Missouri and oversee the livestock and meats judging programs, as well as the 4-H livestock areas of the Missouri State Fair. Little did Tylan know, this opportunity would turn into a full-time career. While working full-time, Tylan was able to complete his PhD program in December of 2020. 